Министерство науки и высшего образования Российской Федерации Институт проблем управления им. В.А. Трапезникова РОССИЙСКОЙ АКАДЕМИИ НАУК

М.Е. Бывайков, А.Г. Полетыкин, В.Н.Степанов, И.У. Сахабетдинов

\title{
ПРОГРАММНЫЙ ИНТЕРФЕЙС МЕЖДУ ВЕРХНИМ И НИЖНИМ УРОВНЯМИ \\ АВТОМАТИЗИРОВАННОЙ СИСТЕМЫ УПРАВЛЕНИЯ ТЕХНОЛОГИЧЕСКИМИ ПРОЦЕССАМИ (АСУ ТП) АТОМНОЙ ЭЛЕКТРОСТАНЦИИ (АЭС)
}

НАУЧНОЕ ЭЛЕКТРОННОЕ ИЗДАНИЕ

Москва

ИПУ РАН

2021 
УДК 621.039.681.5

ББК 31.47

Б95

Бывайков М.Е. Программный интерфейс между верхним и нижним уровнями автоматизированной системы управления технологическими процессами (АСУ ТП) атомной электростанции (АЭС) : монография / М.Е. Бывайков, А.Г. Полетыкин, В.Н. Степанов, И.У. Сахабетдинов; Институт проблем управления им. В.А. Трапезникова РАН, Минобрнауки России. - Электрон. текстовые дан. (1 файл: 2,0 Мб). Москва : ИПУ РАН, 2021. - 1 CD-R. - Систем. требования:

Pentium 4; 1,3 ГГц и выше; Internet Explorer; Acrobat Reader 4.0 или

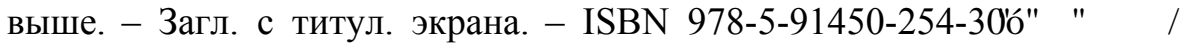

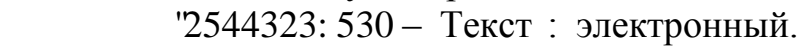

В монографии рассматривается шлюзовое (интерфейсное) программное обеспечение, предназначенное для обмена данными между системой верхнего уровня и смежными системами нижнего уровня АСУ ТП АЭС.

Работа содержит описание методов, алгоритмов и структуры обмена данными на основе протокола, единого для различных смежных систем.

Научное электронное издание предназначено для специалистовразработчиков АСУ ТП АЭС и автоматизированных систем контроля и управления сложными техническими объектами. Монография также представляет собой пособие для специалистов-программистов и ученых, решающих задачи интеграции сложных систем.

Рецензенты: д.т.н., проф. Е.В. Юркевич

д.т.н., проф. М.П.Фархадов

Утверждено к изданию Редакционным советом Института

Текст воспроизводится в виде, утвержденном

Редакиионным советом Института 


\section{ОГЛАВЛЕНИЕ}

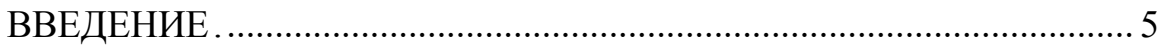

ГЛАВА 1. Назначение программного интерфейса............................. 13

ГЛАВА 2. Область применения программного интерфейса ............... 14

ГЛАВА 3. Описание задачи ............................................................. 16

3.1. Структура массивов в общей памяти...................................... 20

3.2. Программное обеспечение доступа к массивам в общей

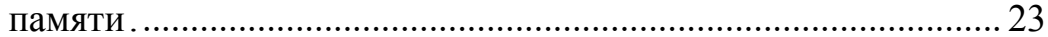

3.3. Программное обеспечение доступа к буферам в общей

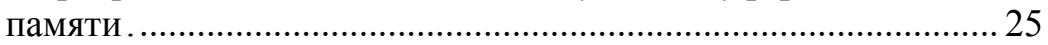

3.4. Обмен сигналами через общую память................................. 29

ГЛАВА 4. Входные и выходные данные......................................... 42

4.1. Структура посылок при обмене данными между CGP и

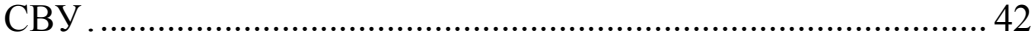

4.2. Инициализация передачи сигналов ........................................... 43

4.3. Передача сигналов от СGР к СВУ ......................................... 45

4.4. Передача сигналов от СВУ к СGP ........................................ 49

4.5. Диагностика шлюза в системе АТПС.................................... 50

4.6. Обмен периодическими контрольными посылками ................ 51

ГЛАВА 5. Частные процессы жизненного цикла............................... 52

5.1. Инсталляция...................................................................... 52

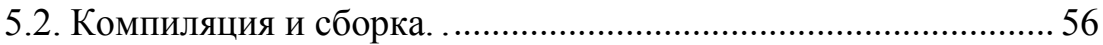

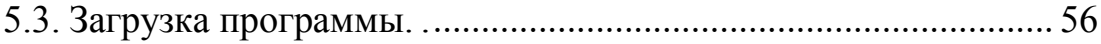

5.4. Процедура автоконфигурации ПО шлюза............................... 59

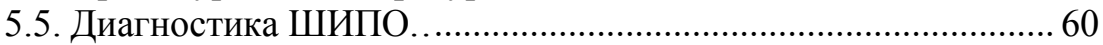

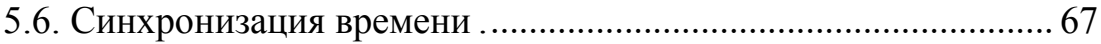

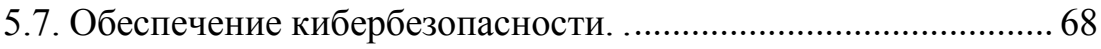

5.8. Настройка параметров ШИПО ............................................... 70

5.9. Оценка потоков обмена данными между ПО шлюза и ПО смежной системы АСУ ................................................ 71 
ПРИЛОЖЕНИЕ 1. Обмен сигналами между модулями GATE и

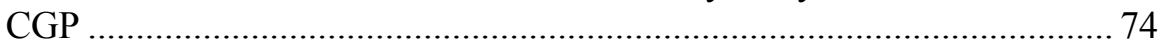

ПРИЛОЖЕНИЕ 2. Алгоритмы обработки информации при взаимодействии с системой ТПТС................................................... 78

ПРИЛОЖЕНИЕ 3. Алгоритмы обработки информации при взаимодействии с системой КТПС-ПН ................................................ 91

ПРИЛОЖЕНИЕ 4. Алгоритмы обработки информации при взаимодействии с системой SICAM ……………………………..... 100

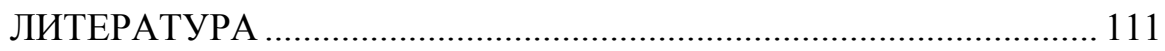

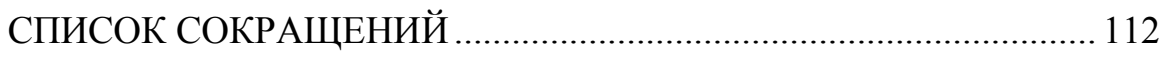




\section{ВВЕДЕНИЕ}

В середине 90-х годов прошлого века атомная промышленность России начала стремительный выход на мировой рынок. Ряд стран (Иран, Индия, Китай и другие) проявили заинтересованность в приобретении отечественных энергоблоков с реакторами на легкой воде типа ВВЭР-1000. Потенциальных заказчиков устраивали экономические характеристики российских АЭС, их надежность и безопасность. Вместе с тем, ряд подсистем АЭС их не устраивал.

К ним, в первую очередь, относились автоматизированные системы управления технологическими процессами (АСУ ТП), которые строились на основе традиционных средств автоматики с жесткой логикой, а программируемые контроллеры практически не применялись. Кроме этого, средства контроля и управления блочного пульта АЭС создавались на основе архаичных средств - стрелочные приборы, самописцы, световые индикаторы, ключи индивидуального управления оборудованием и т.п. В результате отечественные АСУ ТП АЭС занимали огромные помещения, требовали большого количества эксплуатационного и ремонтного персонала. Не были также реализованы алгоритмы контроля, управления и диагностики, повышающие безопасность АЭС, наличие которых является обязательным в соответствии с требованиями МАГАТЭ. К ним, в частности, относятся: система представления параметров безопасности АЭС, система регистрации важных параметров эксплуатации и другие.

В целом, отечественные АСУ ТП АЭС практически по всем параметрам уступали своим зарубежным аналогам. При этом для АЭС «Бушер», строившейся в Иране, закупки зарубежных технологий были невозможны из-за эмбарго. Было решено создать собственную лицензионно-чистую цифровую АСУ ТП, которую можно поставлять в любые страны без ограничений. Она должна соответствовать требованиям по безопасности в области атомной энергетики, широко применять программируемые контроллеры, цифровые средства передачи информации, включать расчетные и диагностические задачи. Причем в центре АСУ ТП должна находиться интегрирующая часть - вычислительная система верхнего блочного уровня (СВБУ), которая должна концентрировать информационные потоки и предо- 
ставить оперативному персоналу АЭС удобные, надежные и быстрые средства управления АЭС, на современном уровне решать как традиционные задачи, так и задачи, повышающие уровень безопасности АЭС.

Задача создания СВБУ была успешно решена усилиями нескольких организаций, включая ОАО «Атомэнергопроект», ЭНИЦ, ФГУП «ФНПЦ НИИИС» и ИПУ РАН. Основные сведения о работе представлены в открытой печати на русском и английском языках. Наиболее подробно сведения изложены в монографии [2], доступной по ссылке: http://www.ipu.ru/sites/default/files/page_file/busher.pdf

Технические решения по СВБУ АСУ ТП АЭС «Бушер» успешно используются на действующих АЭС за рубежом (АЭС «Куданкулам», блоки 1-2 в Индии) и на строящихся АЭС («Куданкулам», блоки 3-4 в Индии).

К системам верхнего уровня (СВУ) АСУ ТП АЭС относятся:

- Система верхнего блочного уровня (СВБУ, рис.1);

- Система верхнего станционного уровня (СВСУ, рис.2);

- Система регистрации важных параметров эксплуатации (СРВПЭ, рис.3).

СВБУ предназначена для реализации информационных, управляющих и вспомогательных функций во всех режимах работы энергоблока АЭС.

СРВПЭ предназначена для регистрации, хранения и выдачи информации о техническом состоянии энергоблока до, во время и после аварии в объеме, достаточном для последующего анализа аварийной ситуации и выяснения причин ее возникновения, путей развития, а также анализа действий персонала по ее локализации, ликвидации и предупреждению.

СВСУ предназначена для:

- реализации функции сбора и представления информации о состоянии основного технологического оборудования и систем энергоблоков АЭС, общестанционных технологических систем (АСРК, СКУ ЭЧ, МПУ);

- интеграции информации по обще станционным системам АСУ ТП и важной информации по энергоблокам;

- передачи данных во внешние системы. 


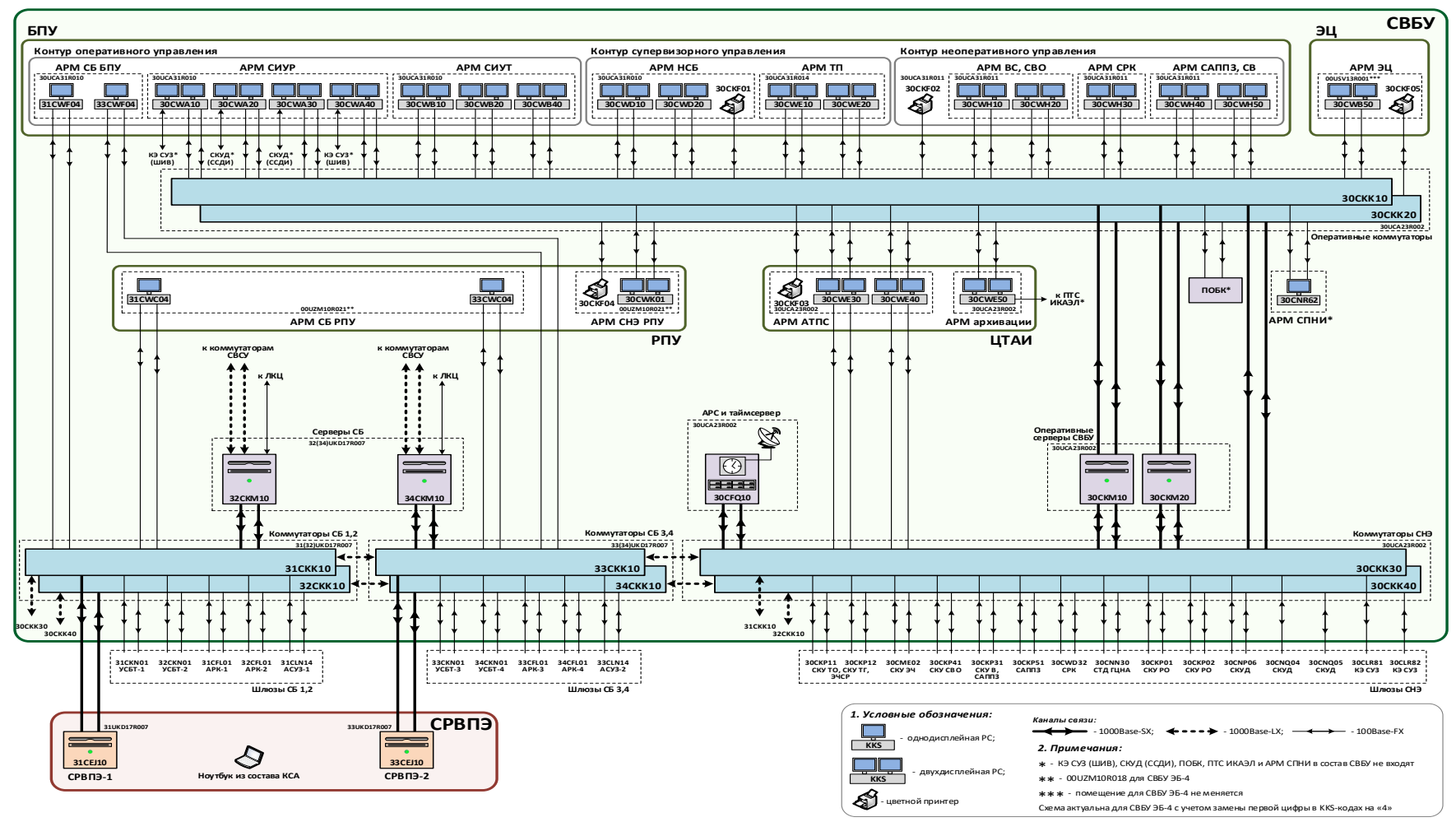

Рис. 1. Структурная схема СВБУ (типовая) 


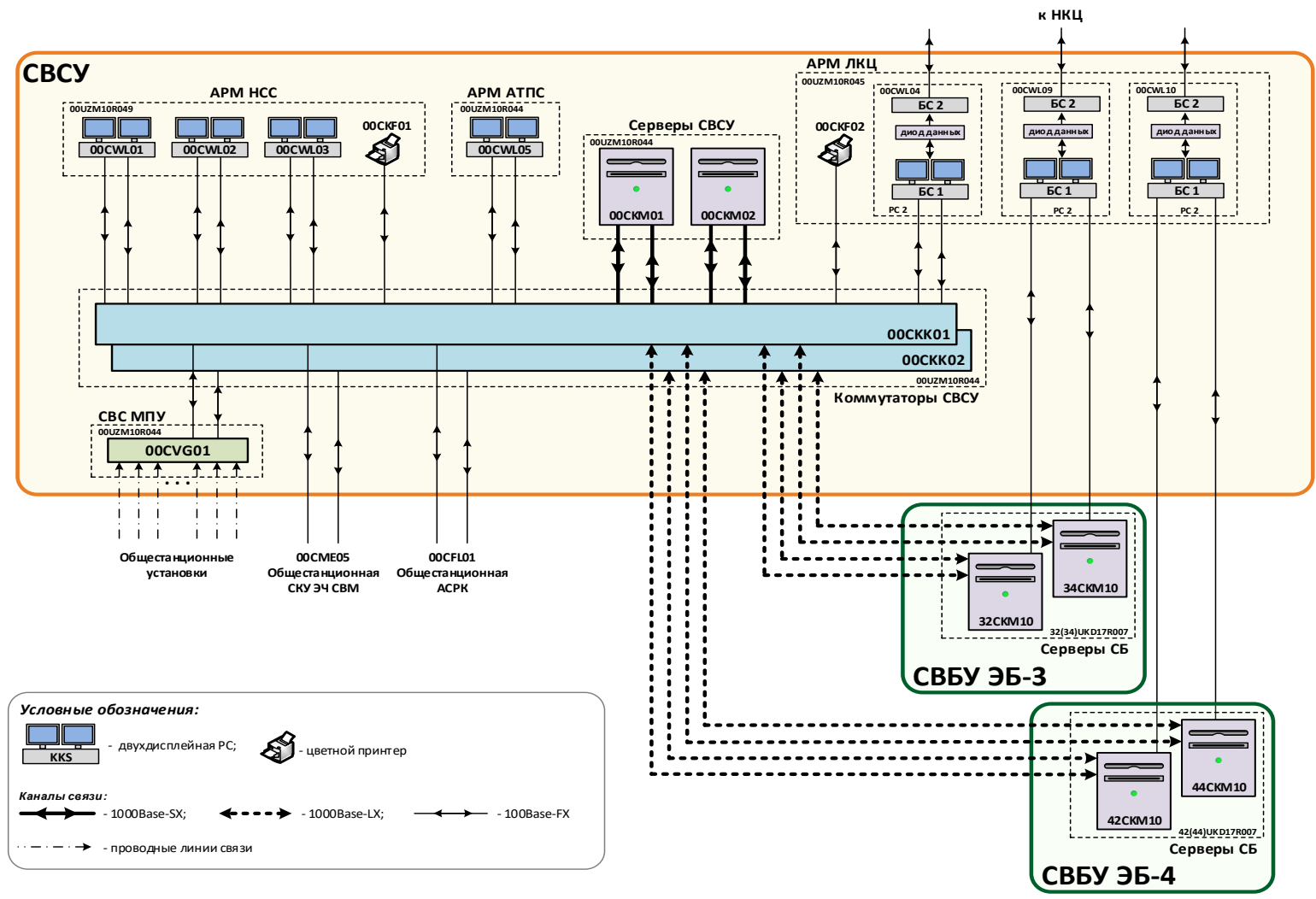

Рис. 2. Структурная схема СВСУ (пример) 


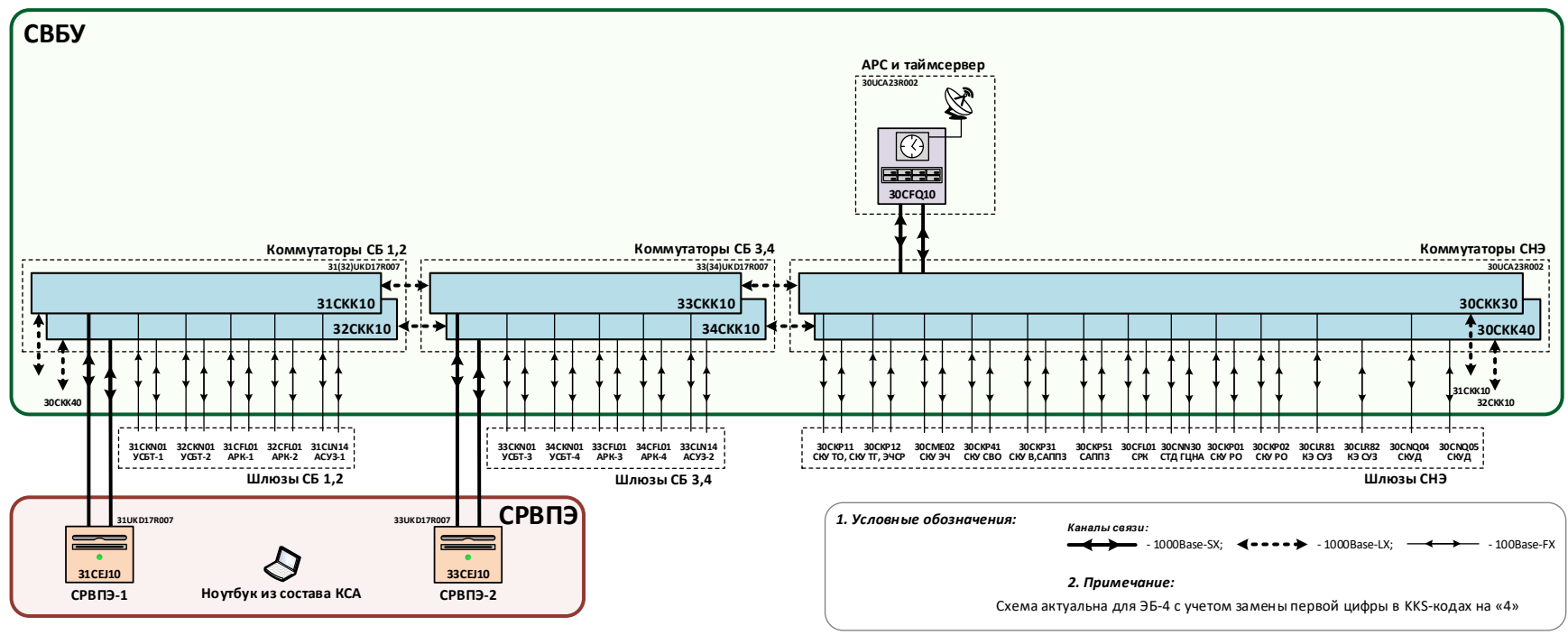

Рис.3. Структурная схема СРВПЭ (пример). 
РВПЭ - это регистратор, не включенный в контур управления, а СВБУ и СВСУ - системы человеко-машинной коммуникации, вовлеченные в управлениенепосредственно. СВБУ автоматизирует работу нескольких основных категорий персонала:

- Операторов-технологов реакторного отделения;

- Операторов-технологов турбинного отделения;

- Операторов систем неоперативного контура (систем спецводоочистки, пожаротушения и вентиляции и др.);

- Начальников смены блока (НСБ);

- Персонала цеха ТАИ АСУ ТП.

АРМы первых трех категорий персонала расположены в помещении блочного пульта или в примыкающих помещениях (АЭС «Бушер-1»). АРМ для персонала цеха ТАИ расположен в удаленных помещениях вблизи помещений для оборудования АСУ ТП.

Для прочего персонала выделены несколько АРМ, через которые можно производить контроль состояния АЭС и анализировать архив.

Определяющей особенностью человеко-машинного интерфейса СВБУ и СВСУ является способ контроля состояния АЭС и управления оборудованием посредством рабочих станций (РС). РС может иметь один или несколько (2-3) пассивных дисплеев, устройства типов трекбол-мышь, обычную и функциональную клавиатуру. Рабочие места (АРМ) СВБУ и СВСУ включают несколько РС, расположенных в ряд. Имеются РС, встроенные в панели ТС ОДУ, но они решают вспомогательные задачи. На приборных (пультовых) стойках РС располагаются отдельные органы управления особо важными агрегатами. В рамках одного АРМ отдельные РС могут иметь специализированное назначение или дублировать друг друга.

ЧМИ СВБУ российских АЭС включают также экраны коллективного пользования (ЭКП), расположенные на блочном пульте управления (БПУ), на которых выводятся данные для всеобщего обзора, дублирующие информацию на РС.

Стиль представления информации и навигации на РС в основном един, но может иметь инородные включения в виде окон, связанных напрямую с низовыми системами АСУ ТП (несколько РС СВБУ АЭС «Куданкулам» имеют возможность отображать окна КЭ СУЗ и СКУД). 
Отображение сигнализации на СВБУ и СВСУ включает привлечение внимания звуком, цветовое и символьное кодирование, обобщение и представление информации различными способами. Фрагментарно сигнализация дублируется на ТС ОДУ.

С технической точки зрения СВБУ и СВСУ представляют собой многомашинные вычислительные комплексы, связанные с другими системами АСУ ТП (через шлюзы) и между собой локальной вычислительной сетью (ЛВС). Комплексы строятся из приборных стоек основных трех видов: приборная стойка РС, приборная стойка сервера, приборная стойка телекоммуникационная. К ним могут присоединяться принтеры, приемники систем спутниковых сигналов (времени), ленточные и иные накопители и т.п.

ЛВС строятся на основе промышленных волоконно-оптических линий связи и сетевого оборудования и общепромышленных протоколов передачи информации (IP-протоколы).

Приборные стойки конструируются на основе модулей различных производителей. Стойки обладают свойством ремонтопригодности: отказавшие модули могут заменяться на ЗИП эксплуатационным персоналом.

Киберзащита включает средства обеспечения защиты от несанкционированного доступа: механическими запорами, ключами, блокировкой сервисов, разграничением доступа, парольной защитой и др.

СВБУ, СВСУ и СРВПЭ разрабатывались по нормам, правилам и традициям СССР. При этом применялись решения, доступные на мировом рынке промышленной электроники, а особенности этого рынка не учитывались. В частности, не было учтено, что показатели надежности компонент не достоверны. Не учитывалось также отсутствие долгосрочных гарантий выпуска продукции в период эксплуатации СВУ и многое другое.

Обслуживание СВБУ, СРВПЭ производится персоналом цеха ТАИ энергоблоков. В этом участвует: сменный персонал (3 смены по 8 часов на пульте АТПС) в составе:

- Оператора АТПС;

- Инженера по эксплуатации программного обеспечения;

- Ремонтный персонал. 
Обслуживающий персонал должен иметь среднюю квалификацию по специальности, связанной с эксплуатацией вычислительной техники, и пройти специальное обучение.

Оператор АТПС должен постоянно находиться на пульте и контролировать работу всего АСУ ТП, включая СВБУ, СВСУ и СРВПЭ.

Наличие инженера по эксплуатации ПО и ремонтников (2 человека в 3 смены) связано с необходимостью выполнения требований по обеспечению надежности, обнаружению отказов и ремонту: например, на АЭС «Бушер-1» отказы должны диагностироваться с задержкой не более 10 секунд, а ремонт (замена сменных узлов) не должен превышать 2-х часов.

Обслуживание СВСУ аналогично, но используется отдельный персонал, не связанный с энергоблоками.

Многолетний опыт внедрения рассматриваемых в данной работе методов позволяет рекомендовать их разработчикам не только АСУ ТП АЭС, но также автоматизированных систем контроля и управления другими сложными техническими объектами. 


\section{ГЛАВА 1 \\ НАЗНАЧЕНИЕ ПРОГРАММНОГО ИНТЕРФЕЙСА}

В данной работе рассматривается компонента комплекса программ $[1,2]$, разработанного в Институте проблем управления им. В.А.Трапезникова Российской академии наук, - «Шлюзовое (интерфейсное) программное обеспечение» (ШИПО), которое включается в состав программного обеспечения шлюзов, предназначенных для сопряжения системы верхнего уровня (СВУ) АСУ ТП со смежными системами (нижнего уровня) АСУ ТП.

ШИПО предназначено для разработки программного обеспечения шлюзов, обеспечивающих обмен информацией между СВУ и смежными системами АСУ ТП. ШИПО обеспечивает единый протокол обмена информацией между СВУ и смежными системами АСУ ТП. ШИПО входит в программно-технические комплексы (ПТК) смежных систем и взаимодействует с программным обеспечением (ПО) этих систем.

Данная работа содержит описание методов унификации алгоритмов обмена данными между программным обеспечением (ПО) СВУ и ПО смежных систем, используемых в АСУ ТП энергоблоков АЭС «Бушер-1» (Иран) и АЭС «Куданкулам-1,2» (Индия), введенных в эксплуатацию, а также строящихся энергоблоков АЭС «Куданкулам-3,4» 


\section{ГЛАВА 2 \\ ОБЛАСТЬ ПРИМЕНЕНИЯ ПРОГРАММНОГО ИНТЕРФЕЙСА}

ШИПО написано на языке программирования C [3]. Для его компиляции используется компилятор gcc (GNU project C compiler.) версии не ниже 3.4 .

Для функционирования ШИПО могут использоваться технические средства:

- шлюзы ПТК систем АСУ ТП, смежных с СВУ;

- серверы и рабочие станции СВУ,с установленными операционными системами с ядром Linux версии 2.6 или выше.

Используемые операционные системы должны включать средства поддержки сетевого протокола ТCP/IP [4-9], используемые для обмена данными между СВУ и шлюзами, на которых устанавливается ШИПО.

Системное время шлюзов должно быть синхронизовано с единым временем СВУ по протоколу NTP [10].

Состав смежных систем нижнего уровня зависит от конкретного энергоблока АЭС. В АЭС «Куданкулам» (Индия) ПО СВУ обменивается данными со следующими смежными системами нижнего уровня АСУ ТП АЭС:

- ПТК систем нормальной эксплуатации АЭС на базе «Типовых программно-технических средств» (ТПТС) разработки Всероссийского научно-исследовательского института автоматики им. Н.Л.Духова (Приложение 2);

- ПТК управляющей системы безопасности технологической (УСБТ) на базе «Комплекса программнотехнических средств повышенной надежности» (КТПСПН) разработки Московского завода «Физприбор» (Приложение 3);

- $\quad$ аппаратурой системы управления и защиты (АСУЗ) разработки Специализированного научноисследовательского института приборостроения;

- $\quad$ комплексом электрооборудования системы управления и защиты (КЭ СУЗ) разработки Всероссийского научноисследовательского института электромеханики; 
- системой контроля, управления и диагностики (СКУД) реакторной установки разработки Национального исследовательского центра «Курчатовский институт»;

- системой технической диагностики главных циркуляционных насосных агрегатов (СТД ГЦНА) разработки Центрального конструкторского бюро машиностроения Кировского завода (Санкт-Петербург);

- системой автоматической противопожарной защиты (САППЗ) разработки Приборного завода «Тензор» (г.Дубна);

- $\quad$ автоматизированной системой радиационного контроля (АСРК) разработки Конструкторского бюро «Проминжиниринг»;

- системой контроля и управления электрической частью (СКУ ЭЧ) на базе контроллеров SICAM производства фирмы Siemens (Приложение 4);

- системой ввода сигналов местных пунктов управления (СВС МПУ) разработки Научно-исследовательского института измерительных систем им. Ю.Е.Седакова (Нижний Новгород).

Связь технических средств СВУ со шлюзами, входящими в состав ПТК на базе всех систем нижнего уровня, осуществляется с использованием сетевого оборудования, реализующего каналы связи сети Ethernet. 


\section{ГЛАВА 3 \\ ОПИСАНИЕ ЗАДАЧИ}

ШИПО состоит из программных модулей:

- основной программный модуль CGP (Communication Gateway Program);

- библиотека функций обмена сигналами с другими модулями ПО шлюза через общую память в виде общих глобальных переменных языка программирования C;

- сетевая библиотека в части функций языка программирования $\mathrm{C}$.

- ПО шлюза, кроме ШИПО, включает:

- программный модуль GATE, обеспечивающий обмен сигналами с модулем CGP;

- другие программные модули ПО шлюза, состав и назначение которых определяется особенностями смежной системы.

ШИПО и модуль GATE собираются в виде одного исполняемого файла ПО шлюза. Модули CGP и GATE обмениваются сигналами между собой через общую память (в виде значений общих глобальных переменных языка программирования С) с использованием библиотеки функций обмена сигналами (рис. 4).

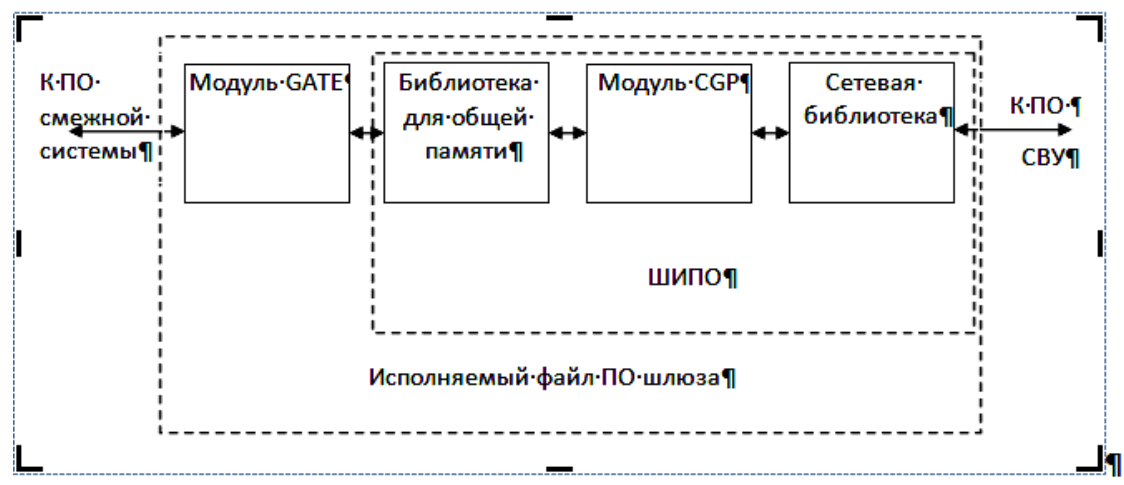

Рис 4. Схема обмена сигналами между модулями CGP и GATE

Общая память модулей CGP и GATE состоит из: 
- массивов, содержащих информацию о текущих значениях сигналов;

- буферов для хранения данных о передаваемых сигналах в порядке их поступления.

Массивы текущих значений сигналов контроля описывают текущее состояние технологического объекта управления (ТОУ). Буфера, хранящие данные о поступивших сигналах, образуют оперативный архив.

Библиотека функций для выполнения операций с массивами и буферами входит в ШИПО.

Структура массивов и буферов неизменна. Размеры массивов определяются количеством сигналов контроля и управления. Буфера имеют кольцевую структуру.

Массивы и буфера создаются модулем CGP при ее инициализации с использованием конфигурационных файлов, содержащих списки проектных технологических индексов всех сигналов. Адреса массивов и буферов в оперативной памяти передаются модулю GATE в виде значений глобальных переменных.

Для уменьшения интенсивности информационных потоков данные, поступающие от смежной системы в СВУ, включают только сигналы контроля, текущие значения которых отличны от предыдущих значений. Признаком изменения аналогового сигнала служит изменение его абсолютного значения на величину больше или равную заданной апертуре сигнала.

Алгоритм функционирования ШИПО определяется алгоритмом обмена сигналами модуля CGP с модулем GATE, описанным в подразделах 3.4.1, 3.4.3, 3.4.5, и алгоритмом обмена сигналами с CBУ, описанным в подразделах 4.2-4.4.

Алгоритм передачи данных из модуля CGP в ПО СВУ можно сформулировать следующим образом:

1) после установления каналов связи модуль CGP посылает процессам ПО СВУ все сигналы, относящиеся к этому шлюзу;

2) процессы CBУ посылают модулю CGP запросы прислать обновившиеся данные;

3) в ответ на каждый поступающий из процесса СВУ запрос модуль CGP посылает сигналы, изменившиеся после предыдущего запроса. 
Интенсивность посылок запросов данных модулю CGP зависит от скорости обработки данных процессом СВУ. Применяемый алгоритм передачи входных сигналов позволяет избежать неконтролируемого накопления очередей необработанных данных в буферах сетевых каналов связи в условиях большой интенсивности потока данных из смежных систем АСУ ТП в СВУ.

Посылка команд управления операторов из процессов СВУ в модуль CGP осуществляется без предварительных запросов, поскольку большая интенсивность потока команд управления невозможна, что позволяет ускорить прохождение команд.

Каждый массив текущих значений входных сигналов состоит из элементов, описывающих все сигналы соответствующего типа (подраздел 3.1). Запись данных в массивы текущих значений входных сигналов выполняется при получении ПО шлюза обновленных значений соответствующих сигналов или при изменении признаков недостоверностей значений сигналов. Считывание данных из массивов текущих значений входных сигналов выполняется при дальнейшей передаче данных процессам СВУ.

Каждому массиву текущих значений входных сигналов соответствует кольцевой буфер, предназначенный для сохранения предыдущих значений сигналов. Копирование информации из массива текущих значений в кольцевой буфер выполняется перед обновлением данных в массиве текущих значений при условии, что предыдущее обновление сигнала не было считано из массива текущих значений для дальнейшей передачи процессам СВУ.

При поступлении из процесса СВУ очередного запроса данных модуль CGP посылает в ответ:

- все сигналы из массивов текущих значений входных сигналов, обновившиеся после предыдущего запроса;

- все сигналы из кольцевых буферов входных сигналов, сохраненные после предыдущего запроса.

Совместное использование массивов текущих значений входных сигналов и кольцевых буферов в условиях применения алгоритма передачи сигналов по схеме «запрос-ответ» позволяет оперативно передавать в ПО СВУ актуальные данные без потерь хронологии поступления данных, которая сохраняется в архиве СВУ. 


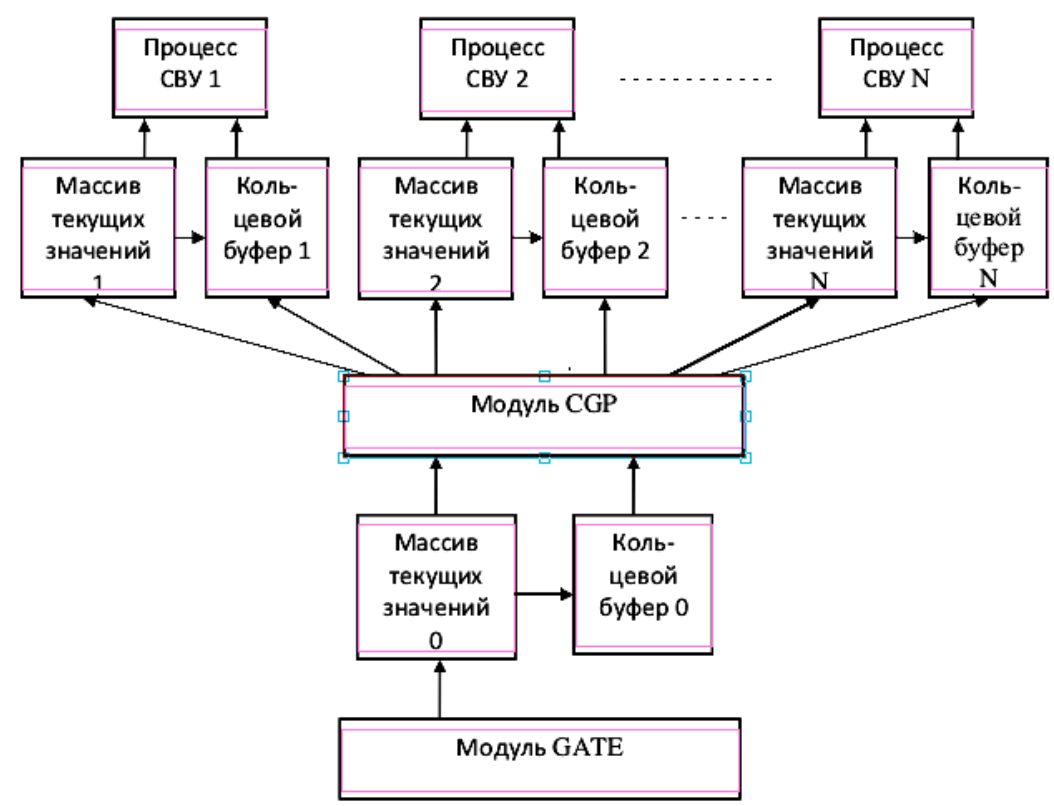

Рис. 5 - Схема передачи входных сигналов через ПО шлюза

На рис.5 представлена схема передачи входных сигналов одного типа (подраздел 3.1) из модуля GATE в модуль CGP и далее N процессам СВУ. Для передачи сигналов каждому процессу СВУ, устанавливающему связь с ПО шлюза, модуль CGP использует отдельные массив текущих значений и кольцевой буфер (на рис.5 массивы и буфера с номерами $1,2 \ldots \mathrm{N})$. Для передачи сигналов из модуля GATE в модуль CGP используются массив текущих значений и кольцевой буфер, обозначенные на рис. 5 номером 0.

Поскольку поток команд управления операторов не может иметь большую интенсивность, передача выходных сигналов из процессов CBУ в модуль CGP и далее в модуль GATE выполняется с использованием только кольцевых буферов, в которые записываются и считываются все выходные сигналы соответствующего типа в порядке их поступления. 


\section{1. Структура массивов в общей памяти}

Для обмена сигналами между модулями CGP и GATE через общую память используются массивы типов, представленных в таблице 1.

\section{Таблица 1}

массивы в общей памяти

\begin{tabular}{|c|c|}
\hline Имя массива & $\overline{\text { OII }}$ \\
\hline INPUT A & BXO2 \\
\hline INPUT_D & ний входных диск \\
\hline INPUT AV & ний входных аналоговых векторных сигналов \\
\hline INPUT_DV & тных векторных сигналов \\
\hline INPUT_DF & $\begin{array}{l}\text { массив значений входных дискретных диагностических сиг- } \\
\text { налов }\end{array}$ \\
\hline NAME_IA & $\begin{array}{l}\text { массив проектных технологических индексов входных ана- } \\
\text { логовых сигналов }\end{array}$ \\
\hline NAME_ID & $\begin{array}{l}\text { массив проектных технологических индексов входных дис- } \\
\text { кретных сигналов }\end{array}$ \\
\hline NAME_IAV & $\begin{array}{l}\text { массив проектных технологических индексов входных ана- } \\
\text { логовых векторных сигналов }\end{array}$ \\
\hline NAME_IDV & $\begin{array}{l}\text { массив проектных технологических индексов входных дис- } \\
\text { кретных векторных сигналов }\end{array}$ \\
\hline NAME_IDE & $\begin{array}{l}\text { массив проектных технологических индексов входных дис- } \\
\text { кретных диагностических сигналов }\end{array}$ \\
\hline NAME_OA & $\begin{array}{l}\text { массив проектных технологических индексов выходных } \\
\text { аналоговых сигналов }\end{array}$ \\
\hline NAME_OD & $\begin{array}{l}\text { массив проектных технологических индексов выходных } \\
\text { дискретных сигналов }\end{array}$ \\
\hline APERTURE & в значений апертур входных аналоговых сигналов \\
\hline APERTURE_V & $\begin{array}{l}\text { массив значений апертур входных аналоговых векторных } \\
\text { сигналов }\end{array}$ \\
\hline TIME_A & $\begin{array}{l}\text { массив моментов времени последнего изменения входных } \\
\text { аналоговых сигналов }\end{array}$ \\
\hline TIME_D & $\begin{array}{l}\text { массив моментов времени последнего изменения входных } \\
\text { дискретных сигналов }\end{array}$ \\
\hline TIME_AV & $\begin{array}{l}\text { массив моментов времени последнего изменения входных } \\
\text { аналоговых векторных сигналов }\end{array}$ \\
\hline
\end{tabular}




\begin{tabular}{|l|l|}
\hline Имя массива & \multicolumn{1}{|c|}{ Описание массива } \\
\hline TIME_DV & $\begin{array}{l}\text { массив моментов времени последнего изменения входных } \\
\text { дискретных векторных сигналов }\end{array}$ \\
\hline TIME_DF & $\begin{array}{l}\text { массив моментов времени последнего изменения входных } \\
\text { дискретных диагностических сигналов }\end{array}$ \\
\hline UPDATE_IA & массив флагов обновления входных аналоговых сигналов \\
\hline UPDATE_ID & массив флагов обновления входных дискретных сигналов \\
\hline UPDATE_IAV & $\begin{array}{l}\text { массив флагов обновления входных аналоговых векторных } \\
\text { сигналов }\end{array}$ \\
\hline UPDATE_IDV & $\begin{array}{l}\text { массив флагов обновления входных дискретных векторных } \\
\text { сигналов }\end{array}$ \\
\hline UPDATE_IDF & $\begin{array}{l}\text { массив флагов обновления входных дискретных диагности- } \\
\text { ческих сигналов }\end{array}$ \\
\hline
\end{tabular}

Примечание. Термины «входные», «выходные» сигналь характеризуют направление передачи данных по отночению к СВУ.

Элементы массивов INPUT_A, NAME_IA, APERTURE, TIME_A, UPDATE_IA соответствуют друг другу по их номеру.

Элементы массивов INPUT_D, NAME_ID, TIME_D, UPDATE_ID соответствуют друг другу по их номеру.

Элементы массивов INPUT_AV, NAME_IAV, APERTURE_V, TIME_AV, UPDATE_IAV соответствуют друг другу по их номеру.

Элементы массивов INPUT_DV, NAME_IDV, TIME_DV, UPDATE_IDV соответствуют друг другу по их номеру.

Элементы массивов INPUT_DF, NAME_IDF, TIME_DF, UPDATE_IDF соответствуют друг другу по их номеру.

B терминах языка программирования C массивы INPUT_A, OUTPUT_A, APERTURE, APERTURE_V состоят из элементов типа float (4-байтовое вещественное число с плавающей точкой). Массивы INPUT_D, OUTPUT_D, UPDATE_IA, UPDATE_ID, UPDATE_IAV, UPDATE_IDV, UPDATE_EDF, UPDATE_OA, UPDATE_OD состоят из элементов типа char (1-байтовое целое число).

Массив INPUT_AV состоит из элементов, каждый из которых является массивом размерности IAV_SIZE с элементами типа float. Массивы INPUT_DV, INPUT_DF состоят из элементов, каждый из которых является массивом размерности IDV_SIZE с элементами 
типа char. Константы IAV_SIZE, IDV_SIZE определены в файле gate_shm.h (подраздел 3.2). В данной версии ШИПО константы IAV_SIZE, IDV_SIZE установлены равными 16.

Массивы NAME_IA, NAME_ID, NAME_IAV, NAME_IDV, NAME_IDF, NAME_OA, NAME_OD состоят из элементов типа char* (указатель на строку символов). При этом количество символов (включая завершающий символ ' $\backslash 0^{\prime}$ ) для каждого элемента не должно превышать значения константы NAME_LENGTH, определенной в файле gate_shm.h.

Элементами массивов TIME_A, TIME_D, TIME_AV, TIME_DV, TIME_DF являются структуры, тип которых определен в файле gate_shm.h:

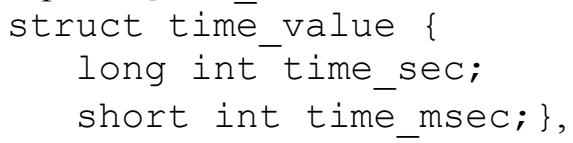

где

time_sec - время в секундах с 00:00:00 1 января 1970г.,

time_msec - время в миллисекундах.

В поле time_msec для значения времени используются первые 10 бит. В 10-том бите (нумерация бит начинается с 0) содержится признак недостоверности значения сигнала: 1 - недостоверность, 0 - достоверность. В 11-том бите содержится признак недостоверности времени изменения сигнала: 1 - недостоверность, 0 - достоверность. В 12-том бите содержится признак того, что сигнал не должен записываться в архив СВУ: 1 - не записывается, 0 - записывается. В 13-том бите содержится признак того, что сигнал получен модулем GATE от ПО смежной системы первый раз после загрузки: 1 - первый раз, 0 - не первый раз. В 14-том бите содержится признак того, что сигнал имитируется в модуле GATE (а не получен от ПО смежной системы): 1 - имитируется, 0 - не имитируется.

Списки проектных технологических индексов сигналов, являющихся значениями элементов массивов NAME_IA, NAME_ID, NAME_IAV, NAME_IDV, NAME_IDF, NAME_OA, NAME_OD, содержатся в следующих текстовых (ASCII) конфигурационных файлах:

- name_ia.dat - входные аналоговые сигналы; 
- name_id.dat - входные дискретные сигналы;

- name_iav.dat - входные аналоговые векторные сигналы;

- name_idv.dat - входные дискретные векторные сигналы;

- name_idf.dat - входные дискретные диагностические сигналы;

- name_oa.dat - выходные аналоговые сигналы;

- name od.dat - выходные дискретные сигналы.

Каждая строка этих файлов содержит следующие значения, разделенные пробелами:

- проектный технологический индекс сигнала;

- номер соответствующего элемента в массиве (нумерация элементов начинается с нуля).

B каждой строке файлов name_ia.dat, name_iav.dat после перечисленных значений содержится значение апертуры соответствующего входного аналогового сигнала, присваиваемое элементу массивов APERTURE, APERTURE_V.

\section{2. Программное обеспечение доступа к массивам в общей памяти}

Для операций с массивами в общей памяти модулей CGP и GATE служит библиотека функций, написанных на языке программирования С и содержащихся в файле gate_shm. с. Константы, типы данных и прототипы функций определены в файлах gate_shm.h, cgp_err.h.

Функция int aopen(char * name_array, enum array_types type_array) создает в общей памяти массивы для сигналов, тип которых задается параметром name_array. Строка name_array должна иметь завершающий символ ' $\backslash 0$ ' и может принимать одно из следующих значений:

- INPUT_A - для входных аналоговых сигналов;

- INPUT_D - для входных дискретных сигналов; 
- INPUT_AV - для входных аналоговых векторных сигналов;

- INPUT_DV - для выходных дискретных векторных сигналов;

- INPUT_DF - для выходных дискретных диагностических сигралов;

- OUTPUT_A - для выходных аналоговых сигналов;

- OUTPUT_D - для выходных дискретных сигналов.

Параметр type_array перечислимого типа array_types (определенного в файле gate_shm.h) указывает тип общей памяти и имеет в данной версии ШИПО значение DIN - динамическая оперативная память.

Функция aopen возвращает в качестве своего значения 0 при нормальном завершении или -1 при выходе с ошибкой. При создании массивов всем их элементам присваиваются нулевые значения.

Функция aopen создает массивы на основе конфигурационных файлов name_ia.dat, name_id.dat, name_iav.dat, name_idv.dat, name_idf.dat, name_oa.dat, name_od.dat (подраздел 3.1). Число элементов массивов не должно превосходить значений следующих констант, задаваемых в файле gate_shm. h:

- M_INPUT_A - для входных аналоговых сигналов;

- M_INPUT_D - для входных аналоговых сигналов;

- M_INPUT_AV - для входных аналоговых векторных сигналов;

- M_INPUT_DV - для входных дискретных векторных Сйналов;

- M_INPUT_DF - для входных дискретных диагностических сигналов;

- M_OUTPUT_A - для выходных аналоговых сигналов;

- M_OUTPUT_D - для выходных дискретных сигналов.

Функция long int ainit(char * name_array) в качестве своего значения возвращает ссылочный номер на массив, имя которого задается строкой name_array и должно совпадать с одним из имен массивов, приведенных в таблице 1. Строка 
name_array должна иметь завершающий символ ' $\backslash 0$ '. При выходе с ошибкой функция возвращает нулевое значение 0L.

Функция int anumber (long int narray)в качестве своего значения возвращает число элементов массива со ссылочным номером narray.

Функция char * aread(long int narray, int nelement) в качестве своего значения функция возвращает указатель на область памяти, содержащую значение элемента с номером nelement в массиве со ссылочным номером narray. Размер этой области памяти определяется типом элементов массива. При выходе с ошибкой функция возвращает нулевой указатель NULL.

Функция int awrite(long int narray, int nelement, char * value) присваивает элементу с номером nelement в массиве со ссылочным номером narray значение из области памяти, передаваемое по указателю value. Размер этой области памяти определяется типом элементов массива. В качестве своего значения функция возвращает значение 0 при нормальном завершении или -1 при выходе с ошибкой.

Функция int aclose ( ) освобождает общую память, занятую всеми массивами, возвращая в качестве своего значения 0 при нормальном завершении или -1 при выходе с ошибкой.

\section{3. Программное обеспечение доступа к буферам в общей памяти}

Для операций с кольцевыми буферами в общей памяти модулей CGP и GATE служит библиотека функций, написанных на языке программирования $\mathrm{C}$ и содержащихся в файле gate_shm. c. Константы, типы данных и прототипы функций определены в файлах gate_shm.h, cgp_err.h.

Функция long int cbinit(char * name_array, enum array_types type_array) создает кольцевой буфер в общей памяти для сигналов, тип которых задается параметром name_array. Строка name_array должна иметь завершающий символ ' 10 ' и может принимать одно из следующих значений:

- INPUT_A - буфер для входных аналоговых сигналов; 
- INPUT_D - буфер для входных дискретных сигналов;

- INPUT_AV - буфер для входных аналоговых векторных сигналов;

- INPUT_DV - буфер для входных дискретных векторных сигналов;

- INPUT_DF - буфер для входных дискретных диагностических сигналов;

- OUTPUT_A - буфер для выходных аналоговых сигналов;

- OUTPUT_D - буфер для выходных дискретных сигналов.

Параметр type_array перечислимого типа array_types (определенного в файле gate_shm.h) указывает тип общей памяти и имеет в данной версии ШИПО значение DIN - динамическая оперативная память.

Функция cbinit возвращает в качестве своего значения ссылочный номер этого буфера или значение OL при выходе с ошибкой.

Буфера, создаваемые функцией cbinit, состоят из структур, типы которых определены в файле gate_shm.h. Буфер для входных аналоговых сигналов состоит из структур:

struct analog_i

unsigned short int elem;

float fvalue;

struct time value tvalue;,

где

elem - номер сигнала в массиве NAME_IA;

fvalue - значение сигнала;

tvalue - момент времени, в который значение сигнала стало равным fvalue.

Буфер для входных дискретных сигналов состоит из структур: struct discrete_i

unsigned short int elem;

char cvalue;

struct time_value tvalue; \},

где

elem - номер сигнала в массиве NAME_ID;

cvalue - значение сигнала; 
tvalue - момент времени, в который значение сигнала стало равным cvalue.

Буфер для входных аналоговых векторных сигналов состоит из структур:

struct analog_iv \{

unsigned short int elem;

float fvalue[IAV SIZE];

struct time_value tvalue;,

где

elem - номер сигнала в массиве NAME_IAV;

fvalue - массив значений сигнала;

tvalue - момент времени, в который значение сигнала стало равным cvalue.

Буфер для входных дискретных векторных или диагностических сигналов состоит из структур:

struct discrete_iv \{

unsigned short int elem;

char cvalue[IDV_SIZE];

struct time value tvalue; ,

где

elem - номер сигнала в массиве NAME_IDV или NAME_IDF;

cvalue - массив значений сигнала;

tvalue - момент времени, в который значение сигнала стало равным cvalue.

Буфер для выходных аналоговых сигналов состоит из структур: struct analog_o \{

unsigned short int elem;

float fvalue;

где

elem - номер сигнала в массиве NAME OA;

fvalue - значение сигнала.

Буфер для выходных дискретных сигналов состоит из структур struct discrete $\circ$ \{

unsigned short int elem;

char cvalue; ,

где

elem - номер сигнала в массиве NAME_OD;

cvalue - значение сигнала. 
Размеры кольцевых буферов (число структур в буферах) определяются значениями следующих констант, ограничивающих количество значений параметров в буфере (см. файл gate_shm.h):

- CBSIZE_IA - для входных аналоговых сигналов;

- CBSIZE_ID - для входных дискретных сигналов;

- CBSIZE_IAV - для входных аналоговых векторных сигналов;

- CBSIZE_IDV - для входных дискретных векторных сигналов;

- CBSIZE_IDF - для входных дискретных диагностических сигналов;

- CBSIZE_OA - для выходных аналоговых сигналов;

- CBSIZE_OD - для выходных дискретных сигналов.

Операции записи и считывания для кольцевых буферов реализуют поток данных: считанные данные удаляются из потока. Если считывающая программа не успевает освобождать буфер, то он может переполниться (число записей в потоке может превысить размер буфера). Переполнение буфера приводит к потере данных.

Функция int cbread(long int ncircle, char * value) считывает очередное значение сигнала из кольцевого буфера со ссылочным номером ncircle. Параметр value передает указатель на структуру, в которую записываются считываемые данные. Тип этой структуры (один из перечисленных выше типов) должен соответствовать типу сигналов. Функция cbread возвращает значение:

- 1 - из буфера считано очередное значение сигнала;

- 0 - буфер не содержит новых данных для считывания (с момента предыдущего считывания не было новых записей);

- $\quad-1$ - выход с ошибкой.

Для того, чтобы считать все новые данные, записанные с момента предыдущего считывания, необходимо выполнять функцию cbread в цикле до тех пор, пока она возвращает значение 1.

Функция int cbwritellong int ncircle, char * value) записывает очередное значение сигнала в кольцевой буфер со ссылочным номером ncircle. Параметр value передает указа- 
тель на структуру, которая содержит записываемые данные. Тип этой структуры (один из перечисленных выше типов) должен соответствовать типу буфера. Функция cbwrite возвращает значение:

- 0 - нормальное завершение;

- 1 - запись очередного сигнала с переполнением буфера (с потерей одного наиболее старого сигнала);

- $\quad-1$ - выход с ошибкой.

Функция int cbclose(long int ncircle) освобождает общую память, занятую кольцевым буфером со ссылочным номером ncircle, возвращая в качестве своего значения 0 при нормальном завершении или -1 при выходе с ошибкой.

\section{4. Обмен сигналами через общую память}

Сигналы контроля, передаваемые от модуля GATE к модулю CGP (от ТОУ к СВУ), необходимы для:

- отображения текущего состояния ТОУ;

- архивирования поступающих сигналов.

Данные для отображения текущего состояния объекта поступают из массивов текущих значений сигналов в общей памяти (подраздел 3.2). Данные для архива поступают как из массивов текущих значений, так и из буферов (подраздел 3.3), что предотвращает возможную потерю информации при пиковых потоках данных (при больших скоростях обновления текущих значений в массивах).

Сигналы управления, передаваемые от модуля CGP к модулю GATE, необходимы для передачи управляющих воздействий от CBУ к ТОУ. Поскольку одновременная передача всех сигналов управления, как правило, не требуется, то сигналы управления передаются через буфера в общей памяти (подраздел 3.3).

Необходимость приема сигналов в данный момент времени (наличие хотя бы одного нового сигнала с момента предыдущего считывания) характеризуется флагами обновления в следующей структуре, описанной в файле gate_shm.h:

struct tchange \{

char flag_cgp; /* прием сигналов модулем CGP */

char flag_gate; /* прием сигналов модулем GATE */

\} 


\subsection{1. Инициализация общей памяти}

Модуль CGP, написанный на языке программирования C, инициализирует общую память для обмена данными с модулем GATE:

/* Создание массивов текущих данных: */

aopen ("INPUT_A", DIN);
aopen("INPUT_D", DIN);
aopen("INPUT_AV", DIN);
aopen("INPUT_DV", DIN);
aopen("INPUT_DF", DIN);
aopen("OUTPUT_A", DIN);
aopen("OUTPUT_D", DIN);

/* Присвоение ссылочных номеров массивов следующим глобальным nеременным типа long int: */

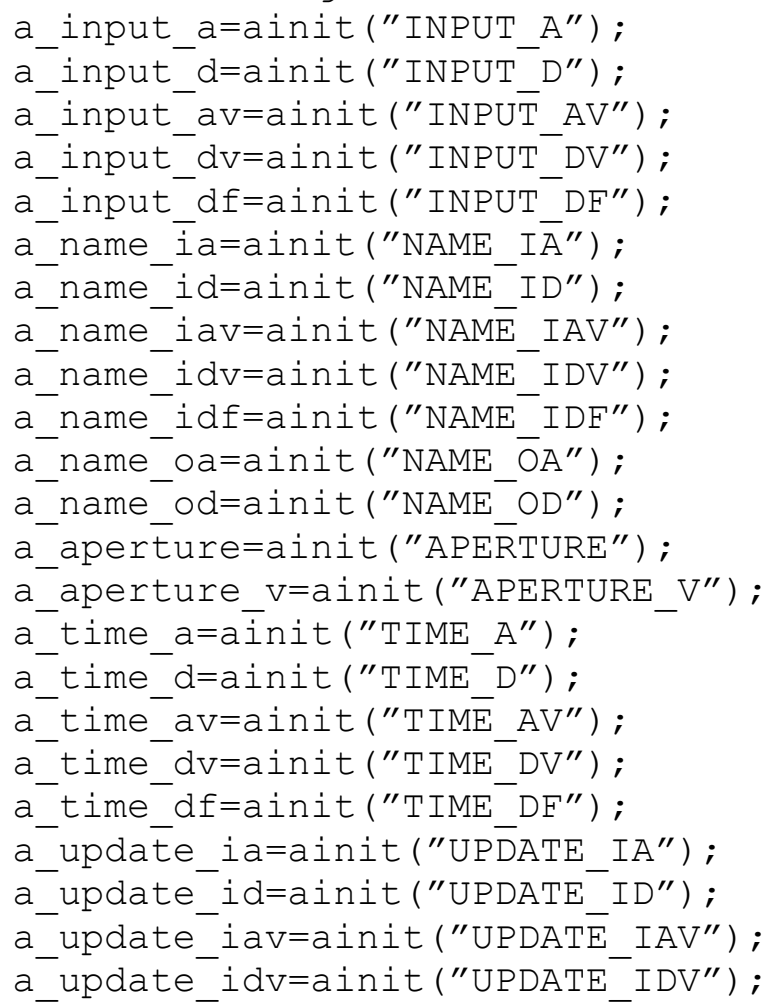


a_update_idf=ainit ("UPDATE_IDF") ;

/* Присвоение числа элементов в массивах следующим глобальным nеременным muna int:*/

n_input_a=anumber (a_name_ia) ;

n_input_d=anumber (a_name_id);

n_input_av=anumber (áaname_iav);

$n-i n p u t+d v=a n u m b e r(a-n a m e-i d v)$;

n_input_df=anumber (a_name_idf);

n_output_a=anumber (a_name_oa) ;

n_output_d=anumber (a_name_od);

/* Создание кольцевых буферов с присвоением ссылочных номеров, следующим глобальным переменным типа long int: */

a_circle_ia=cbinit ("INPUT_A") ;
a_circle_id=cbinit ("INPUT_D") ;
a_circle_iav=cbinit ("INPUT_AV") ;
a_circle_idv=cbinit ("INPUT_DV") ;
a_circle_idf=cbinit ("INPUT_DF") ;
a_circle_oa=cbinit ("OUTPUT_A");
a_circle_od=cbinit ("OUTPUT_D");

/* Инициализаичия глобальной переменной stchange, являющейся структурой muna tchange: */

stchange.flag_cgp $={ }^{\prime} \backslash 000^{\prime}$;

stchange.flag_gate $={ }^{\prime} \backslash 000^{\prime}$;

Значения перечисленных глобальных переменных передаются модулю GATE в виде значений глобальных переменных.

При завершении работы модуль CGP освобождает общую память путем обращения к функциям aclose, cbclose.

\subsection{2. Передача сигналов от GATE к CGP}

\subsubsection{1. Передача значения аналогового сигнала уа}

Модуль GATE, написанный на языке программирования C, передает модулю CGP значение аналогового сигнала va с номером n:

\{ int $\mathrm{n}$; $\operatorname{char} \mathrm{c}, \mathrm{cu}=^{\prime} \backslash 001^{\prime}$;

float va, val, aper; struct analog_i cbval_ia; 
/* Предыдущее значение сигнала: */

va0 $=*(($ float $*)$ aread (a_input_a, n) );

/* Апертура сигнала: */

aper $=$ * ( float *) aread (a_aperture, $\mathrm{n}))$;

/* Если новое значение сигнала отличается по абсолютному значению от предыдущего значения не мене, чем на апертуру: */

if ( $(\mathrm{va}<=$ vaO - aper) || (va $>=$ va 0 taper) )

/* Состояние флага обновления: */

$$
\mathrm{c}=\text { * aread (a_update_ia, n); }
$$

/* Если предыдущее значение сигнала не было считано модулем CGP: */

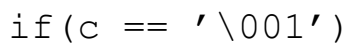

/* Сохранение предыдущих значений сигнала и соответствующего времени его изменения в кольиевом буфере: */

cbval_ia.elem =n; cbval_ia.fvalue= va0;

cbval_ia.tvalue $=$ *( (struct time_value *) aread (a_time_a, n));

cbwrite(a_circle_ia, (char *) \&cbval_ia);

\}

/* Запись текущего значения сигнала: */

awrite (a_input_a, n, (char *) \&va);

/* Запись времени изменения сигнала, являющегося значением переменной timev muna struct time_value: */

awrite (a_time_a, n, (char *) \&timev);

/ Установка флагов обновления: */

\section{$\prime \backslash 001^{\prime} ;$}

awrite (a_update_ia, $\mathrm{n}$, \&cu); stchange.flag_cgp =

\}

\}

Более подробно передача аналогового сигнала от GATE к CGP, включая передачу признаков недостоверностей, описана в Приложении 1. 


\subsubsection{2. Передача значения дискретного сигнала vd}

Передача модулем GATE модулю CGP значения дискретного сигнала $\mathrm{vd}$ c номером $\mathrm{n}$ происходит аналогично:

\{ int $\mathrm{n}$; char $\mathrm{vd}, \mathrm{vdO}, \mathrm{c}, \mathrm{cu}={ }^{\prime} \backslash 001^{\prime}$;

struct discrete_i cbval_id;

/* Предыдущее значение сигнала: */

$\mathrm{vdO}=\star$ aread (a_input_d, n);

/* Если новое значение сигнала отллчается от предыдущего: */

if( $\mathrm{vd} !=\mathrm{vdO})$

\{

/* Состояние флага обновления: */

$\mathrm{c}=$ * aread (a_update_id, n);

/* Если предыдущее значение сигнала не было считано модулем CGP: */

$$
\text { if }\left(\mathrm{C}==' \backslash 001^{\prime}\right)
$$

/* Сохранение предыдущих значений сигнала и соответствующего времени его изменения в кольиевом буфере: */

cbval_id.elem =n; cbval_id.cvalue= vd0;

cbval_id.tvalue $=$ *( (struct time_value *) aread (a_time_d, n));

cbwrite (a_circle_id, (char *) \&cbval_id);

/* Запись текущего значения сигнала: */

awrite (a_input_d, n, \&vd);

/* Запись времени изменения сигнала, являющегося значением переменной timev muna struct time_value: */

awrite (a_time_d, n, (chär *) \&timev);

/* Установка филагов обновления: */

awrite (a_update_id, $\mathrm{n}, \mathrm{ccu}$ );

stchange.flag_cgp $={ }^{\prime} \backslash 001^{\prime}$;

\}

\}

Более подробно передача дискретного сигнала от GATE к CGP, включая передачу признаков недостоверностей, описана в Приложении 1. 


\subsubsection{3. Передача значения векторного аналогового}

\section{сигнала уау}

Модуль GATE передает модулю CGP значение векторного аналогового сигнала vav с номером n:

\{ int $\mathrm{n}, \mathrm{i}, \mathrm{k}$; $\operatorname{char} \mathrm{c}, \mathrm{cu}=\mathbf{\prime}^{\prime} \backslash 001^{\prime}$;

float vav[IAV_SIZE], vav0[IAV_SIZE], aper;

struct analog_iv cbval_iav;

/* Предыдущее значение сигнала: */

memcpy ( (char *) vav0, aread (a_input_av, n), IAV_SIZE*sizeof(float));

/* Anертура сигнала: */

aper $=*(($ float $*)$ aread (a_aperture_v, n ) ) ;

/* Если хотя бы одно из новых значений сигнала отличается по абсолютному значению от предыдущего значения не менее чем на anepmypy: */

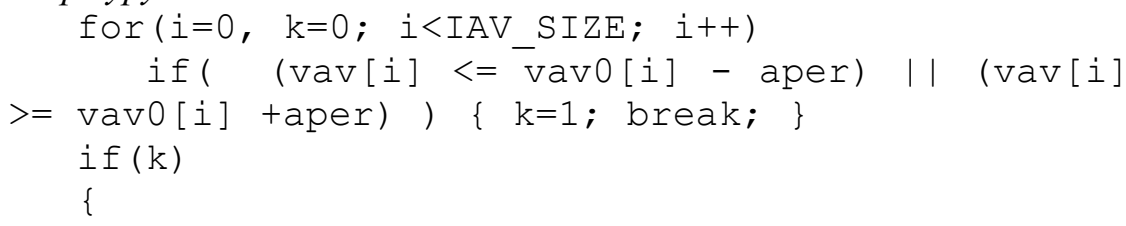

/* Состояние флага обновления: */

$\mathrm{c}=\star \operatorname{aread}(\mathrm{a}$ update_iav, n);

/* Если предыдущее значение сигнала не было считано модулем CGP:*/

$$
\text { if }\left(\mathrm{c}==\prime \backslash 001^{\prime}\right)
$$

/* Сохранение предыдущих значений сигнала и соответствующего времени его изменения в кольиевом буфере: */

cbval_iav.elem $=n$;

memcpy ((char *) (cbval_iav.fvalue), (char *) vav0, IAV SIZE*sizeof(float)) ;

cbval_iav.tvalue $=$ ((struct time value *) aread (a_time_av, n)) ;

cbwrite (a_circle_iav, (char *) \&cbval_iav);

* Запись текущих значений сигнала: */

awrite (a_input_av, n, (char *) vav); 
/* Запись времени изменения сигнала, являющегося значением переменной timev muna struct time value: */

awrite (a time av, n, (char *) \&timev);

/* Установка фолагов обновления: */

awrite (a_update_iav,

$\mathrm{n}$

$\& \mathrm{Cu})$; stchange.fläg_cgp $=\prime \backslash 001^{\prime}$;

\}

\}

3.4.2.4. Передача значения векторного дискретного сигнала vdv

Модуль GATE передает модулю CGP значение векторного дискретного сигнала $\mathrm{vdv}$ с номером $\mathrm{n}$ :

\{ int $\mathrm{n}, \mathrm{i}, \mathrm{k}$;

char vdv[IDV_SIZE], vdv0[IDV_SIZE], char c, $\mathrm{cu}={ }^{\prime} \backslash 001^{\prime}$;

struct discrete_iv cbval_idv;

/* Предыдущее значение сигнала: */

memcpy (vdv0, aread (a_input_dv, n), IDV_SIZE) ;

/ Если хотя бы одно из новых значений сигнала отличается от предьдущего значения: * /

for ( $i=0, k=0 ; i<\operatorname{IDV}$ SIZE; $i++)$

if( $\mathrm{vdv}[\mathrm{i}] \mathrm{l}=\mathrm{v} \overline{\mathrm{d}} \mathrm{v} 0[\mathrm{i}]) \quad\{\mathrm{k}=1$; break;

if $(k)$

\{

/* Состояние флага обновления: */

$\mathrm{c}=\star \operatorname{aread}\left(\mathrm{a} \_\right.$update_idv, n);

/ Если предыдущее значение сигнала не было считано модулем $C G P: * /$

$$
\text { if }\left(\mathrm{C}=={ }^{\prime} \backslash 001^{\prime}\right)
$$

/* Сохранение предыдущих значений сигнала и соответствуюшего времени его изменения в кольиевом буфере: */

cbval_idv.elem $=n$;

memcpy ( cbval idv.fvalue, vdv0, IDV_SIZE);

cbval_idv.tvalue $=*($ (struct time_value $*)$

aread (a time $d v, n)$ );

ç̄oritē (a_circle_idv,

(char

*)

\&cbval_idv) ; 
/* Запись текуших значений сигнала: */

awrite (a_input_dv, $\mathrm{n}, \mathrm{vdv}$ ) ;

* Запись времени изменения сигнала, являющегося значением переменной timev muna struct time value: */

awrite (a_time dv, n, (char *) \&timev) ;

/* Установка флагов обновления: */ $八 001^{\prime} ;$

awrite (a_update_idv, n, \&cu); stchange.flag_cgp =

\subsection{3. Прием сигналов в CGP от GATE}

\subsubsection{1. Проверка состояние флага обновления}

Модуль CGP, написанный на языке программирования C, при приеме сигналов от модуля GATE проверяет состояние флага обновления stchange.flag_cgp. Если этот флаг находится в состоянии ' $\backslash 001$ ', то модуль CGP устанавливает его равным ' $\backslash 000^{\prime}$ и проверяет состояние флагов обновления всех сигналов контроля.

Для аналогового сигнала с номером $\mathrm{n}$ :

\{ float va; int $\mathrm{n}$; char $\mathrm{cu}={ }^{\prime} \backslash 000^{\prime}$; struct time value timev;

/* Проверка состояния флага обновления: */

if $\left(\right.$ * aread (a_update_ia, n) $\left.==\prime^{\prime} \backslash 001^{\prime}\right)$

/* Текущее значение сигнала: */

$$
\mathrm{va}=\star\left((\text { float } *) * \operatorname{aread}\left(a_{-} \text {input_a, } \mathrm{n}\right)\right) \text {; }
$$

/* Время изменения сигнала: */

$$
\text { timev }=*((\text { struct time_value *) * }
$$

aread (a time a));

/* Установка флага обновления: */

awrite (a update ia, n, \&cu);

/* Передача значения сигнала vа и времени timev в СВУ: */ 
Для дискретного сигнала с номером n:

\{ char $\mathrm{vd}, \mathrm{cu}={ }^{\prime} \backslash 000^{\prime}$; int $\mathrm{n}$; struct time value timev;

/* Проверка состояния флага обновления: */

if $\left(* \operatorname{aread}(a\right.$ update_id, $\left.\mathrm{n})=={ }^{\prime} \backslash 001^{\prime}\right)$

\{

/* Текущее значение сигнала: */

$\mathrm{vd}=* \operatorname{aread}\left(a_{-}\right.$input_d, n));

/* Время изменения сигнала: */

timev $=*(($ struct time_value $*) *$

$\operatorname{aread}($ a_time_d)) ;

/* Установка флага обновления: */

awrite (a_update_id, n , \&cu);

/* Передача значения сигнала vd и времени timev в CВУ: */

\}

Для аналогового векторного сигнала с номером n:

\{ float vav[IAV SIZE]; int $\mathrm{n}$; char $\mathrm{cu}={ }^{\prime} \backslash 000^{\prime}$; struct time_value timev;

/* Проверка состояния флага обновления: */

if $\left(* \operatorname{aread}\left(\right.\right.$ a_update_iav, n) $\left.=={ }^{\prime} \backslash 001^{\prime}\right)$

\{

/* Текущее значение сигнала: */

memcpy ((char *) vav, aread (a_input_av, n), IAV_SIZE * sizeof(float));

/* Веремя изменения сигнала: */

$$
\text { timev }=*((\text { struct time_value *) * }
$$

$\operatorname{aread}($ a_time_av));

/* Установка флага обновления: */

awrite(a_update_iav, n, \&cu);

/* Передача массива значений сигнала vav и времени timev в СВУ: */

\}

Для дискретного векторного сигнала с номером n:

\{ char vdv[IDV_SIZE], $\quad \mathrm{cu}^{\prime \prime} \backslash 000^{\prime} ;$ int $\mathrm{n}$; struct time_value timev; 
* Проверка состояния флага обновления: */

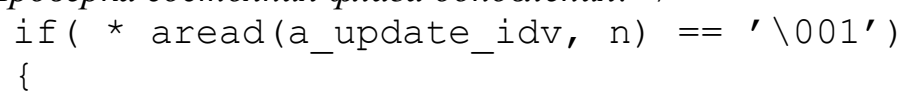

/* Текущее значение сигнала: */

memcpy (vdv, aread (a_input_dv, n), IDV_SIZE) ; /* Время изменения сигнала: */

$$
\text { timev }=\text { *( struct time_value *) * }
$$

aread (a_time_dv));

/* Установка флага обновления: */

awrite (a_update_idv, n, \&cu) ;

/* Передача массива значений сигнала vdv и времени timev в СВУ: */

\}

\}

3.4.3.2. Проверка наличия данных в буферах для

\section{архивирования}

Кроме проверки флагов обновления, модуль CGP проверяет наличие данных в буферах для архивирования.

Для аналоговых сигналов:

\{ struct analog_i cbval_ia;

/* Считывание всех данных из буфрера со ссылочным номером a_circle_ia: */

while (cbread(a_circle_ia, (char *) \&cbval_ia) $>0$ )

/* Передача в СВУ номера сигнала сbval_ia.elem, значения сигнала cbval_ia.fvaluе и времени cbval_ia.tvalue: */

\}

Для дискретных сигналов:

\{ struct discrete_i cbval_id;

/* Считьвание всех данныхх из буфера со ссылочным номером a_circle_id: */

while (cbread (a_circle_id, (char *) \&cbval_id) $>0$ ) 
/* Передача в СВУ номера сигнала сbval_id.elem, значения сигнала cbval_id.cvalue и времени сbval_id.tvalue: */

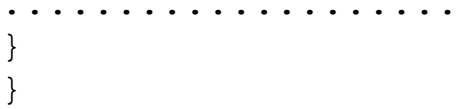

Для аналоговых векторных сигналов:

\{ struct analog_iv cbval_iav;

/* Считывание всех данных из буфера со ссылочным номером a_circle_iav:*/

while(cbread (a_circle_iav, (char *) \&cbval_iav) > 0 )

\{

* Передача в СВУ номера сигнала cbval_iav.elem, массива значений сигнала сbval_iav.fvalue $и$ времени cbval_iav.tvalue: */

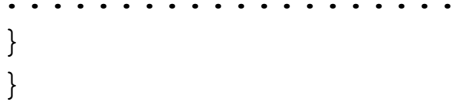

Для дискретных векторных сигналов:

\{ struct discrete_iv cbval_idv;

* Считывание всех данных из буфера со ссылочным номером a_circle_idv: */

while (cbread (a_circle_idv, (char *) \&cbval_idv) >0)

* Передача в СВУ номера сигнала cbval_idv.elem, массива значений сигнала сbval_idv.cvalue $u$ времени cbval idv. tvalue: */ 


\subsection{4. Передача сигналов от CGP к GATE}

\subsubsection{1. Передача значения аналогового сигнала уа}

Модуль CGP передает модулю GATE значение аналогового сигнала va (типа float) с номером n (типа int):

\{ struct analog_o cbval_oa;

/* Значение сигнала: */

cbval_oa.fvalue = va;

/* Номер сигнала: */

cbval_oa.elem = n;

/* Запись данных в буфер со ссылочным номером а_circle_oa: */ cbwrite (a_circle_oa, (char *) \&cbত̄al_oa);

/* Установка флага обновления: */

stchange.flag_gate $={ }^{\prime} \backslash 001^{\prime}$;

\}

\subsubsection{2. Передача значения дискретного сигнала vd}

Передача модулю GATE модулем CGP значения дискретного сигнала vd (типа char) с номером n (типа int) происходит аналогично:

\{ struct discrete_o cbval_od;

/* Значение сигнала: */

cbval od. cvalue $=\mathrm{vd}$;

/* Номер сигнала: */

cbval_od.elem = n;

/* Запись данных в буфер со ссылочным номером а_circle_od: */ cbwrite (a_circle_od, (char *) \&cbval_od); / Установка флага обновления: */

stchange.flag_gate $={ }^{\prime} \backslash 001^{\prime}$;

\}

\subsection{5. Прием сигналов в GATE от CGP}

Модуль GATE при приеме сигналов от модуля CGP проверяет состояние флага обновления stchange.flag_gate. Если этот флаг находится в состоянии ' $\backslash 001$ ', то модуль GATE устанавливает его равным ' $\backslash 000^{\prime}$ и проверяет наличие сигналов управления в буферах. 
Для аналоговых сигналов:

\{ structanalog_ocbval_oa;

/* Считывание всех данных из буфера со ссылочным номером a_circle_oa: */ while (cbread (a_circle_oa, (char *) \&cbval_oa)

$>0$ )

/ Передача в ПО смежной системь сигнала с номером cbval_oa.elemи значением cbval_oa.fvalue: */

\}

\}

Для дискретных сигналов:

\{ struct discrete_o cbval_od;

/* Считьвание всех данныхх из буфера со ссылочным номером a_circle_od: */

while (cbread (a_circle_od, (char *) \&cbval_od)

$>0)$

\{

* Передача в ПО смежной системь сигнала с номером cbval_od.elemи значением cbval_od.cvalue: */ 


\section{ГЛАВА 4 ВХОДНЫЕ И ВЫХОДНЫЕ ДАННЫЕ}

Входными данными для модуля CGP являются:

- входные сигналы, принимаемые от модуля GATE;

- выходные сигналы, принимаемые от СВУ («выходные сигналы» по отношению к СВУ);

- конфигурационные файлы, содержащие списки сигналов.

Выходными данными для модуля CGP являются:

- выходные сигналы, передаваемые модулю GATE;

- входные сигналы, передаваемые в СВУ («входные сигналы» по отношению к СВУ);

- диагностические сигналы, передаваемые в систему Администрирования технических и программных средств (АТПС) (подразделы 4.5, 5.5).

Описание данных, которыми модуль CGP обменивается с модулем GATE, дано в подразделах 3.1, 3.4.1, 3.4.3, 3.4.5. Описание конфигурационных файлов, содержащих списки сигналов, дано в подразделе 3.1. В данном разделе описываются данные, которыми модуль CGP обменивается с СВУ и с АТПС.

\section{1. Структура посылок при обмене данными между CGP и CBY}

Обмен сигналами между модулем CGP и CBУ осуществляется в виде посылок, передаваемых и принимаемых по сетевым каналам с установлением связи (по протоколу ТСР/IP). В начало каждой физической посылки вставляется 4-байтовое целое число, значение которого равно длине посылки - числу последующих байт в посылке. Длина посылки (без учета указанного числа) не должна превышать размера буфера, заданного константой BUFF_SIZE в файле nettcp.h (подраздел 5.1).

Каждая логическая посылка представляет собой последовательность 4-байтных слов вида:

\begin{tabular}{|l|l|l|l|}
\hline type & word 2 & word 3 & $\ldots . .$. \\
\hline
\end{tabular}

где type - целое число, кодирующее тип посылки, 
word 2, word 3...- целые или вещественные числа, представляющие собой передаваемые данные.

Все числа в посылках представляются в сетевом формате, принятом в протоколе ТCP/IP.

Посылки передаются и отправляются с использованием библиотеки функций, написанных на языке программирования С и содержащихся в файлах netblk. c, nettcppd.c. Константы, типы данных и прототипы функций определены в файлах nettcp.h, net_err.h.

Модуль CGP может поддерживать обмен данными одновременно с несколькими процессами СВУ или другими программами, взаимодействующими с модулем CGP по тому же протоколу. При этом обмен данными с каждым из процессов СВУ осуществляется независимо от других процессов, что достигается введением для каждого из процессов своих флагов обновления и буферов.

\section{2. Инициализация передачи сигналов}

Установление связи процессов CBУ с модулем CGP включает последовательное выполнение следующих операций:

1) процесс СВУ выполняет функцию connect для сетевых параметров модуля CGP: имени из системного файла / etc/hosts и номера порта;

2) процесс СВУ посылает модулю CGP в составе посылки определенного формата свои сетевые параметры: имя из файла / etc/hosts и номер порта;

3) модуль CGP выполняет функцию connect для полученных при операции 2) сетевых параметров процесса CВУ;

4) для инициализации передачи сигналов процесс СВУ посылает модулю CGP последовательность посылок, которые содержат списки кодов сигналов, запрашиваемых для обмена данными.

Все множество сигналов контроля, передаваемых в СВУ модулем CGP, разбивается на группы в соответствии со структурой рабочей базы данных СВУ. Группы определяются на этапе инициализации передачи сигналов после установления связи (открытия кана- 
лов приема/передачи). При этом модуль CGP получает от процесса СВУ последовательность посылок следующего вида:

\begin{tabular}{|l|l|l|l|l|l|}
\hline 0 & group & n & code 1 & code 2 & $\ldots . .$. \\
\hline
\end{tabular}

где

0 - тип посылки;

group - номер группы (неотрицательное целое число);

$\mathrm{n}$ - количество сигналов в посылке;

code 1, code 2, .., code $\mathrm{n}$ - коды сигналов, формируемые по правилу:

code $=10 \star i+j$

где

i - номера сигналов в массивах NAME_IA, NAME_ID, NAME_IAV, NAME_IDV, NAME_IDF;

j $=0$ - для аналоговых сигналов контроля (из массива INPUT_A);

j $=2$ - для дискретных сигналов контроля (из массива INPUT_D);

j $=4$ - для аналоговых векторных сигналов контроля (из массива INPUT_AV);

j $=5$ - для дискретных векторных сигналов контроля (из массива INPUT_DV);

j $=6$ - для дискретных диагностических сигналов контроля (из массива INPUT_DF).

Группа может включать сигналы только одного типа. Большие группы сигналов могут инициализироваться несколькими посылками, следующими друг за другом.

После передачи посылок по всем группам сигналов процесс CBУ передает модулю CGP посылку типа 5:

которая означает конец инициализации.

Количество групп сигналов контроля и количество сигналов в посылке $\mathrm{n}$ не должны превосходить значений констант в файле cgp.h:

- M_GROUP - для количества групп;

- M_SIGNAL - для количества сигналов в посылке. 
Значения констант M GROUP, M SIGNAL должны соответствовать параметрам процесса СВУ.

На этапе инициализации передачи сигналов может контролироваться совпадение версии конфигурационных файлов name_ia.dat, name_id.dat, name_iav.dat, name_idv.dat, name_idf.dat, name_oa.dat, name_od.dat с версией рабочей базы данных (РБД) СВӮ. Для этого процесс СВУ передает модулю CGP посылку типа 9:

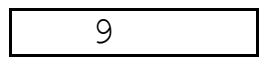

В ответ на этот запрос модуль CGP передает посылку типа -9:

\begin{tabular}{|l|l|}
\hline-9 & version \\
\hline
\end{tabular}

где version - целое число, идентифицирующее версию конфигурационных файлов.

\section{3. Передача сигналов от CGP к СВУ}

Модуль CGP передает сигналы контроля в ответ на запрос данных от процесса СВУ, который передается модулю CGP в виде посылки типа 1:

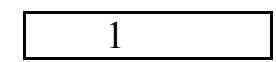

В ответ на запрос, первый после инициализации, модуль CGP передает значения всех сигналов. В ответ на дальнейшие запросы передаются только значения сигналов, изменившиеся после предыдущей передачи.

Текущие значения сигналов (значения из массивов INPUT_A, INPUT_D, INPUT_AV, INPUT_DV, INPUT_DF) передаются модулем CGP в посылках вида:

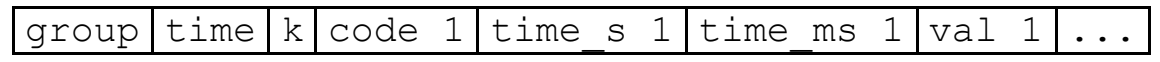

где

- group - номер группы, к которой относятся передаваемые сигналы (номер группы одновременно является типом посылки - отличительным признаком служит, то что целое число является неотрицательным);

- time - текущее время отправки посылки в секундах (отсчитываемое с 00:00:00 1 января 1970г.); 
- $\mathrm{k}$ - количество сигналов, для которых передаются текущие значения: $0<\mathrm{k}<=\mathrm{n}$, где $\mathrm{n}-$ количество сигналов в группе;

- code 1, code 2,...., code k - коды сигналов, определенные при инициализации;

- time_s 1, time_s 2, ..., time_s k - времена изменения сигналов в секундах, взятые из массивов TIME_A, TIME_D, TIME_AV, TIME_DV, TIME_DF;

- time_ms 1, time_ms $\overline{2}, \ldots$, time_ms $\mathrm{k}$ - времена изменения сигналов в миллисекундах, взятые из массивов TIME_A, TIME_D, TIME_AV, TIME_DV, TIME_DF;

- $\operatorname{val} 1$, val 2, ..., val k-значения сигналов, взятые из массивов INPUT_A, INPUT_D, INPUT_AV, INPUT_DV, INPUT_DF:

- для аналоговых сигналов - вещественные числа с плавающей точкой;

- для дискретных сигналов - целые числа;

- для аналоговых векторных сигналов - массивы вещественных чисел размерности IAV_SIZE;

- для дискретных векторных и диагностических сигналов - массивы целых чисел размерности IDV_SIZE (размер вещественных и целых чисел - 4 байта).

Для дискретных сигналов значение сигнала передается в нулевом бите, при этом целые числа могут принимать значение 0 или 1. Для дискретных векторных и диагностических сигналов в нулевом бите целого числа передается значение элемента вектора, в первом бите - признак изменения значения элемента вектора (с целью определения какие элементы вектора изменились), при этом целые числа могут принимать значения:

- 0 - элемент вектора имеет не изменившееся значение 0 ;

- 1 - элемент вектора имеет не изменившееся значение 1 ;

- 2 - элемент вектора имеет изменившееся значение 0 ;

- 3 - элемент вектора имеет изменившееся значение 1. 
При значении константы конфигурации NDV_COMPR, равном 1 (подраздел 5.1), значения дискретных векторных и диагностических сигналов передаются в сжатом виде. При этом каждому элементу вектора соответствуют два бита: 0-ой и 1-ый биты - значение и признак изменения 0-го элемента вектора, 2-ой и 3 -ий биты - значение и признак изменения 1-го элемента вектора и т.д. Размер значения дискретного векторного или диагностического сигнала выравнивается до целого числа слов и при значении константы конфигурации IDV_SIZE, равном 16 (установленном в данной версии ШИПО), соответствует одному слову.

Значения сигналов из кольцевых буферов (используемые только для архивации) передаются модулем CGP в посылках того же вида, что и текущие значения, но с номером группы (типом посылки):

- -2 - для аналоговых сигналов контроля (в посылку включаются все значения из буфера со ссылочным номером a_circle_ia);

- -3 - для дискретных сигналов контроля (в посылку включаются все значения из буфера со ссылочным номером a_circle_id);

- -7 - для аналоговых векторных сигналов контроля (в посылку включаются все значения из буфера со ссылочным номером a_circle_iav);

- -6 - для дискретных векторных сигналов контроля (в посылку включаются все значения из буфера со ссылочным номером a_circle_idv);

- -8 - для дискретных диагностических сигналов контроля (в посылку включаются все значения из буфера со ссылочным номером a_circle_idf).

Если произошла потеря архивных данных о сигналах контроля в кольцевых буферах из-за их переполнения, то модуль CGP информирует об этом процесс СВУ, передавая вместо типов посылки -2, $3,-7,-6,-8$, соответственно, типы -12, $-13,-17,-16,-18$.

Модуль CGP передает посылки в следующей последовательности: посылки сигналов из буферов (если они не пустые), затем посылки, содержащие текущие значения сигналов.

Последней передается посылка типа -1 : 


$$
\begin{array}{l|r}
-1 & \text { time } \\
\hline
\end{array}
$$

которая служит для процесса СВУ признаком окончания передачи данных модулем CGP в ответ на запрос ( $t$ ime - общая метка времени посылок в секундах).

Если с момента предыдущей передачи данных не изменился ни один из сигналов контроля, то в ответ на запрос процесса СВУ передается только посылка типа -1 .

Если данные от смежной системы АСУ ТП не поступают в шлюз вследствие неисправностей (или поступают в неполном объеме), то в ответ на запрос данных от процесса СВУ (подраздел 4.3) модуль CGP вместо последней посылки типа -1 передает посылку типа -10 :

$$
\begin{array}{l|l}
-10 & \text { time }
\end{array}
$$

которая служит для процесса СВУ признаком необходимости переключиться на резервный шлюз.

При переключении на резервный шлюз (или после восстановления связи с нерезервированным шлюзом) процесс СВУ посылает модулю CGP запрос данных, изменившихся за определенный интервал времени, в виде посылки типа 3:

\begin{tabular}{|l|l|l|l|l|}
\hline 3 & time_s & time_ms & dtime_s & dtime ms \\
\hline
\end{tabular}

где

- time_s и time_ms - верхняя граница интервала времени в секундах и миллисекундах;

- dtime_s и dtime_ms - размер интервала времени в секундах и миллисекундах.

В ответ на запрос этого типа модуль CGP передает значения всех сигналов, изменившиеся за указанный в запросе интервал времени.

Перед переключением на резервный шлюз процесс СВУ может послать модулю CGP запрос о состоянии шлюза в виде посылки типа 8:

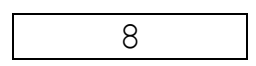

В ответ на запрос этого типа модуль CGP передает посылку типа -1 или типа -10 соответственно при исправном или неисправном состоянии шлюза. 


\section{4. Передача сигналов от СВУ к СGP}

Процесс CBУ передает сигналы управления модулю CGP в посылке следующего вида:

\begin{tabular}{|l|l|l|ll|l|}
\hline 2 & $\mathrm{k}$ & code 1 & val & 1 & $\ldots$. \\
\hline
\end{tabular}

где

$$
\begin{aligned}
& \text { - } 2 \text { - тип посылки; } \\
& \text { - } \text { k - количество передаваемых сигналов; } \\
& \text { - } \quad \text { code } 1 \text {, code 2, . ., code k - коды сигналов, }
\end{aligned}
$$
формируемые по правилу: code $=10 \star i+j$, где

- $\quad$ - номера сигналов в массивах NAME_OA, NAME_OD;

- $j=\overline{1}$ - для аналоговых сигналов управления (из массива OUTPUT_A);

- $\quad j=3$-для дискретных сигналов управления (из массива OUTPUT_D).

- $\operatorname{val} 1, \operatorname{val} 2, \ldots, \operatorname{val} \mathrm{k}$ - значения сигналов:

Для аналоговых сигналов используются вещественные числа с плавающей точкой, для дискретных сигналов - целые числа.

Для архивации сигналов управления модуль CGP передает всем процессам СВУ ответные посылки того же вида, что и при передаче сигналов контроля (подраздел 4.3). При этом слова в посылках принимают значения:

Группа (тип посылки):

- $\quad-4$ - для дискретных сигналов управления,

- $\quad$-5 - для аналоговых сигналов управления;

- code 1, . . - коды сигналов управления;

- time_s 1, time_ms 1, .. - времена получения сигналов управления модулем CGP в секундах и миллисекундах;

- $\operatorname{val~1,...-~значения~полученных~сигналов.~}$

Если произошла потеря архивных данных о сигналах управления в кольцевых буферах из-за их переполнения, то модуль CGP информирует об этом процесс СВУ, передавая вместо типов посылки $-4,-5$ соответственно типы $-14,-15$. 
Процесс CBУ передает модулю CGP признак того, что следует запросить телеграммы типа PL системы TПTC, в посылке следующего вида:

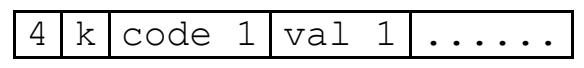

где

- 4 - тип посылки;

- $\mathrm{k}$ - количество передаваемых сигналов запроса;

- code 1, code 2,..., code k- коды сигналов, формируемые по правилу: code $=10 \star i+3$, где $i-$ номера сигналов запросов в массиве NAME_OD;

- $\operatorname{val} 1$, val 2, ..., val k - значения сигналов: целые числа, принимающие значение 1 или 2: 1 - для запросов, зависимых от содержания информации на дисплеях рабочих станций СВУ, 2 - для независимых запросов.

\section{5. Диагностика шлюза в системе АТПС}

Модуль CGP отправляет в систему Администрирования технических и программных средств (АТПС) СВУ посылки, содержащие диагностические сигналы состояния ШИПО, модуля GATE и других модулей ПО шлюза. Посылки отправляются без установления сетевых каналов связи (по протоколу UDP/IP) с заданным периодом и содержат все диагностические сигналы (не только изменившиеся). Каждая посылка представляет собой последовательность 4-байтных слов, представляющих собой целые или вещественные числа в сетевом формате, принятом в протоколе ТСР/IP.

Эти посылки имеют вид:

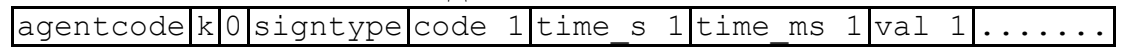

где

- agentcode - код, идентифицирующий данный шлюз в системе АТПС;

- $\mathrm{k}$ - количество сигналов в посылке;

- 0 - зарезервированное поле;

- signtype - код типа передаваемых сигналов:

- 0 - аналоговые сигналы; 


$$
\begin{aligned}
& \text { - } 1 \text { - дискретные сигналы; } \\
& \text { - } 2 \text { - дискретные векторные сигналы; } \\
& \text { - code 1, code 2, ...., code k - коды сигналов, }
\end{aligned}
$$

Для аналоговых сигналов используются вещественные числа с плавающей точкой, для дискретных и дискретных векторных сигналов - целые числа. Для дискретных сигналов значение сигнала передается в нулевом бите, при этом целые числа могут принимать значение 0 или 1. Для дискретных векторных сигналов, состоящих из 16 элементов, каждому элементу вектора соответствуют два бита: 0 -ой и 1-ый биты - значение и признак изменения 0-го элемента вектора, 2-ой и 3-ий биты - значение и признак изменения 1-го элемента вектора и т.д.

\section{6. Обмен периодическими контрольными посылками}

Модуль CGP и процессы CBУ, установившие связь с модулем CGP, обмениваются периодическими контрольными посылками. При ошибке передачи контрольной посылки или при превышении таймаута ожидания ответа на контрольную посылку модуль CGP закрывает сетевые каналы с процессом СВУ.

Периодические контрольные посылки имеют вид:

$$
\begin{array}{|l|l|l|}
\hline 1885693259 & 1768710495 & \text { code_alive } \\
\hline
\end{array}
$$

где

два первых 4-байтных числа идентифицируют тип посылки периодическая контрольная;

код code_alive принимает значения:

- 538994038 при передаче контрольной посылки;

- 538994030 при ответе на контрольную посылку;

- 538994031 при передаче контрольной посылки, не требующей ответа.

Период передачи контрольных посылок и таймаут ожидания ответа устанавливаются в секундах значением константы ALIVE_SEC в файле сgp.h (подраздел 5.1). 


\section{ГЛАВА 5 \\ ЧАСТНЫЕ ПРОЦЕССЫ ЖИЗНЕННОГО ЦИКЛА}

\section{1. нсталляция}

Для инсталляции ШИПО необходимо скопировать с инсталляционного CD ШИПО на жесткий диск компьютера, где выполняется компиляция и сборка исполняемого файла ПО шлюза, файлы, содержащие текст программы ШИПО:

- cgp. с - основной цикл модуля CGP;

- cgp1. с - функции обмена данными модуля CGP с процессами СВУ;

- $\quad$ cgp.h - константы, типы данных и прототипы функций для модуля CGP;

- gate_shm.c - библиотека функций для операций c массивами и кольцевыми буферами в общей памяти модулей CGP и GATE;

- gate_shm.h - константы, типы данных и прототипы функций для библиотеки, содержащейся в файлах gate_shm.c;

- cgp_err.h - коды ошибок для модуля CGP;

- nettcppd.c - основные функции сетевой библиотеки;

- netblk.c - функции сетевой библиотеки для обмена строками данных;

- nettcp.h - константы, типы данных и прототипы функций для сетевой библиотеки;

- net_err.h -коды ошибок для сетевой библиотеки.

После копирования файлов перед их компиляцией необходимо проконтролировать и возможно отредактировать значения следующих констант конфигурации.

Константа APPL в файле gate_shm.h определяет параметры условной компиляции с учетом особенностей смежной с СВУ системы.

Константы M_INPUT_A, M_INPUT_D, M_INPUT_AV, M_INPUT_DV, M_INPUT_DF, M_OUTPUT_A, M_OUTPUT_D в файле 
gate_shm.h устанавливают максимально возможное число элементов в массивах в общей памяти (подраздел 3.2).

Константы CBSIZE_IA, CBSIZE_ID, CBSIZE_IAV, CBSIZE_IDV, CBSIZE_IDF, CBSIZE_OA, CBSIZE_OD в файле gate shm.h устанавливают размеры кольцевых буферов (подраздел 3.3). Константы CBSIZE_OAA и CBSIZE_ODA в файле gate_shm.h устанавливают размеры кольцевых буферов для архивации аналоговых и дискретных сигналов управления (подраздел 4.4). Константа CBSIZE_REQ в файле gate_shm.h устанавливает размер кольцевого буфера для приема сигналов запросов телеграмм типа PL системы ТПТC.

Константы M_GROUP, M_SIGNAL в файле cgp.h устанавливают максимально возможное количество групп сигналов контроля и максимальное количество сигналов в посылке при инициализации передачи сигналов (подраздел 4.2). Значения этих констант должны соответствовать параметрам процессов СВУ.

Модуль CGP может взаимодействовать с процессами СВУ в двух режимах:

- проверка поступления по сети посылок от процессов СВУ без ожидания;

- ожидание поступления по сети посылок от процессов СВУ в течение времени, не превышающего заданный интервал.

Режим без ожидания необходим, если модуль GATE должен проверять поступление данных от смежной системы с максимально возможной частотой. Режим с ожиданием применяется, если исполняемый файл ПО шлюза должен разделять ресурсы времени с другими задачами на одном компьютере. Константы WAIT_SEC, WAIT_MSEC в файле cgp. с устанавливают период ожидания в секундах и микросекундах. Если обе константы равны 0, то устанавливается режим без ожидания.

Константа ALIVE_SEC в файле cgp. h устанавливает период (в секундах) для периодических контрольных посылок (подраздел 4.6) по сетевым каналам между модулем CGP и процессами CBУ. Константа KTOUT в файле cgp. с устанавливает коэффициент увеличения этой периодичности на этапе инициализации передачи сигна- 
лов. Значения этих констант должны соответствовать аналогичным параметрам процессов СВУ.

Константа MAX_DB в файле cgp.h устанавливает максимально возможное число процессов CBУ, с которыми модуль CGP может обмениваться данными. Значение константы MXSOCK в файле nettcp.h устанавливает максимальное число сетевых каналов. Значение константы MXSOCK должно быть больше значения константы MAX_DB не менее, чем в 2 раза.

Константа SWITCH_FULL в файле cgp1. с устанавливает объем данных, посылаемых процессу СВУ в ответ запрос данных, изменившихся за определенный интервал времени (запрос в виде посылки типа 3), см. подраздел 4.3. Константа SWITCH_FULL может принимать следующие значения:

- 0 - посылаются данные, изменившиеся за запрашиваемый интервал; времена изменения сигналов получены от модуля GATE;

- 1 - посылаются те же данные, что и при значении константы 0; дополнительно посылаются данные, изменившиеся за запрашиваемый интервал, но с временами изменения, равными текущему системному времени (с признаками недостоверности времени изменения);

- 2 - посылаются те же данные, что и при значении константы 0; дополнительно посылаются все входные сигналы с временами изменения, равными текущему системному времени (с признаками недостоверности времени изменения).

Константа NDV_COMPR в файле cgp. с устанавливает или отменяет сжатие значений дискретных векторных и диагностических сигналов при передаче процессу СВУ (при значении 1 - сжатие установлено, при значении 0 - отменено).

Константа IDV_COMPR в файле gate_shm.h устанавливает или отменяет сжатие значений дискретных векторных и диагностических сигналов при хранении их оперативной памяти шлюза (при значении 1 - сжатие установлено, при значении 0 - отменено).

Значение константы BUFF_SIZE в файле nettcp.h устанавливает размер буфера для физических посылок при обмене данными 
между модулем CGP и процессами CBУ (подраздел 4.1). Значение этой константы должно соответствовать аналогичному параметру процессов СВУ.

Значение константы BIT64 в файле nettcp.h определяет режим 64-битовых типов данных и указателей при компиляции ШИПО:

- 1 - установка 64-битового режима;

- 0- отмена 64-битового режима.

Значения констант CGP_LOG, NET_LOG и GATE_LOG в файле nettcp.h определяют режим записи диагностических сообщений в текстовые файлы-протоколы (log-файлы) соответственно для модуля CGP, сетевой библиотеки и модуля GATE:

- 1 - установка режима записей в $\log$-файлы;

- 0 - отмена режима записей в $\log$-файлы.

Константы READ_TIMEOUT и READ_MTIMEOUT в файле nettcp.h устанавливают предельное время (в секундах и миллисекундах) выполнения операций приема данных (во избежание зависания программ). При отрицательном значении READ TIMEOUT время выполнения не ограничено.

Константы SEND_TIMEOUT и SEND_MTIMEOUT в файле nettcp.h устанавливают предельное время (в секундах и микросекундах) выполнения операций передачи данных. При отрицательном значении SEND_TIMEOUT время выполнения ограничено только установками операционной системы.

Константы CONNECT TIMEOUT и CONNECT MTIMEOUT в файле nettcp.h устанавливают предельное время (в секундах и микросекундах) выполнения операций открытия сетевых каналов для передачи данных. При отрицательном значении CONNECT_TIMEOUT время выполнения ограничено только установками операционной системы.

Константы CLOSE_TIMEOUT и CLOSE_MTIMEOUT в файле nettcp.h устанавливают предельное время (в секундах и микросекундах) выполнения операций закрытия сетевых каналов. При отрицательном значении CLOSE_TIMEOUT время выполнения ограничено только установками операционной системы. 
Константа ADM SEC в файле cgp. с устанавливает период (в секундах) посылок- диагностических сигналов в систему АТПС (подраздел 4.5).

\section{2. Компиляция и сборка}

ШИПО компилируется и собирается вместе с модулем GATE в виде одного исполняемого файла ПО шлюза с использованием компилятора gcc (GNU project C compiler) версии не ниже 3.4.

\section{3. Загрузка программы}

Загрузка ШИПО производится исполняемым файлом ПО шлюза, являющегося результатом сборки (подраздел 5.2).

При загрузке в текущей директории должны быть конфигурационные файлы (подраздел 3.1):

name_ia.dat, name_id.dat, name_iav.dat, name_idv.dat, name_idf.dat, name_oa.dat, name_od.dat

(для пустого списка сигналов соответствующий файл отсутствует). Кроме того, в текущей директории должен быть файл текстовый конфигурации сетевых каналов nettcp.cfg, содержащий строки вида:

cgp_from_db db_to_cgp hostgate portnum0_cgp portnumd_cgp \# host for CGP

adm any hostadm portnum0_adm portnumd_adm \# host for ADM

admd any hostadmd portnum0_admd portnumd_admd \# host for ADMD,

в которых вместо переменной hostgate подставляется сетевое имя (или IP-адрес) шлюза (локальное сетевое имя для модуля CGP). Вместо переменных portnum0_cgp и portnumd_cgp подставляются нижняя граница и размер диапазона номеров портов для модуля CGP (диапазон номеров портов должен соответствовать файлу конфигурации сетевых каналов процессов СВУ). Вместо переменной hostadm подставляется основное сетевое имя для посылок в систему АТПС. Вместо переменной hostadmd подставляется резервное сетевое для посылок в систему АТПС. Вместо переменных portnum0_adm, portnum0_admd и portnumd_adm, portnumd_admd 
подставляются нижние границы и размеры диапазонов номеров для посылок в систему АТПС соответственно по основному и резервному адресам.

Значения констант конфигурации, установленные при инсталляции (подраздел 5.1), могут быть изменены при загрузке, если текущая директория содержит текстовые файлы set_up.cfg, set_up1.cfg, состоящие из строк вида:

NAME VALUE,

где

- NAME - имя одной из констант:

M_INPUT_A, M_INPUT_D, M_INPUT_AV, M_INPUT_DV, M_INPUT_DF, M_OUTPUT A, M_OUTPUT_D, CBSIZE_IA, $\overline{C B S I Z E}{ }_{-}^{-I D,}$

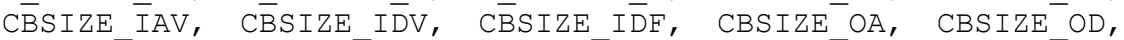
CBSIZE_OAA, CBSIZE_ODA, CBSIZE_REQ, M_SIGNAL, ALIVE_SEC, KTOUT, WAIT_SEC, WAIT_MSEC, ADM_SEC, NDV_COMMPR, READ TIMEOUT, READ_MTIMEOUT, SEND_TIMEOUT, SEND MTIMEOUT, CONNECT TIMEOUT, - CONNECT MTIMEOUT, CLOSE TIMEOUT, CLOSE_MTIMEOUT, SWITCH_FULL.

- VALUE - значение этой константы. Для всех перечисленных констант поиск строк осуществляется в двух файлах: set_up.cfg и set_upl.cfg (установки в файле set_upl.cfg имеют более высокий приоритет).

Содержание посылок в систему АТПС определяется конфигурационными файлами set_up.cod, agent.cod, name_ia.cod, name_id.cod, name_idv.cod, kks_cgp.cod.

Конфигурационный файл set_up . cod содержит строку вида: gatename gatename1 adm admd, где

- gatename - проектный индекс элемента системы АТПС для отображения состояния программных средств шлюза;

- gatename1 - проектный индекс элемента системы АТПС для отображения состояния технических средств шлюза;

- adm - значение переменной в файле nettcp.cfg в строке, предназначенной для конфигурирования основного адреса при посылках в систему АТПС (первая переменная в строке); 
- admd - значение переменной в файле nettcp.cfg в строке, предназначенной для конфигурирования резервного адреса при посылках в систему АТПС (первая переменная в строке).

Конфигурационный файл agent.cod (общий для всей системы АТПС) для каждого элемента системы АТПС, посылающего информацию в систему АТПС, содержит строку вида:

agentname agentcode,

где

- agentname - проектный символьный индекс элемента;

- agentcode - численный код элемента.

Модуль CGP при инициализации выполняет поиск в файле agent.cod индекса agentname, совпадающего с индексом gatename в файле set_up.cod, и использует соответствующий код agentcode в качестве первого слова в посылках в систему АТПС (подраздел 4.6).

Конфигурационные файлы name_ia.cod, name_id.cod и name_idv.cod содержат списки диагностических сигналов данного шлюза в системе АТПС соответственно для аналоговых, дискретных и дискретных векторных сигналов в виде строк вида:

signalname signalnumber, где

- signal name - проектный символьный индекс сигнала;

- signalnumber - номер сигнала в списке (нумерация сигналов начинается с нуля).

Проектные символьные индексы диагностических сигналов шлюза в системе АТПС состоят из двух частей (вторая часть следует за первой без пробелов): первая часть - проектный индекс элемента gatename или gatename1 из файла set_up.cod; вторая часть kkstype - проектный индекс типа сигнала. В конфигурационном файле kks_cgp.cod устанавливается соответствие между проектными индексами типов сигналов kkstype и идентификаторами типов сигналов srctype в тексте программы модуля CGP в виде строк вида:

srctype kkstype 
В текстовом файле cp_date. ini содержится 4-х байтовое целое число, используемое для контроля совпадения версии конфигурационных файлов name_ia.dat, name_id.dat, name iav.dat, name_idv.dat, name_idf.dat, name_oa.dat, name_od.dat c версией РБД процесса СВУ.

Для выгрузки исполняемого файла ПО шлюза пользователь может создать в текущей директории текстовый файл cgp.cmd, coдержащий строку

stop

\section{4. Процедура автоконфигурации ПО шлюза}

Процедура автоконфигурации ПО шлюза предназначена для автоматического копирования конфигурационных файлов шлюза с сервера СВУ перед загрузкой исполняемого файла ПО шлюза.

Для инсталляции процедуры автоконфигурации необходимо:

- Скопировать с инсталляционного CD ШИПО файл autoconf.tar в текущую директорию исполняемого файла ПО шлюза и разархивировать файл autoconf.tar командой:

tar xvf autoconf.tar

- Скопировать разархивированный файл . netrc в корневую директорию пользователя, для которого будет загружаться исполняемый файл ПО шлюза. Отредактировать файл . netrc:

- заменить переменную HOSTSERV1 на сетевое имя основного сервера СВУ;

- заменить переменную HOSTSERV2 на сетевое имя резервного сервера СВУ;

- заменить переменную USER на имя пользователя на серверах $\mathrm{CBУ}$, для которого разрешено копирование конфигурационных файлов шлюза;

- заменить переменную PASSW на пароль пользователя на серверах СВУ, для которого разрешено копирование конфигурационных файлов шлюза.

- Установить в сеансе системного администратора атрибуты файла . netrc, выполнив команды: 


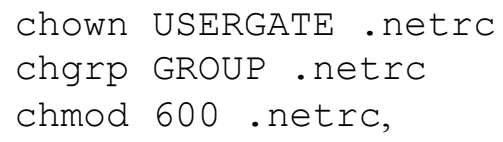

USERGATE и GROUP - имя пользователя и имя группы, для которых будет запускаться исполняемый файл ПО шлюза.

- Отредактировать разархивированные командные файлы autocfg1, autocfg2:

- заменить переменную HOSTSERV1 на сетевое имя основного сервера СВУ;

- заменить переменную HOSTSERV2 на сетевое имя резервного сервера СВУ;

- заменить переменную РАТН на имя директории, в которой на серверах СВУ находятся конфигурационные файлы для данного ПО шлюза (для основного и резервного ПО шлюза эти директории различные).

- Сделать файлы autoconf, autocfg1, autocfg2 исполняемыми командой

chmod $\mathrm{u}+\mathrm{x}$ autoconf autocfg 1 autocfg2

- Перед загрузкой исполняемого файла ПО шлюза выполнить командный файл autoconf.

\section{5. Диагностика ШИПО}

\subsection{1. Диагностика ШИПО в системе АТПС}

Модуль CGP передает в систему АТПС диагностические сигналы ШИПО следующих типов.

Аналоговый сигнал, содержащий оценку разности (в миллисекундах) системного времени шлюза и единого времени СВУ: код сигнала в тексте программы модуля GATE srctype="SOF", проектный индекс типа сигнала kkstype="1AXQ70".

Аналоговый сигнал, содержащий оценку количества входных сигналов, передаваемых модулем CGP процессу CBУ за секунду: srctype $="$ SCOUNT", kkstype $=" 1$ AXQ $91 "$. 
Аналоговый сигнал, содержащий оценку времени цикла работы модуля CGP (в миллисекундах): srctype="SCYCLE", kkstype="1AXQ92".

Дискретные сигналы:

- сигнал наличия диагностических сигналов от данного шлюза в системе АТПС (признак того, что шлюз работает и передает диагностические сигналы в АТПС): srctype $="$ FNETO", kkstype $=" 1 \mathrm{NXPO} 4 "$;

- сигнал переполнения кольцевых буферов: srctype="FOVER", kkstype="1 KXP92".

Дискретные векторные сигналы:

- сигнал ошибок модуля CGP с кодом: srctype $="$ EL12", kkstype $=" 1$ VXP92";

- сигнал ошибок сетевой библиотеки: srctype="EL13", kkstype="1VXP93";

- сигнал состояния синхронизации системного времени шлюза: srctype="SL1", kkstype="1VXP80".

Для дискретных векторных сигналов в столбцах таблицы 5.1 приведены:

- проектный индекс kkstype типа сигнала (элемента вектора дискретного векторного сигнала),код ошибки в файле cgp_err.h или net_err.h;

- код srctype дискретного векторного сигнала в тексте программы модуля CGP, проектный индекс kkstype типа дискретного векторного сигнала, номер элемента вектора (нумерация элементов вектора начинается с 1);

- наименование сигнала;

- рекомендуемые действия в случае сообщения об ошибке. 


\section{Таблица 2}

Диагностические векторные сигналь ШИПО в системе АТПС

\begin{tabular}{|c|c|c|}
\hline $\begin{array}{c}\text { Тип сигнала в проекте, } \\
\text { код ошибки }\end{array}$ & $\begin{array}{c}\text { Код } \\
\text { вектора, } \\
\text { тип вектора } \\
\text { в проекте, } \\
\text { номер элемента } \\
\text { вектора }\end{array}$ & $\begin{array}{l}\text { Описание } \\
\text { сигнала }\end{array}$ \\
\hline 1KXP81, ECGP_ALLOC & $\begin{array}{l}\operatorname{EL} 12, \\
1 \operatorname{VXP} 92,1\end{array}$ & $\begin{array}{l}\text { Не хватает опера- } \\
\text { тивной памяти для } \\
\text { модуля CGP }\end{array}$ \\
\hline 1KXP82, ECGP_MSIGN_IA & $\begin{array}{l}\text { EL12, } \\
1 \operatorname{VXP} 92,2\end{array}$ & $\begin{array}{l}\text { Слишком много } \\
\text { входных аналого- } \\
\text { вых сигналов }\end{array}$ \\
\hline 1KXP83，ECGP_MSIGN_ID & $\begin{array}{l}\text { EL12, } \\
1 \text { VXP92, } 3\end{array}$ & $\begin{array}{l}\text { Слишком много } \\
\text { входных дискрет- } \\
\text { ных сигналов }\end{array}$ \\
\hline 1KXP84, ECGP_MSIGN_OA & $\begin{array}{l}\text { EL12, } \\
1 \text { VXP92, } 4\end{array}$ & $\begin{array}{l}\text { Слишком много } \\
\text { выходных анало- } \\
\text { говых сигналов }\end{array}$ \\
\hline 1KXP85, ECGP_MSIGN_OD & $\begin{array}{l}\text { EL12, } \\
\text { 1VXP92, } 5\end{array}$ & $\begin{array}{l}\text { Слишком много } \\
\text { выходных дис- } \\
\text { кретных сигналов }\end{array}$ \\
\hline 1KXP86,ECGP_MSIGN_IAV & $\begin{array}{l}\text { EL12, } \\
1 \operatorname{VXP} 92,6\end{array}$ & $\begin{array}{l}\text { Слишком много } \\
\text { входных аналого- } \\
\text { вых векторных } \\
\text { сигналов }\end{array}$ \\
\hline 1KXP87,ECGP_MSIGN_IDV & $\begin{array}{l}\text { EL12, } \\
\text { 1VXP92, } 7\end{array}$ & $\begin{array}{l}\text { Слишком много } \\
\text { входных дискрет- } \\
\text { ных векторных } \\
\text { сигналов }\end{array}$ \\
\hline 1KXP88,ECGP_MSIGN_IDF & $\begin{array}{l}\text { EL12, } \\
\text { 1VXP92, } 8\end{array}$ & $\begin{array}{l}\text { Слишком много } \\
\text { входных дискрет- } \\
\text { ных диагностиче- } \\
\text { ских сигналов }\end{array}$ \\
\hline 1KXP90,ECGP_ARRAY & $\begin{array}{l}\text { EL12, } \\
1 \operatorname{VXP} 92,10\end{array}$ & $\begin{array}{l}\text { Ошибка описания } \\
\text { массива обмена } \\
\text { данными }\end{array}$ \\
\hline 1KXP91,ECGP_CBUFFER & $\begin{array}{l}\text { EL12, } \\
1 \operatorname{VXP} 92,11\end{array}$ & $\begin{array}{l}\text { Ошибка описания } \\
\text { кольцевого буфера }\end{array}$ \\
\hline
\end{tabular}




\begin{tabular}{|c|c|c|}
\hline $\begin{array}{c}\text { Тип сигнала в проекте, } \\
\text { код ошибки }\end{array}$ & $\begin{array}{c}\text { Код } \\
\text { вектора, } \\
\text { тип вектора } \\
\text { в проекте, } \\
\text { номер элемента } \\
\text { вектора }\end{array}$ & $\begin{array}{c}\text { Описание } \\
\text { сигнала }\end{array}$ \\
\hline 1KXP94,ECGP_DATEXCH & $\begin{array}{l}\text { EL12, } \\
\text { 1VXP92, } 13\end{array}$ & $\begin{array}{l}\text { Ошибка при об- } \\
\text { мене данными с } \\
\text { процессом СВУ }\end{array}$ \\
\hline 1KXP96,ECGP_ADMDG & $\begin{array}{l}\text { EL12, } \\
1 \operatorname{VXP} 92,15\end{array}$ & $\begin{array}{l}\text { Ошибка при по- } \\
\text { сылках в систему } \\
\text { АТПС }\end{array}$ \\
\hline 1KXP97,ECGP_NODATA & $\begin{array}{l}\text { EL12, } \\
1 \operatorname{VXP} 92,16\end{array}$ & $\begin{array}{l}\text { Обобщенная неис- } \\
\text { правность модуля } \\
\text { GATE }\end{array}$ \\
\hline 1NXP81,ENET_ALLOC & $\begin{array}{l}\text { EL13, } \\
1 \operatorname{VXP} 93,1\end{array}$ & $\begin{array}{l}\text { Не хватает опера- } \\
\text { тивной памяти для } \\
\text { сетевых каналов }\end{array}$ \\
\hline 1NXP82,ENET_MCHAN & $\begin{array}{l}\text { EL13, } \\
\text { 1VXP93, } 2\end{array}$ & $\begin{array}{l}\text { Слишком много } \\
\text { сетевых каналов }\end{array}$ \\
\hline 1NXP83,ENET_CONFIG & $\begin{array}{l}\text { EL13, } \\
1 \operatorname{VXP} 93,3\end{array}$ & $\begin{array}{l}\text { Недопустимый } \\
\text { файл сетевой кон- } \\
\text { фигурации }\end{array}$ \\
\hline 1NXP84,ENET_OPEN & $\begin{array}{l}\text { EL13, } \\
\text { 1VXP93, } 4\end{array}$ & $\begin{array}{l}\text { Ошибка открытия } \\
\text { сетевого канала }\end{array}$ \\
\hline 1NXP85,ENET_BUFFER & $\begin{array}{l}\text { EL13, } \\
1 \operatorname{VXP} 93,5\end{array}$ & $\begin{array}{l}\text { Недостаточный } \\
\text { размер сетевого } \\
\text { буфера }\end{array}$ \\
\hline 1NXP86,ENET_SETPAR & $\begin{array}{l}\text { EL13, } \\
1 \operatorname{VXP} 93,6\end{array}$ & $\begin{array}{l}\text { Ошибка установки } \\
\text { параметра сетево- } \\
\text { го канала }\end{array}$ \\
\hline 1NXP87,ENET_DCHAN & $\begin{array}{l}\text { EL13, } \\
\text { 1VXP93, } 7\end{array}$ & $\begin{array}{l}\text { Ошибка описания } \\
\text { сетевого канала }\end{array}$ \\
\hline 1NXP89,ENET_CONNECT & $\begin{array}{l}\text { EL13, } \\
\text { 1VXP93, } 9\end{array}$ & $\begin{array}{l}\text { Ошибка установки } \\
\text { сетевой связи }\end{array}$ \\
\hline $1 \mathrm{NXP} 05$ & $\begin{array}{l}\text { SL1, } \\
\text { 1VXP80, } 1\end{array}$ & $\begin{array}{l}\text { Нет связи с основ- } \\
\text { ным сервером } \\
\text { синхронизации } \\
\text { времени }\end{array}$ \\
\hline
\end{tabular}




\begin{tabular}{|c|c|c|}
\hline $\begin{array}{c}\text { Тип сигнала в проекте, } \\
\text { код ошибки }\end{array}$ & $\begin{array}{c}\text { Код } \\
\text { вектора, } \\
\text { тип вектора } \\
\text { в проекте, } \\
\text { номер элемента } \\
\text { вектора }\end{array}$ & $\begin{array}{c}\text { Описание } \\
\text { сигнала }\end{array}$ \\
\hline $2 \mathrm{NXP} 05$ & $\begin{array}{l}\text { SL1, } \\
1 \mathrm{VXP} 80,2\end{array}$ & $\begin{array}{l}\text { Нет связи с ре- } \\
\text { зервным сервером } \\
\text { синхронизации } \\
\text { времени }\end{array}$ \\
\hline $1 \mathrm{NXP} 06$ & $\begin{array}{l}\text { SL1, } \\
1 \mathrm{VXP} 80,3\end{array}$ & $\begin{array}{l}\text { Синхронизация } \\
\text { времени от основ- } \\
\text { ного сервера }\end{array}$ \\
\hline 2 NXPO 6 & $\begin{array}{l}\text { SL1, } \\
1 \mathrm{VXP} 80,4\end{array}$ & $\begin{array}{l}\text { Синхронизация } \\
\text { времени от ре- } \\
\text { зервного сервера }\end{array}$ \\
\hline 1NXP 99 & $\begin{array}{l}\text { SL1, } \\
1 \mathrm{VXP} 80,5\end{array}$ & $\begin{array}{l}\text { Активная синхро- } \\
\text { низация времени } \\
\text { системы ТПТС }\end{array}$ \\
\hline
\end{tabular}

При ошибках ECGP_ALLOC, ECGP_MSIGN_IA, ECGP_MSIGN_ID, ECGP MSIGN OA, ECGP MSIGN OD, ECGP MSIGN IAV, ECGP MSIGN IDV, ECGP_MSIGN_IDF, ECGP_ARRAY, ECGP_CBUFFER, ECGP_NODATA модуль CGP передает процессам СВУ признак необходимости переключиться на резервный шлюз в посылке типа -10 (подраздел 4.3).

Сообщения об ошибках ШИПО также выводятся на экран дисплея.

\subsection{2. Диагностика ШИПО в файлах-протоколах}

Диагностические сообщения ШИПО записываются в текстовые файлы-протоколы (log-файлы) при отличных от нуля следующих константах условной компиляции (подраздел 5.1) и значениях следующих глобальных переменных, больших или равных 1:

- для модуля CGP константы CGP_LOG и глобальной переменной cgp_log типа int (определенной в файле cgp.c); 
- для сетевой библиотеки константы NET_LOG и глобальной переменной net_log типа int (определенной в файле net tcppd.c).

Значения глобальных переменных cgp_log, net_log устанавливают уровень подробности сообщений в log-файлах. При значениях cgp_log, net_log, равных 1, в log-файлы записываются сообщения об ошибках, а также информационные сообщения об операциях установления связи процессов CBУ с модулем CGP и о загрузке/выгрузке ШИПО. При значениях сgp_log, net_log, равных 2 или 3, в log-файлы, также записываются информационные сообщения соответственно с уровнями подробности 2 или 3.

B log-файлы ШИПО также могут записываться диагностические сообщения модуля GATE при отличной от нуля константе условной компиляции GATE_LOG (подраздел 5.1) и значении глобальной переменной уровня подробности gate_log типа int, определенной в модуле GATE, большем или равным 1.

Диагностические сообщения в log-файлах имеют формат: msgcode-msgtime* msgtype msglevel| msgtext, где:

- msgcode - уникальный идентификатор ошибки, состоящий из имени компоненты (“CGP” для модуля CGP , "NET" для сетевой библиотеки, “GATE” для модуля GATE) и численного кода ошибки в файлах cgp_err.h, net_err.h;

- msgtime - время записи сообщения в формате час:минуты:секунды число-месяц-год;

- msgtype - тип сообщения: "E” - ошибка, "W" - предупреждение, "I" - информационное сообщение;

- msglevel - уровень ошибки (целое число); чем больше уровень ошибки, тем она более серьезна при данном типе ошибки;

- msgtext - текст сообщения.

Диагностические log-файлы создаются в директории, имя которой устанавливается значением глобальной переменной path_log, определенной в файле сgp. с (в текущей версии модуля CGP переменная path_log имеет имя поддиректории «log»). 
Имена log-файлов имеют вид: cgp_yymmdd.log, где уу, mm, $\mathrm{dd}$-год, месяц и день создания файла. Удаление устаревших logфайлов выполняется командным файлом sys_stat, который периодически загружается модулем CGP в текущей директории ПО шлюза. Период вызова (в секундах) командного файла sys_stat устанавливается значением глобальной переменной log_dtime, определенной в файле сgр. с.

Значения глобальных переменных cgp_log, net_log, gate_log, log_dtime, могут быть установлены при загрузке, если текстовые файлы set_up.cfg, set_up1.cfg (подраздел 5.4), содержат строки вида:

NAME VALUE,

где:

- NAME - принимает значения имен CGP_LOG, NET_LOG, GATE_LOG, LOG_DTIME соответственно для переменных cgp_log, net_log, gate_log, log_dtime;

- VALUE - значение этой переменной.

Текущие значения входных сигналов можно контролировать путем вывода данных в текстовые log-файлы. Для их записи пользователь может создать в текущей директории исполняемого файла ПО шлюза текстовый файл cgp. cmd, содержащий строку:

signtype,

где имя signtype должно принимать значение:

- “іа” - для входных аналоговых сигналов;

- “id” - для входных дискретных сигналов;

- “iav" - для входных аналоговых векторных сигналов;

- “idv" - для входных дискретных векторных сигналов;

- “idf” - для входных дискретных диагностических сигналов.

Эти $\log$-файлы создаются в текущей директории с именами вида:

signtype_timesec.log,

где timesec - время создания файла в секундах (отсчитываемое с 00:00:00 1 января 1970г.). 


\section{6. Синхронизация времени}

Системное время шлюзов синхронизируется с использованием протокола NTP [10] от основного или резервных серверов синхронизации времени СВУ.

Для настройки NTP на шлюзе с операционной системой необходимо в сеансе системного администратора отредактировать файл / etc/ntp.conf так, чтобы он содержал строки:

server HOSTSERV1 minpoll 4 prefer

server HOSTSERV2 minpoll 4

server HOSTSERV3 minpoll 4

server HOSTSERV4 minpoll 4

server HOSTSTRV5 minpoll 4

server HOSTSTRV6 minpoll 4,

где вместо переменной HOSTSERV1 подставляется сетевое имя основного сервера синхронизации времени. Вместо переменных HOSTSERV2, HOSTSERV3, HOSTSERV4, HOSTSERV5, HOSTSERV6 подставляются сетевые имена резервных серверов синхронизации времени.

Для грубой установки системного времени шлюза с помощью команды $n t p d a t e$ от основного или резервных серверов синхронизации, выполняемой автоматически при загрузке операционной системы, необходимо отредактировать файл /etc/ntp/steptickers так, чтобы он содержал строки:

HOSTSERV1

HOSTSERV2

HOSTSERV3

HOSTSERV4

HOSTSERV5

HOSTSERV6

После настройки NTP необходимо перезагрузить операционную систему.

При инсталляции ШИПО для последующего контроля синхронизации времени шлюза в системе АТПС СВУ необходимо скопировать с инсталляционного CD ШИПО файлы ntpq_sel, ntpq. in в текущую директорию ПО шлюза. Затем отредактировать ntpq_sel: 
- заменить переменную HOSTSERV1 на сетевое имя основного сервера синхронизации времени;

- заменить переменные HOSTSERV2, HOSTSERV3, HOSTSERV4, HOSTSERV5, HOSTSERV6 на сетевые имена резервных серверов синхронизации времени.

Сделать файл ntpq_sel исполняемым командой chmod u+x ntpq_sel

\section{7. Обеспечение кибербезопасности}

Таблица 3 содержит требования по кибербезопасности, реализованные при разработке ШИПО, в том числе, при выполнении операций установления связи между процессами CBУ и модулем CGP, см. раздел 4.2.

Таблица 3

Реализачия требований кибербезопасности

\begin{tabular}{|c|c|c|}
\hline № & $\begin{array}{c}\text { Tребование } \\
\text { кибербезопасности }\end{array}$ & Способ реализации требования \\
\hline 1 & $\begin{array}{l}\text { Установлению сетевого со- } \\
\text { единения должна предше- } \\
\text { ствовать аутентификация. }\end{array}$ & $\begin{array}{l}\text { Посылки, получаемые модулем CGP } \\
\text { при выполнении операций установле- } \\
\text { ния связи 2), 4), см. раздел 4.2, содер- } \\
\text { жат сетевые параметры процессов } \\
\text { СВУ и списки кодов сигналов. }\end{array}$ \\
\hline 2 & $\begin{array}{l}\text { В случае ошибки аутентифи- } \\
\text { кации при попытке установ- } \\
\text { ления связи соединение } \\
\text { должно быть заблокировано. }\end{array}$ & $\begin{array}{l}\text { При невыполнении хотя одной из опе- } \\
\text { раций 1)-4), см. раздел 4.2, в том } \\
\text { числе, несоблюдении форматов посы- } \\
\text { лок при операциях 2), 4), установле- } \\
\text { ние связи будет заблокировано. }\end{array}$ \\
\hline 3 & $\begin{array}{l}\text { Установление соединения } \\
\text { должно логироваться. }\end{array}$ & $\begin{array}{l}\text { Записи о выполнении последователь- } \\
\text { ности операций установления связи } \\
\text { 1)-4), см. раздел 4.2, сохраняются в } \\
\text { log-файлах ШИПО, см. подраздел } \\
\text { 5.6.2. }\end{array}$ \\
\hline
\end{tabular}




\begin{tabular}{|c|c|c|}
\hline № & $\begin{array}{c}\text { Требование } \\
\text { кибербезопасности }\end{array}$ & Способ реализации требования \\
\hline 4 & $\begin{array}{l}\text { При обнаружении коммуни- } \\
\text { кационных событий, связан- } \\
\text { ных с безопасностью, собы- } \\
\text { тия должны логироваться. }\end{array}$ & $\begin{array}{l}\text { Выполнение требования № } 3 \text {, а также } \\
\text { сохранение в log-файлах ШиПО, см. } \\
\text { подраздел 5.6.2, записей об ошибках, } \\
\text { обнаруженных при выполнении опе- } \\
\text { раций установления связи 1)-4), см. } \\
\text { раздел 4.2. }\end{array}$ \\
\hline 5 & $\begin{array}{l}\text { Получение любого } \text { некор- } \\
\text { ректного сообщения должно } \\
\text { логироваться. }\end{array}$ & $\begin{array}{l}\text { При получении от процесса CBУ не- } \\
\text { корректного сообщения в log-файле } \\
\text { ШИПО сохраняется запись об ошибе } \\
\text { с кодом ECGP_DATEXCH, см. раздел } \\
\text { 5.6. }\end{array}$ \\
\hline 6 & $\begin{array}{l}\text { Число сетевых соединений } \\
\text { должно быть минимизирова- } \\
\text { но. }\end{array}$ & $\begin{array}{l}\text { Число процессов СВУ, которые могут } \\
\text { установить связь с модулем CGP, } \\
\text { ограничивается константой MAX_DB в } \\
\text { файле cgp.h, см. раздел } 5.1 .\end{array}$ \\
\hline 7 & $\begin{array}{l}\text { Конфигурация не дол-жна } \\
\text { обновляться без соответ- } \\
\text { ствующей аутентификации. }\end{array}$ & $\begin{array}{l}\text { Обновление конфигурационных фай- } \\
\text { лов ПО шлюза выполняется процеду- } \\
\text { рой автоконфигурации, см. раздел } 5.5 \text {, } \\
\text { с параметрами доступа к серверу } \\
\text { СВУ: сетевым именем, именем поль- } \\
\text { зователя и паролем пользователя. }\end{array}$ \\
\hline 8 & $\begin{array}{l}\text { Конфигурация должна об- } \\
\text { новляться по каждому из } \\
\text { дублированных каналов раз- } \\
\text { дельно. Сначала один канал, } \\
\text { затем другой. }\end{array}$ & $\begin{array}{l}\text { Согласно штатной инструкции, об- } \\
\text { новление конфигурационных файлов } \\
\text { для основного и резервного ПО шлю- } \\
\text { за выполняется последовательно: вна- } \\
\text { чале для основного ПО шлюза, затем } \\
\text { для резервного ПО шлюза. }\end{array}$ \\
\hline 9 & $\begin{array}{l}\text { Должна поддерживаться } \\
\text { возможность запрета рекон- } \\
\text { фигурации системы с одной } \\
\text { из сторон соединения. }\end{array}$ & $\begin{array}{l}\text { Процедура автоконфигурации ПО } \\
\text { шлюза (см. раздел 5.5) выполняемая } \\
\text { перед загрузкой ПО шлюза, может } \\
\text { быть отключена путем блокировки } \\
\text { вызова командного файла autoconf. }\end{array}$ \\
\hline 10 & $\begin{array}{l}\text { Должна поддерживаться диа- } \\
\text { гностика соединений. }\end{array}$ & $\begin{array}{l}\text { Модуль CGP и процессы CBУ, устано- } \\
\text { вившие связь с модулем CGP, обмени- } \\
\text { ваются периодическими контрольн-- } \\
\text { ми посылками, см. раздел } 4.6 .\end{array}$ \\
\hline
\end{tabular}




\begin{tabular}{|c|c|c|}
\hline № & $\begin{array}{c}\text { Требование } \\
\text { кибербезопасности }\end{array}$ & Способ реализации требования \\
\hline 11 & $\begin{array}{l}\text { Должна поддерживаться без- } \\
\text { опасная передача данных с } \\
\text { проверкой целостности и } \\
\text { достоверности переданных } \\
\text { данных. }\end{array}$ & $\begin{array}{l}\text { При обмене данными с процессами } \\
\text { СВУ в ШИПО контролируются: фор- } \\
\text { мат физических посылок на уровне } \\
\text { сетевой библиотеки; соблюдение ло- } \\
\text { гического протокола обмена данными } \\
\text { на модуля CGP. }\end{array}$ \\
\hline
\end{tabular}

\section{8. Настройка параметров ШИПО}

В процессе проектирования АСУ ТП энергоблока АЭС и последующих пуско-наладочных работах необходимо настроить параметры ШИПО. Настраиваемые параметры ШИПО включают размеры массивов текущих значений и кольцевых буферов для каждого типа сигналов.

Размеры массивов текущих значений входных сигналов каждого типа устанавливаются не менее максимально возможных количеств сигналов этого типа на одном шлюзе конкретной смежной системы АСУ ТП АЭС.

Размеры кольцевых буферов входных сигналов должны быть установлены так, чтобы эти буфера не переполнялись в условиях пиковых потоков входных данных большой интенсивности. Переполнение кольцевых буферов приводит к потерям входных данных, передаваемых для записи в архив СВУ. Потоки входных данных большой интенсивности могут возникать во время переходных технологических процессов энергоблока АЭС (плановый пуск/останов реактора, срабатывание аварийной защиты, потеря электропитания оборудования и т.д.). Во время стационарной работы энергоблока АЭС на проектной мощности при потоках входных данных нормальной интенсивности передача входных сигналов осуществляется в основном с использованием только массивов текущих значений, с редким использованием кольцевых буферов.

Обозначим для одного из типов входных сигналов (аналоговых, дискретных, векторных) и для ПО конкретного шлюза: 
$S$ - размер кольцевого буфера для этого типа сигналов и этого шлюза (измеряется в количестве сигналов, которые могут храниться в этом буфере);

$f$ - проектный поток входных сигналов этого типа, передаваемых через этот шлюз при стационарной работе энергоблока АЭС на проектной мощности (измеряется в количестве сигналов, передаваемых за единицу времени);

$F_{i}$ - проектный поток входных сигналов этого типа, передаваемых через этот шлюз при $i$-ом переходном технологическом процессе энергоблока АЭС $(i=1,2 \ldots M)$;

$T_{i}$ - максимальная проектная продолжительность $i$-го переходного технологического процесса (измеряется в единицах времени).

Проектный размер кольцевого буфера должен удовлетворять условию:

$$
S \geq \max _{i=1,2 \ldots M}\left(\left(F_{i}-f\right) T_{i}\right)
$$

\section{9. Оценка потоков обмена данными между ПО шлюза и ПО смежной системы АСУ ТП}

В процессе проектирования ПО шлюза необходимо настроить параметры программных каналов обмена данными между ПО шлюза и ПО смежной системы АСУ ТП АЭС, включающие:

- количество шлюзов в смежной системе;

- распределение сигналов СВУ по шлюзам;

- периоды для циклической передачи пакетов данных.

Одно из основных требований при таком проектировании состоит в том, чтобы поток данных (объем информации, передаваемый в единицу времени) по программным каналам смежной системы не превышал максимально допустимую загрузку этих каналов.

Рассмотрим методы оценки потоков данных на примере системной шины ПТК на базе ТПТС (Приложение 2).

Введем обозначения для максимально возможных потоков данных различных типов: $A$ - для циклической передачи пакетов дан- 
ных (телеграмм), $B$ - для событийной передачи пакетов данных, $C$ - для передачи пакетов данных по запросу. Тогда требование к загрузке системной шины ТПТС можно записать в виде:

$$
A+B+C \leq D
$$

где $D$ - максимально допустимая загрузка системной шины ТПТС.

Постоянный во времени поток данных в пакетах, поступающих в ПО шлюза циклически, определяется формулой:

$$
A=\sum_{n=1}^{N} \sum_{m=1}^{M}\left(V_{n m} / P_{n m}\right)
$$

где $V_{n m}$ - объем информации для $m$-ого поступающего циклически пакета данных $(m=1,2 \ldots M) n$-го типа $(n=1,2 \ldots N)$; $P_{n m}-$ период передачи этого пакета данных.

Максимальные потоки данных в пакетах, поступающих в ПО шлюза событийно, наблюдаются во время переходных технологических процессов энергоблока АЭС (плановый пуск/останов реактора, срабатывание аварийной защиты, потеря электропитания оборудования и т.д.). Для максимально возможного потока данных в пакетах, поступающих в ПО шлюза событийно, можно записать:

$$
B=\sum_{n=1}^{N}\left(\max _{k=1,2 \ldots K}\left(S_{n k} / T_{k}\right)\right)
$$

где $S_{n k}$ - суммарный объем информации в передаваемых событийно пакетах данных $n$-го типа $(n=1,2 \ldots N)$, поступающих в ПО шлюза в течение $k$-го переходного технологического процесса энергоблока АЭС $(k=1,2 \ldots K), T_{k}$ - длительность (по времени) этого переходного технологического процесса.

Максимальные потоки данных в пакетах, поступающих в ПО шлюза в ответ на запросы, зависят от максимального объема информации, который оператор на СВУ может запросить в единицу времени, используя одну рабочую станцию, и от количества рабочих станций. Для максимально возможного потока данных в пакетах, поступающих в ПО шлюза по запросам, можно записать: 


$$
C=\sum_{n=1}^{N} \sum_{l=1}^{L}\left(U_{n l}+R_{n l}\right)
$$

где $U_{n l}$ - максимальный поток данных в пакете $n$-го типа $(n=1,2 \ldots N)$, поступающем в ПО шлюза из ПО нижнего уровня в ответ на запрос оператора с $l$-ой рабочей станции СВУ $(l=1,2 \ldots L), R_{n l}$ - максимальный поток данных в пакете $n$-го типа, посылаемых из ПО шлюза в ПО смежной системы в результате ввода команд управления оператором на $l$-ой рабочей станции CBY. 


\section{ПРИЛОЖЕНИЕ 1. \\ ОБМЕН СИГНАЛАМИ МЕЖДУ МОДУЛЯМИ GАТЕ И СGP}

\section{П1.1. Передача сигналов от GATE к CGP}

\section{П1.1.1. Передача аналогового сигнала}

Модуль GATE, написанный на языке программирования C, передает модулю CGP значение аналогового сигнала va c номером $\mathrm{n}$, временем изменения timev, признаком недостоверности nv значения сигнала, признаком недостоверности SV времени изменения:

$\{$ int $\mathrm{n}, \mathrm{nv}, \mathrm{sv}, \mathrm{nv0}, \mathrm{cv}$;

float va, va0, aper; struct time_value timev, timev0;

struct analog_i cbval_ia; char c, cu=' $\backslash 001^{\prime}$; /* Предыдущее значение сигнала: */

$\mathrm{vaO}=\star(($ float *) aread (a_input_a, n));

/* Время предьдущего изменения значения сигнала (включая бить признаков недостоверности): */

$$
\text { timev0 = *( (struct time_value *) }
$$

aread (a_time_a, n)) ;

/* Признак недостоверности пv0 предыдущего значения сигнала : */

if(timev0.time msec \& 1024) nv0 = 1; else nv0 $=0$;

/* Апертура сигнала: */

aper $=$ *( (float *) aread (a_aperture, n));

/* Флаг обновления CV признака недостоверности: */

if $((\mathrm{nv} !=\mathrm{nv0}) \quad||($ timev0.time_sec $==0 \mathrm{~L})) \mathrm{cV}$ $=1$;

else $\mathrm{CV}=0$;

/* Если новое значение сигнала отличается по абсолютному значению от предыдущего значения не менее, чем на апертуру, или изменился признак недостоверности: */

if ( va $<=$ vaO - aper) || (va $>=$ vaO taper)

| $1 \mathrm{CV})$

/* Состояние флага обновления: */

$\mathrm{c}=\star \operatorname{aread}\left(\mathrm{a} \_\right.$update_ia, n) ; 
/* Если предыдущее значение сигнала не было считано модулем CGP:*/

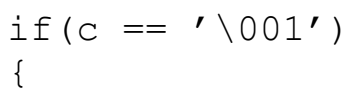

/* Сохранение предьдущих значений сигнала и соответствующего времени его изменения (с признаками недостоверности) в кольцевом буфере: */

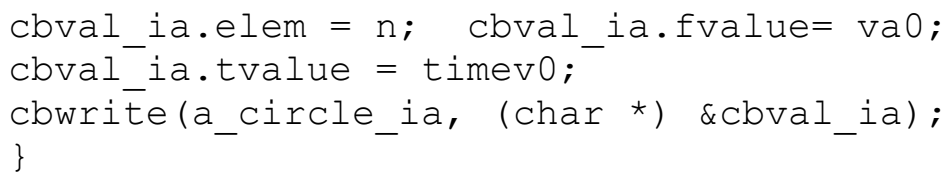

/* Запись текущего значения сигнала: */

awrite (a_input_a, n, (char *) \&va);

/* Запись признака недостоверности значения : */

if (nv) timev.time msec |= 1024;

/* Запись признака недостоверности времени изменения : */

if (sv) timev.time_msec |= 2048;

/* Запись признака значения, первого после загрузки : */ 8192 ;

if(timev0.time_sec $==$ OL) timev.time_msec $\mid=$

/* Запись времени изменения сигнала (включая биты признаков недостоверности): */

awrite(a_time_a, n, (char *) \&timev) ;

/* Установка филагов обновления : */

awrite (a_update_ia, n \&cu); stchange.fläg_cgp $=$ ' \001';

\}

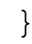

\section{П1.1.2. Передача дискретного сигнала}

Передача модулем GATE модулю CGP значения дискретного сигнала $\mathrm{vd}$ c номером $\mathrm{n}$, признаком недостоверности nv значения сигнала, признаком недостоверности SV времени изменения:

\{ int $\mathrm{n}, \mathrm{nv}, \mathrm{sv}, \mathrm{nv0}, \mathrm{cV}$;

char $\mathrm{vd}, \mathrm{vdO}, \mathrm{c}, \mathrm{cu}=^{\prime} \backslash 001^{\prime}$; struct time value timev, timev0;

struct discrete_i cbval_id; 
/* Предыдущее значение сигнала: */

$\mathrm{vdO}=$ * aread (a_input_d, n);

/* Время предыдущего изменения значения сигнала (включая биты признаков недостоверности): */

timev0 $0 \quad *(($ struct time_value *)

aread (a_time_d, n));

/* Признак недостоверности пv0 предыдущего значения сигнала: */

if(timev0.time_msec \& 1024) nv0 = 1; else nv0

$=0$;

/* Флаг изменения сv признака недостоверности: */

if $((\mathrm{nv} !=\mathrm{nvO}) \quad||$ (timev0.time_sec $==0 \mathrm{~L})) \mathrm{CV}$

$=1$;

else $\mathrm{CV}=0$;

/* Если новое значение сигнала отличается от предыдущего или изменился признак недостоверности: */

if $(\mathrm{vd} !=\mathrm{vdO}) \quad|| \mathrm{cv})$

\{

/* Состояние флага обновления: */

$\mathrm{c}=$ * aread (a_update_id, n);

/* Если предыдущее значение сигнала не было считано модулем $C G P: * /$

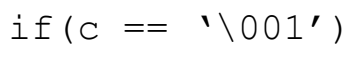

/* Сохранение предыдущих значений сигнала и соответствующего времени его изменения (с признаками недостоверности) в кольцевом бурере: */

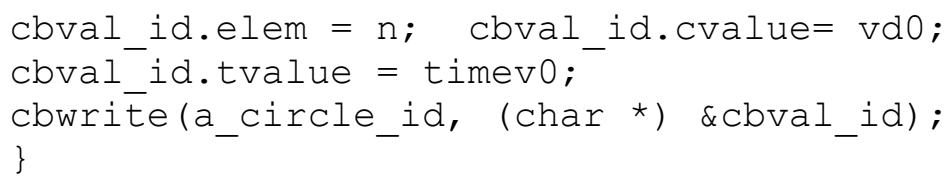

/* Запись текущего значения сигнала: */ awrite (a_input_d, n, \&vd);

/* Запись признака недостоверности значения: */

if(nv) timev.time msec |= 1024;

/* Запись признака недостоверности времени изменения: */

if(sv) timev.time_msec $\mid=2048$;

/* Запись признака значения, первого после загрузки: */ 
if(timev0.time $\sec ==$ OL) timev.time msec $\mid=$

/* Запись времени изменения сигнала (включая биты признаков недостоверности) : */

awrite (a time d, n, (char *) \&timev);

/* Установка филагов обновления: */

awrite (a_update_id, n

n $\quad \& C u) ;$

stchange.fläg_cgp $=$ ' $\backslash 001^{\prime}$;

\}

\section{П1.2. Вызов функций модуля GATE из модуля CGP}

Модуль GATE должен включать функции языка программирования C, вызываемые из модуля CGP. Эти функции имеют следующее типовое описание.

Функция int data_open (void) вызывается из модуля CGP при его совместной с модулем GATE загрузке и должна включать открытие каналов обмена данными ПО шлюза с ПО смежной системы.

Функция int data_close(void) вызывается из модуля CGP при его совместной с модулем GATE выгрузке и должна включать закрытие каналов обмена данными ПО шлюза с ПО смежной системы.

Функция int data_read(void) вызывается из модуля CGP циклически и должна включать передачу данных из модуля GATE в модуль CGP. Общая для модулей CGP и GATE функция main языка программирования С включена в модуль CGP.

В качестве своих значений функции data_open, data_close, data_read должны возвращать значение 0 при нормальном завершении или - 1 при выходе с ошибкой.

Если ПО шлюза должно выполнять передачу команд управления операторов CBУ в ПО смежной системы, то модуль GATE должен включать функцию void data_write (void) которая вызывается из модуля CGP в случае поступления команд управления операторов СВУ и должна включать прием выходных сигналов в модуле GATE от модуля CGP . 


\section{ПРИЛОЖЕНИЕ 2.}

\section{АЛГОРИТМЫ ОБРАБОТКИ ИНФОРМАЦИИ ПРИ ВЗАИМОДЕЙСТВИИ С СИСТЕМОЙ ТПТС}

\section{П2.1 Обмен данными между СВУ и ТПТС}

ПТК на базе системы типовых программно-технических средств (ТПТС) [11] составляют значительную часть ПТК нижнего уровня, используемых в АСУ ТП энергоблоков АЭС «Бушер» (Иран) и АЭС «Куданкулам» (Индия).

Обмен данными между СВУ и смежными ПТК на базе ТПТС, реализуется в шлюзах с использованием телеграмм (сообщений), передаваемых по шине ТПТС.

Существуют следующие форматы данных при обмене данными между шлюзом и СВУ:

- для передачи аналоговых сигналов, значений уставок формат числа с плавающей точкой;

- для передачи дискретных сигналов - формат целого числа со значащим младшим битом;

- для передачи слов из телеграмм ТПТС - формат целого числа со значащими 16 младшими битами.

Значения сигналов поступают от шлюзов в СВУ с метками времени и атрибутами достоверности. Различаются следующие значения атрибутов достоверности:

- достоверность значения сигнала;

- достоверность метки времени.

Возможны следующие способы передачи информационных сообщений (телеграмм), посылаемые из ПТК на базе ТПТС в ПО шлюза и из ПО шлюза в ПТК:

- циклическая передача аналоговых сигналов из ПТК в ПО шлюза;

- циклическая передача дискретных сигналов из ПТК в ПО шлюза;

- событийная передача аналоговых сигналов из ПТК в ПО шлюза; 
- событийная передача дискретных сигналов из ПТК в ПО шлюза;

- передача аналоговых сигналов из ПТК по запросу ПО шлюза;

- передача дискретных сигналов из ПТК по запросу ПО шлюза;

- передача аналоговых сигналов из ПО шлюза в ПТК;

- передача дискретных сигналов из ПО шлюза в ПТК.

Циклическая передача выполняется с заданным периодом времени и включает все сигналы в телеграммах данного типа. Событийная передача включает передачу только изменений сигналов (событий): изменений значений сигналов или признаков недостоверностей сигналов.

Изменением значения аналогового сигнала является увеличение или уменьшение соответствующего параметра на величину, которая превышает апертуру сигнала, устанавливаемую с целью фильтрации шумов (случайной составляющей) значения параметра. Изменением дискретного сигнала является смена значения соответствующего параметра на противоположное. Если происходит потеря связи СВУ с источником сигнала из ПТК на базе ТПТС, то ПО шлюза устанавливает признак недостоверности сигнала, обозначающий отсутствие информации о текущем значении сигнала.

На рис. 6 представлена структура типов телеграмм ТПТС.

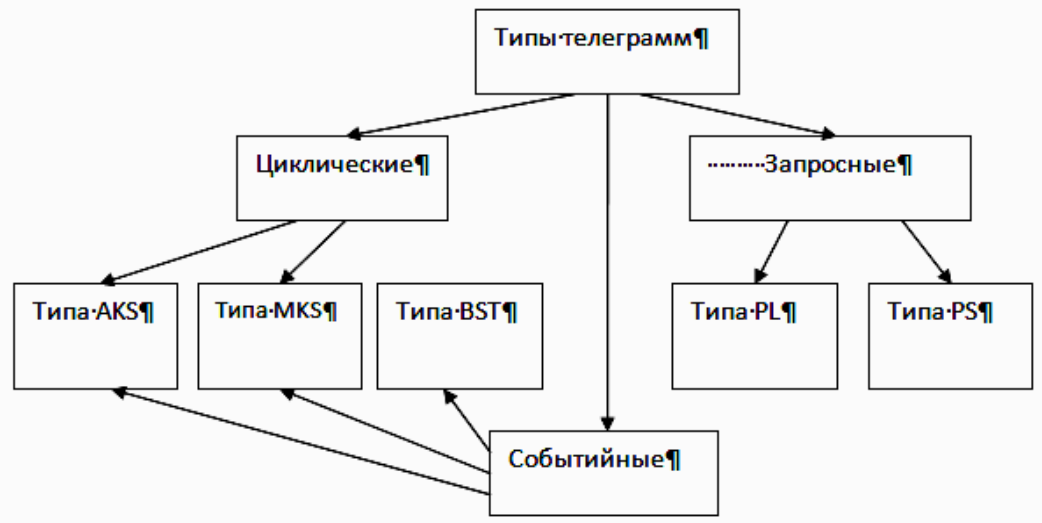

Рис. 6 - Структура типов телеграмм ТПТС 
Для передачи данных из ПТК в ПО шлюза используются следующие типы телеграмм:

- $\mathrm{AKS}$ - аналоговые сигналы, передаваемые циклически или событийно;

- $\mathrm{MKS}$ - дискретные сигналы, передаваемые циклически или событийно;

- BST - дискретные сигналы, передаваемые событийно;

- $\mathrm{PL}$ - аналоговые или дискретные сигналы, передаваемые в ответ на запрос ПО шлюза.

Для передачи команд управления из ПО шлюза в ПТК используются телеграммы типа PS - аналоговые или дискретные сигналы, адресуемые в терминах каналов функциональных модулей ПТК.

Адрес каждого сигнала в ПО шлюзов ТПТС включает:

- адрес шлюза в ЛВС СВУ;

- адрес шлюза на шине ТПТС;

- адрес модуля управления приборной стойкой на шине ТПТС;

- адрес функционального модуля ТПТС в приборной стойке;

- номер программного канала в функциональном модуле ТПТС;

- тип телеграммы;

- номер телеграммы (уникальный среди телеграмм одного типа для приборной стойки);

- номер сигнала в телеграмме.

Протокол обмена телеграммами между ПО шлюза и ПО приборных стоек ТПТС реализован с учетом:

- большого количества сигналов в базе данных АСУ ТП АЭС;

- ограничений на интенсивность потока данных по системной шине ТПТС.

На рис. 7 представлена схема передачи телеграмм различных типов для входных сигналов в ПО шлюза ТПТС.

В качестве основного способа обмена телеграммами типа AKS и MKS используется событийная передача, поскольку технические 
характеристики системной шины ТПТС не позволяют установить периоды передачи телеграмм этого типа событийным способом, достаточно короткими для требуемой актуальности контроля над протеканием технологических процессов АСУ ТП АЭС. Циклический способ передачи телеграмм типа AKS и MKS используется для тех же сигналов шлюза в качестве дополнительного (резервного) способа передачи с целью предотвращения возможной потери актуальности информации в ПО СВУ в результате потери телеграммы, переданной событийным способом. Такая потеря телеграммы, вызванная неисправностью системной шины ТПТС, может произойти с небольшой вероятностью, но для надежности требуется повторная передача той же телеграммы циклическим способом, гарантирующим поступление данных в СВБУ хотя бы и с большей задержкой по времени, чем при событийном способе передачи.

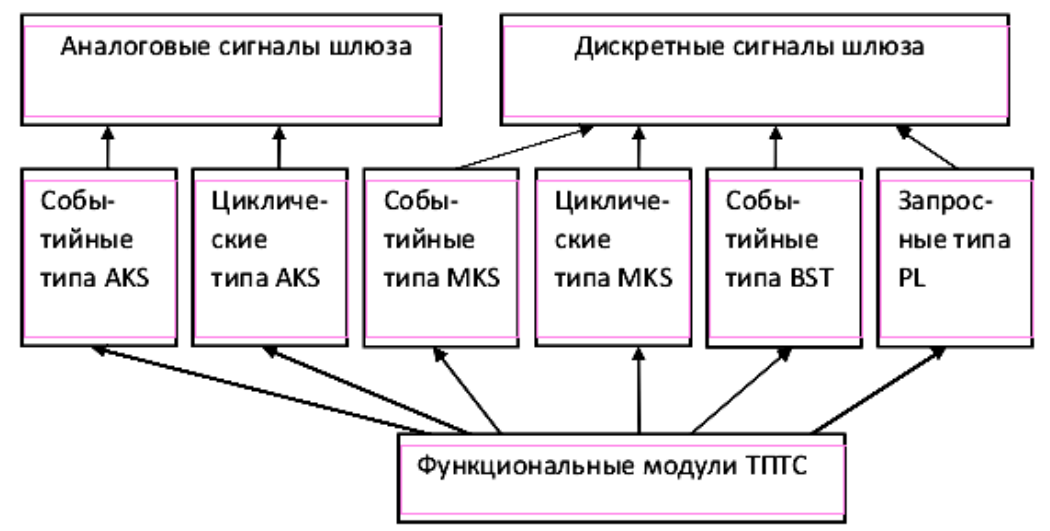

Рис. 7 - Схема передачи входных сигналов в ПО шлюза ТПТС

Телеграммы типа BST могут передаваться только событийным способом. В качестве дополнительного (резервного) способа передачи сигналов, включенных в телеграммы типа BST, используются запросные телеграммы типа PL, включающие те же сигналы и циклически запрашиваемые ПО шлюза из ПО приборных стоек ТПТС.

Часть входных дискретных сигналов может передаваться только с использованием запросных телеграмм типа PL. Источником запросов для таких телеграмм типа PL служат запросы информации, поступающие из ПО СВУ в ПО шлюза и далее в ПО приборных 
стоек ТПТС. ПО СВУ посылает эти запросы на основе требований к содержанию информации, необходимой оператору на CВУ в текущий момент времени. Такие запросы передаются через ПО шлюза циклически в течение всего интервала времени, когда соответствующая информация необходима оператору СВУ.

Для передачи в ПО приборных стоек ТПТС команд, введенных операторами на СВУ, используются выходные аналоговые и дискретные сигналы, передаваемые из ПО в составе телеграмм типа PS.

\section{П2.2. Контроль и управление технологическим оборудованием с использованием системы ТПТС}

П2.2.1. Алгоритмы обработки информации для запорной арматуры, управляемой канальным оператором ES системы TIITC

Состояние запорной арматуры определяется по значениям сигналов канального оператора ES:

- ARAF - состояние «открыто»;

- ARZU - состояние «закрыто»;

- LAFF - состояние «мерцание открыто»;

- LZUF - состояние «мерцание закрыто»,

- $\mathrm{RMF2} \mathrm{-} \mathrm{неисправность} \mathrm{цепей} \mathrm{сигналов} \mathrm{моментных}$ муфт.

При поступлении значения одного или нескольких сигналов формируется состояние арматуры.

Для получения значений сигналов LAFF, LZUF, в случае если запорная арматура находится в промежуточном положении (не открыта и не закрыта), выполняются периодические запросы. Запросы формируются только в случае, когда сигнал RMF2 равен 0. 
Таблица 4.

Состояние запорной арматуры для канального оператора ES

\begin{tabular}{|c|c|}
\hline $\begin{array}{c}\text { Состояние запорной } \\
\text { арматуры }\end{array}$ & Значения сигналов \\
\hline Начальное (неопределенное) & $\begin{array}{l}\text { Отсутствуют значения } \\
\text { ARAF или ARZU }\end{array}$ \\
\hline Открыто & $\mathrm{ARAF}=1, \mathrm{ARZU}=0$ \\
\hline Закрыто & $\mathrm{ARAF}=0, \mathrm{ARZU}=1$ \\
\hline Открывается & $\begin{array}{l}\mathrm{ARAF}=0, \mathrm{ARZU}=0, \\
\mathrm{LAFF}=1, \mathrm{LZUF}=0\end{array}$ \\
\hline Закрывается & $\begin{array}{l}\text { ARAF }=0, \text { ARZU }=0, \\
\mathrm{LAFF}=0, \mathrm{LZUF}=1\end{array}$ \\
\hline Стоп & $\begin{array}{l}\mathrm{ARAF}=0, \mathrm{ARZU}=0, \\
\mathrm{LAFF}=0, \mathrm{LZUF}=0\end{array}$ \\
\hline $\begin{array}{l}\text { Промежуточное. Арматура сошла с концевого вы- } \\
\text { ключателя из состояния “открыто”, данных о дви- } \\
\text { жении нет }\end{array}$ & $\mathrm{ARAF}=0, \mathrm{ARZU}=0$ \\
\hline $\begin{array}{l}\text { Промежуточное. Арматура сошла с концевого вы- } \\
\text { ключателя из состояния “закрыто”, данных о дви- } \\
\text { жении нет }\end{array}$ & $\mathrm{ARAF}=0, \mathrm{ARZU}=0$ \\
\hline Предыдущее состояние & $\begin{array}{l}\text { Значения ARAF=1, } \\
\text { ARZU }=1\end{array}$ \\
\hline
\end{tabular}

Для управления запорной арматуры используются сигналы, передаваемые в телеграммах типа PS на вход канального оператора ES:

- $\mathrm{BHS}$ - команда «закрыть»;

- $\mathrm{BHOE} \mathrm{-} \mathrm{команда} \mathrm{«открыть»;}$

- FHD - подтверждение команды;

- $\mathrm{BST}$ - дистанционная команда «стоп».

При вводе команды на открытие арматуры на вход канального оператора ES одновременно передаются сигналы BHOE, FHD.

При вводе команды на закрытие арматуры на вход канального оператора ES одновременно передаются сигналы BHS, FHD.

При вводе команды на останов на вход канального оператора ES одновременно передаются сигналы BST, FHD.

При квитировании состояния арматуры на вход канального оператора ES одновременно передаются сигналы BHS, BНОЕ без подтверждения. 
П2.2.2. Алгоритмы обработки информации для электродвигателей, электронагревателей и электромагнитных клапанов, управляемых канальными операторами ЕМ системы TIITC

Состояние оборудования определяется по значениям сигналов канального оператора EM:

- ARA - состояние «включено»;

- $\mathrm{ARE}$ - состояние «выключено».

Таблица 5

Состояние оборудования для канального оператора ЕМ

\begin{tabular}{|l|l|}
\hline \multicolumn{1}{|c|}{ Состояние оборудования } & \multicolumn{1}{c|}{ Значения сигналов } \\
\hline Начальное (неопределенное) & Отсутствуют значения ARA или ARE \\
\hline Включено & $\mathrm{ARA}=1, \mathrm{ARE}=0$ \\
\hline Выключено & $\mathrm{ARA}=0, \mathrm{ARE}=1$ \\
\hline Предыдущее состояние & $\mathrm{ARA}=1, \mathrm{ARE}=1$ или $\mathrm{ARA}=0, \mathrm{ARE}=0$ \\
\hline
\end{tabular}

Для управления используются сигналы, передаваемые в телеграммах типа PS на вход канального оператора EM:

- ВНА - команда «выключить»;

- ВНЕ - команда «включить»;

- FHD - подтверждение команды.

При вводе команды на включение оборудования на вход канального оператора ЕМ одновременно передаются сигналы ВНЕ, FHD.

При вводе команды на выключение оборудования на вход канального оператора ЕМ одновременно передаются сигналы ВНА, FHD.

При квитировании состояния оборудования на вход канального оператора ЕМ одновременно передаются сигналы ВНА, ВНЕ без подтверждения. 
П2.2.3. Алгоритмы обработки и представления информации для переключателей, управляемых канальными операторами TE (ITE) системы TITC

Состояние переключателей определяется по значениям сигналов канального оператора ТЕ (ITE):

- $\mathrm{A}$ - состояние «включен»;

- $\mathrm{H}$ - состояние «выключен».

Таблица 6

Состояние переключателей для канальных операторов ТЕ (ITE)

\begin{tabular}{|l|l|}
\hline \multicolumn{1}{|c|}{$\begin{array}{c}\text { Состояние } \\
\text { переключателя }\end{array}$} & \multicolumn{1}{c|}{ Значения сигналов } \\
\hline Начальное (неопределенное) & Отсутствуют значения А или $\mathrm{H}$ \\
\hline Включен & $\mathrm{A}=1, \mathrm{H}=0$ \\
\hline Выключен & $\mathrm{A}=0, \mathrm{H}=1$ \\
\hline Предыдущее состояние & $\mathrm{A}=0, \mathrm{H}=0$ или $\mathrm{A}=1, \mathrm{H}=1$ \\
\hline
\end{tabular}

Для изменения состояния переключателя используются сигналы, передаваемые в телеграммах типа PS на вход канального оператора TE (ITE):

- $\mathrm{BH} / \mathrm{A}$ - команда переключения состояния на противоположное;

- $\quad \mathrm{FHD}$ - подтверждение команды.

При вводе команды на переключение на вход канального оператора TE (ITE) передаются сигналы BH/А и FHD.

При квитировании состояния переключателя на вход канального оператора TE (ITE) передаются сигналы ВН/А без подтверждения.

П2.2.4. Алгоритмы обработки и представления информации для блоков выбора, управляемых канальными операторами VL (IVL) системы THTC

Для управления блоками выбора, предназначенными для выбора от одного из двух или трех устройств, используется канальный 
оператор VL (IVL), который для каждого устройства имеет два состояния «выбран» или «не выбран».

Состояние выбора 1-го устройства определяется по значению сигнала VW1V канального оператора VL (IVL), состояние выбора 2го устройства - по значению сигнала VW2V, состояние выбора 3-го устройства - по значению сигнала VW3V.

\section{Таблица 7}

Состояние блоков выбора для канального оператора VL (IVL).

\begin{tabular}{|l|l|}
\hline \multicolumn{1}{|c|}{$\begin{array}{c}\text { Состояние выбора } \mathbf{N}-г о \\
(\mathbf{N = 1 , 2 , 3 )}\end{array}$} & устройства \\
\hline Начальное (неопределенное) & Отсутствует значение \\
\hline Выбран & 1 \\
\hline Не выбран & 0 \\
\hline
\end{tabular}

Для управления блоком выбора используются сигналы, передаваемые в телеграммах типа PS на вход канальных операторов VL (или IVL):

- VW1 - команда выбора 1-го устройства;

- VW2 - команда выбора 2-го устройства;

- VW3 - команда выбора 3-го устройства;

- FHD - подтверждение команды.

При вводе команды управления на вход канального оператора передаются сигналы VW<N $>$ и FHD.

П2.2.5. Алгоритмы обработки и представления информации для блоков задания уставок регуляторов, управляемых канальными операторами IBR системы TПTС

Режим блока задания уставки регулятора определяется по значениям сигналов канального оператора IBR:

- $\mathrm{A}$ - состояние «автоматический режим управления»;

- $\mathrm{H}$ - состояние «дистанционный режим управления».

Значение уставки регулятора определяется аналоговым сигналом из AKS-телеграммы. 


\section{Таблица 8}

Состояние блока задания уставки регулятора для канального опеpamopa IBR.

\begin{tabular}{|l|l|}
\hline \multicolumn{1}{|c|}{ Состояние } & \multicolumn{1}{|c|}{ Значения сигналов } \\
\hline Начальное (неопределенное) & Отсутствуют значения А или $\mathrm{H}$ \\
\hline Автоматический режим управления & $\mathrm{A}=1, \mathrm{H}=0$ \\
\hline Дистанционный режим управления & $\mathrm{A}=0, \mathrm{H}=1$ \\
\hline Предыдущее состояние & $\mathrm{A}=0, \mathrm{H}=0$ или $\mathrm{A}=1, \mathrm{H}=1$ \\
\hline
\end{tabular}

Для управления блоком задания уставки регулятора используются сигналы, передаваемые в телеграммах типа PS на вход канального оператора IBR:

- $\mathrm{BH} / \mathrm{A}$ - команда переключения режима управления «дистанционный/автоматический»,

- $\mathrm{WH}$ - аналоговый сигнал значения уставки регулятора,

- $\mathrm{FHD}$ - подтверждение команды.

При вводе команды на изменение режима управления заданием уставки регулятора в канальный оператор IBR передаются сигналы $\mathrm{BH} / \mathrm{A}$ и FHD.

При вводе требуемого значения уставки в канальный оператор IBR передаются сигналы WH и FHD.

При квитировании состояния в канальный оператор передается сигнал BH/A.

П2.2.6. Алгоритмы обработки и представления информации для регулирующей арматуры, управляемой канальными операторами SR (KR) системы TITTC

Состояние регулирующей арматуры определяется по значениям сигналов канального оператора SR (KR):

- $\mathrm{A}$ - состояние «автоматический режим управление»;

- $\mathrm{H}$ - состояние «дистанционный режим управления»;

- аналоговый сигнал из AKS-телеграммы для положения регулирующей арматуры в процентах. 
Таблица 9

Состояние регулирующей арматуры для канального оператора $S R$

\begin{tabular}{|l|l|}
\multicolumn{1}{|c|}{$(K R)$} \\
\begin{tabular}{|l}
\multicolumn{1}{|c|}{ Состояние регулирующей } \\
Арматуры
\end{tabular} & \multicolumn{1}{|c|}{ Значения сигналов } \\
\hline Начальное (неопределенное) & Отсутствуют значения А или $\mathrm{H}$ \\
\hline $\begin{array}{l}\text { Автоматический режим управле-- } \\
\text { ния }=1, \mathrm{H}=0\end{array}$ & \\
\hline Дистанционный режим управления & $\mathrm{A}=0, \mathrm{H}=1$ \\
\hline Предыдущее состояние & $\mathrm{A}=0, \mathrm{H}=0$ или $\mathrm{A}=1, \mathrm{H}=1$ \\
\hline
\end{tabular}

Для управления регулирующей арматурой используются сигналы, передаваемые в телеграммах типа PS на вход канального операTopa SR (KR):

- $\mathrm{BHS}$ - команда «закрыть»;

- $\mathrm{BHOE} \mathrm{-} \mathrm{команда} \mathrm{«открыть»;}$

- $\mathrm{BH} / \mathrm{A}$ - команда переключения режима управления «дистанционный/автоматический»;

- $\quad$ FHD - подтверждение команды.

При вводе команды на частичное открытие регулирующей арматуры на вход канального оператора SR (KR) передается одиночный сигнал ВНОЕ.

При вводе команды на частичное закрытие регулирующей арматуры на вход канального оператора SR (KR) передается одиночный сигнал BHS.

При вводе команды на переключение режима управления регулирующей арматурой на вход канального оператора SR (KR) одновременно передаются сигналы BH/A, FHD.

При вводе команды на полное открытие регулирующей арматуры на вход канального оператора SR (KR) многократно передается сигнал ВНОЕ.

При вводе команды на полное закрытие регулирующей арматуры на вход канального оператора SR (KR) многократно передается сигнал BHS.

При квитировании состояния регулирующей арматуры на вход канального оператора SR (KR) поступает сигнал BH/A без подтверждения. 
П2.2.7. Алгоритмы обработки информации по неуправляемому оборудованию, передаваемой в сигналах из MKSтелеграмм

Данные о состоянии неуправляемого оборудования (электродвигателей, задвижек ...) передаются в СВУ в дискретных сигналах из MKS-телеграмм.

Состояние оборудования определяется по значениям дискретных сигналов:

- XВ01 - положение «открыто / включено»;

- XВ02 - положение «закрыто / выключено».

\section{Таблица 10}

Состояние неуправляемого оборудования в дискретных сигналах из $M K S$-телеграмм.

\begin{tabular}{|l|l|}
\hline \multicolumn{1}{|c|}{ Состояние оборудования } & \multicolumn{1}{|c|}{ Значения сигналов } \\
\hline Начальное (неопределенное) & Отсутствуют значения ХВ01 или ХВ02 \\
\hline Открыто / Включено & ХВ01 $=1$, ХВ02 $=0$ \\
\hline Закрыто / Выключено & ХВ01 $=0$, XВ02 $=1$ \\
\hline Предыдущее состояние & ХВ01 $=1$, ХВ02 $=1$ или \\
& ХВ01 $=0$, ХВ02 $=0$ \\
\hline
\end{tabular}

П2.2.8. Алгоритмы обработки и представления информации для программ группового почагового управления в сигналах канального оператора КО системы ТПТС

Состояние программы группового пошагового управления определяется по значениям сигналов канального оператора КО:

- $\mathrm{A}$ - состояние «автоматический режим управления»;

- $\mathrm{H}$ - состояние «дистанционный режим управление»;

- $\mathrm{M}$ - состояние «параллельный режим управления»;

- RSB - состояние "пуск";

- RSS - состояние "останов";

- LBTF - состояние "мерцание пуска";

- LSTF - состояние "мерцание останова". 
Таблица 11

Состояние программы группового пошагового управления для канального оператора КО.

\begin{tabular}{|c|c|}
\hline Состояние & Значение сигнала \\
\hline Неопределенное состояние & Отсутствуют значения А или Н или М \\
\hline $\begin{array}{l}\text { Параллельный режим управле- } \\
\text { ния }\end{array}$ & $\mathrm{M}=1$ \\
\hline $\begin{array}{l}\text { Дистанционный режим управле- } \\
\text { ния }\end{array}$ & $\mathrm{H}=1$ \\
\hline Автоматическое управление & $A=1$ \\
\hline $\begin{array}{l}\text { Автоматическое управление и } \\
\text { пуск программы начат }\end{array}$ & $\mathrm{A}=1, \mathrm{LBTF}=1$ \\
\hline $\begin{array}{l}\text { Автоматическое у управление и } \\
\text { пуск программы выполнен }\end{array}$ & $\mathrm{A}=1, \mathrm{RSB}=1$ \\
\hline $\begin{array}{l}\text { Автоматическое управление и } \\
\text { останов программы начат }\end{array}$ & $\mathrm{A}=1, \mathrm{LSTF}=1$ \\
\hline $\begin{array}{l}\text { Автоматическое управление и } \\
\text { останов программы выполнен }\end{array}$ & $\mathrm{A}=1, \mathrm{RSS}=1$ \\
\hline
\end{tabular}

Для управления используются сигналы, передаваемые в телеграммах типа PS на вход канального оператора КO:

- $\mathrm{OBHU}, \mathrm{OFHD} \mathrm{-} \mathrm{команда} \mathrm{выбора} \mathrm{ветви;}$

- $\mathrm{OBHS}, \mathrm{OFHD} \mathrm{-} \mathrm{команда} \mathrm{останова} \mathrm{программы;}$

- $\quad$ OBHS, OFTI - команда останова шага программы;

- $\mathrm{OBHS}$ - команда квитирования останова программы;

- $\mathrm{OBHB}, \mathrm{OFHD} \mathrm{-} \mathrm{команда} \mathrm{пуска} \mathrm{программы;}$

- $\mathrm{OBHB}, \mathrm{OFTI}$ - команда пуска шага программы;

- $\mathrm{OBHB} \mathrm{-} \mathrm{команда} \mathrm{квитирования} \mathrm{пуска} \mathrm{программы;}$

- $\mathrm{OBHA,} \mathrm{OFHD} \mathrm{-} \mathrm{команда} \mathrm{переключения} \mathrm{режима} \mathrm{управ-}$ ления «Автоматический/Дистанционный»;

- OBHA, OFMU - команда переключения режима управления «Дистанционный/Параллельный»;

- $\mathrm{OFHD} \mathrm{-} \mathrm{подтверждение} \mathrm{команд.}$ 


\section{ПРИЛОЖЕНИЕ 3}

\section{АЛГОРИТМЫ ОБРАБОТКИ ИНФОРМАЦИИ ПРИ ВЗАИМОДЕЙСТВИИ С СИСТЕМОЙ КТПС-ПН}

\section{П3.1. Обмен данными между СВУ и КТПС-ПН}

ПТК на базе комплекса технико-программных средств повышенной надежности (КТПС-ПН) используются в ПТК управляющей системой безопасности технологической (УСБТ) АСУ ТП энергоблоков АЭС «Куданкулам» (Индия).

Обмен данными между СВУ и смежными ПТК на базе КТПСПН реализуется в шлюзах через внутреннюю сеть Ethernet с использованием сетевого протокола IPX или UDP/IP. Информация от функциональных блоков КТПС-ПН поступает в концентратор КТПС-ПН и далее, в шлюз. В концентраторе могут также формироваться дополнительные сигналы - как результат обработки данных от модулей по более сложным алгоритмам.

Далее по тексту принято следующее обозначение сигналов блоков КТПС-ПН:

- DO - выходные дискретные сигналы блоков;

- DI - входные дискретные сигналы блоков;

- $\mathrm{AO}$ - выходные аналоговые сигналы блоков;

- $\mathrm{AI}$ - входные аналоговые сигналы блоков.

Существуют следующие форматы при обмене данными между шлюзом и СВУ:

- для передачи аналоговых сигналов, значений уставок формат числа с плавающей точкой;

- для передачи дискретных сигналов - формат целого числа со значащим младшим битом.

Значения сигналов передаются с метками времени и параметрами качества. Различаются следующие параметры качества:

- достоверность значения сигнала;

- достоверность метки времени. 
Таблица 12

Перечень блоков КТПС-ПН, с которыми взаимодействует СВУ

\begin{tabular}{|l|l|}
\hline \multicolumn{1}{|c|}{ Код блока } & \multicolumn{1}{c|}{ Наименование блока } \\
\hline БКИН, БКИН1 & $\begin{array}{l}\text { Блок контроля сопротивления изоляции и наличия } \\
\text { напряжения }\end{array}$ \\
\hline БКП & Блок контроля предохранителей \\
\hline ПК3 & Контроллер периферийный \\
\hline АДП1, АДП2 & Аналогово-дискретный преобразователь \\
\hline БПК & Блок приема команд защиты \\
\hline БФК & Блок контроля и формирования команд \\
\hline БФИ, БФИ1 & Блок формирования импульсов \\
\hline БЛВ & Блок логический времени \\
\hline БЛП1, БЛП2 & Блок логических преобразований \\
\hline БРП & Блок реле промежуточных \\
\hline БСП & Блок сигнализации промежуточный \\
\hline $\begin{array}{l}\text { АПВ1, АПВ2, } \\
\text { АПВ3, АПВ4 }\end{array}$ & Блок преобразований и вычислений \\
\hline НПТ1, НПТ2 & Блок нормирующего преобразования температуры \\
\hline БПН, БПН3 & Блок преобразования напряжения \\
\hline БУД & Блок управления двигателем \\
\hline БУЗ & Блок управления задвижкой \\
\hline БУК & Блок управления регулирующим клапаном \\
\hline БАР1 & $\begin{array}{l}\text { Блок автоматического включения резервного ме- } \\
\text { ханизма }\end{array}$ \\
\hline БРИ & Блок регулирования импульсный \\
\hline
\end{tabular}

\section{П3.2. Контроль технологического оборудования с использованием системы КТПС-ПН}

\footnotetext{
П3.2.1. Алгоритмы обработки и представления информации по аналоговым параметрам

Источниками информации по аналоговым параметрам являются функциональные блоки АПВ1, АПВ2, АПВ3, НПТ1, НПТ2, БРИ.
} 
Таблица 13

Bыходы блоков АПВ1, АПВ2, АПВЗ, НПТ1, НПТ2, БРИ

\begin{tabular}{|c|c|c|c|}
\hline $\begin{array}{c}\text { Код } \\
\text { блока }\end{array}$ & Выход & Описание & Тип выхода \\
\hline \multirow[t]{21}{*}{ АПВ1 } & IS1 (AO1) & Параметр 1 канал & Аналоговый \\
\hline & IS2 (AO2) & Параметр 2 канал & Аналоговый \\
\hline & IS3 (AO3) & Параметр 3 канал & Аналоговый \\
\hline & IS4 (AO4) & Параметр 4 канал & Аналоговый \\
\hline & IS5 (DO1) & Диагностика & Дискретный \\
\hline & IS6 (DO2) & Выше уставки 1 канал 1 & Дискретный \\
\hline & IS7 (DO3) & Выше уставки 2 к анал 1 & Дискретный \\
\hline & IS8 (DO4) & Ниже уставки 1 канал 1 & Дискретный \\
\hline & IS9 (DO5) & Ниже уставки 2 канал 1 & Дискретный \\
\hline & IS10 (DO6) & Выше уставки 1 канал 2 & Дискретный \\
\hline & IS11 (DO7) & Выше уставки 2 канал 2 & Дискретный \\
\hline & IS12 (DO8) & Ниже уставки 1 канал 2 & Дискретный \\
\hline & IS13 (DO9) & Ниже уставки 2 канал 2 & Дискретный \\
\hline & IS14 (DO10) & Выше уставки 1 канал 3 & Дискретный \\
\hline & IS15 (DO11) & Выше уставки 2 канал 3 & Дискретный \\
\hline & IS16 (DO12) & Ниже уставки 1 канал 3 & Дискретный \\
\hline & IS17 (DO13) & Ниже уставки 2 канал 3 & Дискретный \\
\hline & IS18 (DO14) & Выше уставки 1 канал 4 & Дискретный \\
\hline & IS19 (DO15) & Выше уставки 2 канал 4 & Дискретный \\
\hline & IS20 (DO16) & Ниже уставки 1 канал 4 & Дискретный \\
\hline & IS21 (DO17) & Ниже уставки 2 канал 4 & Дискретный \\
\hline \multirow[t]{14}{*}{ АПВ2 } & IS1 (AO1) & Параметр 1 канал & Аналоговый \\
\hline & IS2 $(\mathrm{AO} 2)$ & Параметр 2 канал & Аналоговый \\
\hline & IS3 (AO3) & Параметр 3 канал & Аналоговый \\
\hline & IS4 (DO1) & Диагностика & Дискретный \\
\hline & IS5 (DO2) & Выше уставки 1 канал 1 & Дискретный \\
\hline & IS6 (DO3) & Выше уставки 2 канал 1 & Дискретный \\
\hline & IS7 (DO4) & Ниже уставки 1 канал 1 & Дискретный \\
\hline & IS8 (DO5) & Ниже уставки 2 канал 1 & Дискретный \\
\hline & IS9 (DO6) & Выше уставки 1 канал 2 & Дискретный \\
\hline & IS10 (DO7) & Выше уставки 2 канал 2 & Дискретный \\
\hline & IS11 (DO8) & Ниже уставки 1 канал 2 & Дискретный \\
\hline & IS12 (DO9) & Ниже уставки 2 канал 2 & Дискретный \\
\hline & IS13 (DO10) & Выше уставки 1 канал 3 & Дискретный \\
\hline & IS14 (DO11) & Выше уставки 2 канал 3 & Дискретный \\
\hline
\end{tabular}




\begin{tabular}{|c|c|c|c|}
\hline $\begin{array}{c}\text { Код } \\
\text { блока } \\
\end{array}$ & Выход & Описание & Тип выхода \\
\hline & IS15 (DO12) & Ниже уставки 1 канал 3 & Дискретный \\
\hline & IS16 (DO13) & Ниже уставки 2 канал 3 & Дискретный \\
\hline \multirow[t]{11}{*}{ АПВ3 } & IS1 (AO1) & Параметр 1 канал & Аналоговый \\
\hline & IS2 (AO2) & Параметр 2 канал & Аналоговый \\
\hline & IS3 (DO1) & Диагностика & Дискретный \\
\hline & IS4 (DO2) & Выше уставки 1 канал 1 & Дискретный \\
\hline & IS5 (DO3) & Выше уставки 2 канал 1 & Дискретный \\
\hline & IS6 (DO4) & Ниже уставки 1 канал 1 & Дискретный \\
\hline & IS7 (DO5) & Ниже уставки 2 канал 1 & Дискретный \\
\hline & IS8 (DO6) & Выше уставки 1 канал 2 & Дискретный \\
\hline & IS9 (DO7) & Выше уставки 2 канал 2 & Дискретный \\
\hline & IS10 (DO8) & Ниже уставки 1 канал 2 & Дискретный \\
\hline & IS11 (DO9) & Ниже уставки 2 канал 2 & Дискретный \\
\hline \multirow[t]{16}{*}{ НПТ1 } & IS1 (AO1) & Параметр 1 канал & Аналоговый \\
\hline & IS2 (AO2) & Параметр 2 канал & Аналоговый \\
\hline & IS3 (AO3) & Параметр 3 канал & Аналоговый \\
\hline & IS4 (DO1) & Диагностика & Дискретный \\
\hline & IS5 (DO2) & Выше уставки 1 канал 1 & Дискретный \\
\hline & IS6 (DO3) & Выше уставки 2 канал 1 & Дискретный \\
\hline & IS7 (DO4) & Ниже уставки 1 канал 1 & Дискретный \\
\hline & IS8 (DO5) & Ниже уставки 2 канал 1 & Дискретный \\
\hline & IS9 (DO6) & Выше уставки 1 канал 2 & Дискретный \\
\hline & IS10 (DO7) & Выше уставки 2 канал 2 & Дискретный \\
\hline & IS11 (DO8) & Ниже уставки 1 канал 2 & Дискретный \\
\hline & IS12 (DO9) & Ниже уставки 2 канал 2 & Дискретный \\
\hline & IS13 (DO10) & Выше уставки 1 канал 3 & Дискретный \\
\hline & IS14 (DO11) & Выше уставки 2 канал 3 & Дискретный \\
\hline & IS15 (DO12) & Ниже уставки 1 канал 3 & Дискретный \\
\hline & IS16 (DO13) & Ниже уставки 2 канал 3 & Дискретный \\
\hline \multirow[t]{9}{*}{ НПТ2 } & IS1 (AO1) & Параметр 1 канал & Аналоговый \\
\hline & IS2 (AO2) & Параметр 2 канал & Аналоговый \\
\hline & IS3 (AO3) & Параметр 3 канал & Аналоговый \\
\hline & IS4 (DO1) & Диагностика & Дискретный \\
\hline & IS5 (DO2) & Выше уставки 1 канал 1 & Дискретный \\
\hline & IS6 (DO3) & Выше уставки 2 канал 1 & Дискретный \\
\hline & IS7 (DO4) & Ниже уставки 1 канал 1 & Дискретный \\
\hline & IS8 (DO5) & Ниже уставки 2 канал 1 & Дискретный \\
\hline & IS9 (DO6) & Выше уставки 1 канал 2 & Дискретный \\
\hline
\end{tabular}




\begin{tabular}{|c|c|c|c|}
\hline $\begin{array}{c}\text { Код } \\
\text { блока }\end{array}$ & Выход & Описание & Тип выхода \\
\hline & IS10 (DO7) & Выше уставки 2 канал 2 & Дискретный \\
\hline & IS11 (DO8) & Ниже уставки 1 канал 2 & Дискретный \\
\hline & IS12 (DO9) & Ниже уставки 2 канал 2 & Дискретный \\
\hline & IS13 (DO10) & Выше уставки 1 канал 3 & Дискретный \\
\hline & IS14 (DO11) & Выше уставки 2 канал 3 & Дискретный \\
\hline & IS15 (DO12) & Ниже уставки 1 канал 3 & Дискретный \\
\hline & IS16 (DO13) & Ниже уставки 2 канал 3 & Дискретный \\
\hline \multirow[t]{17}{*}{ БРИ } & ИС1 (AO1) & Вход регулятора X1 & Аналоговый \\
\hline & ИС2 (АO2) & Вход регулятора X2 & Аналоговый \\
\hline & ИС3 (АO3) & Вход регулятора X3 & Аналоговый \\
\hline & ИС4 (DO1) & Вход регулятора 4 & Дискретный \\
\hline & ИС5 (DO2) & Вход регулятора 5 & Дискретный \\
\hline & ИС6 (DO3) & Вход регулятора 6 & Дискретный \\
\hline & ИС7 (DO4) & Вход регулятора 7 & Дискретный \\
\hline & ИС8 (DO5) & Неисправность & Дискретный \\
\hline & ИС9 (DO6) & Открыть & Дискретный \\
\hline & ИС10 (DO7) & Закрыть & Дискретный \\
\hline & ИC11 (DO8) & Выход Y1 & Дискретный \\
\hline & ИC12 (DO9) & Выход Y2 & Дискретный \\
\hline & ИC13 (DO10) & Выход 1 & Дискретный \\
\hline & ИС14 (DO11) & Выход 2 & Дискретный \\
\hline & ИC15 (DO12) & Выход 3 & Дискретный \\
\hline & ИС16 (DO13) & Выход 4 & Дискретный \\
\hline & ИC17 (DO14) & Диагностика & Дискретный \\
\hline
\end{tabular}

Блоки имеют аналоговые выходы $\mathrm{AO}<\mathrm{N}>$, где $<\mathrm{N}>$ - номер выхода. Для каждого аналогового выхода в блоках АПВ и НПТ предусмотрены дискретные выходы $\mathrm{DO}<\mathrm{N}>$ для уставок аналогового параметра (при необходимости). Каждый блок имеет также выход DO1 - диагностика о неисправности в модуле (для блока БРИ DO2). 
П3.2.2. Алгоритмы обработки информации для запорной арматуры

Источником информации является блок управления запорной арматурой БУЗ.

Таблица 14

Перечень сигналов блока управления запорной арматурой БУЗ

\begin{tabular}{|l|l|}
\hline Выход блока & Описание (Расширение кода сигнала шлюза) \\
\hline ИС1 (DO1) & Дистанционная команда «Открыть» (HBOE) \\
\hline ИС2 (DO2) & Дистанционная команда «Закрыть» (HBS) \\
\hline ИС4 (DO4) & Индикатор неисправность (LSB) \\
\hline ИС6 (DO6) & Состояние «Открыто» (ARAF) \\
\hline ИС7 (DO7) & Состояние «Закрыто» (ARZU) \\
\hline ИС8 (DO8) & Состояние «Ход на закрытие» (LZUF) \\
\hline ИС9 (DO9) & Состояние «Ход на открытие» (LAFF) \\
\hline ИС10 (DO10) & Превышено время хода в направлении закрыто (LZZUV) \\
\hline ИС11 (DO11) & Превышено время хода в направлении открыто (LZAFV) \\
\hline
\end{tabular}

Таблица 15

Состояние запорной арматурь

\begin{tabular}{|l|l|}
\hline Состояние арматуры & Сигналы \\
\hline Неопределенное (нет данных) & Отсутствуют значения ARAF или ARZU \\
\hline Открыто & $\mathrm{ARAF}=1, \mathrm{ARZU}=0$ \\
\hline Закрыто & $\mathrm{ARAF}=0, \mathrm{ARZU}=1$ \\
\hline Открывается & $\mathrm{ARAF}=0, \mathrm{ARZU}=0, \mathrm{LAFF}=1, \mathrm{LZUF}=0$ \\
\hline Закрывается & $\mathrm{ARAF}=0, \mathrm{ARZU}=0, \mathrm{LAFF}=0, \mathrm{LZUF}=1$ \\
\hline Состояние "стоп" & $\mathrm{ARAF}=0, \mathrm{ARZU}=0, \mathrm{LAFF}=0, \mathrm{LZUF}=0$ \\
\hline Предыдущее состояние & $\mathrm{ARAF}=1$ и $\mathrm{ARZU}=1$ \\
\hline
\end{tabular}

П3.2.3. Алгоритмы обработки информации для электродвигателей

Состояние электродвигателя (пускателя, реле, нагревателя) определяется по состояниям выходных сигналов блока управления электродвигателя БУД. 
Таблица 16

Перечень сигналов блока управления электродвигателя БУД

\begin{tabular}{|l|l|}
\hline \multicolumn{1}{|c|}{ Выход блока } & \multicolumn{1}{c|}{ Описание (Расширение кода сигнала шлюза) } \\
\hline ИС1 (DO1) & Дистанционная команда «Включить» (НВЕ) \\
\hline ИС2 (DO2) & Дистанционная команда «Отключить» (HВA) \\
\hline ИС3 (DO3) & Нерабочее положение тележки (Х) \\
\hline ИС4 (DO4) & Снижение давления (Y) \\
\hline ИС5 (DO5) & Обрыв цепей управления (W) \\
\hline ИС6 (DO6) & Индикатор неисправности (LSB) \\
\hline ИС7 (DO7) & Аварийное отключение (AGU) \\
\hline ИС8 (DO8) & Состояние «Включен» (XB01) \\
\hline ИС11 (DO11) & Состояние «Выключен» (XB02) \\
\hline ИС12 (DO12) & Тестовое положение (TЕ) \\
\hline
\end{tabular}

Таблица 17

Состояния электродвигателя

\begin{tabular}{|c|c|}
\hline Состояние электродвигателя & Сигналы \\
\hline Начальное (неопределенное) & Отсутствуют значения ХВ01 или ХВ02 \\
\hline Включен & $\mathrm{XB} 01=1, \mathrm{XB} 02=0$ \\
\hline Выключен & $\mathrm{XB} 01=0, \mathrm{XB} 02=1$ \\
\hline Предыдущее состояние & $\mathrm{XB} 01=1, \mathrm{XB} 02=1$ или $\mathrm{XB} 01=0, \mathrm{XB} 02=0$ \\
\hline
\end{tabular}

П3.2.4. Алгоритмы обработки информации для регулирующей арматуры

Состояния регулирующей арматуры и соответствующего регулятора определяются по значениям выходных сигналов блока управления клапаном БУК.

Таблица 18

Перечень сигналов блока управления клапаном БУК.

\begin{tabular}{|l|l|}
\hline \multicolumn{1}{|c|}{ Выход блока } & \multicolumn{1}{c|}{ Описание (Расширение кода сигнала шлюза) } \\
\hline ИС1 (DO1) & Состояние «Открыто» (ХС01) \\
\hline ИС2 (DO2) & Автоматический режим (ХC11) \\
\hline ИС3 (DO3) & Дистанционный режим (ХC12) \\
\hline ИС4 (DO4) & Состояние «Закрыто» (ХС02) \\
\hline ИС5 (DO5) & Неисправность (ХМ26) \\
\hline
\end{tabular}


Таблица 19

Состояние регулирующей арматуры

\begin{tabular}{|l|l|}
\hline \multicolumn{1}{|c|}{$\begin{array}{c}\text { Состояние регулирующей } \\
\text { арматуры }\end{array}$} & \multicolumn{1}{|c|}{ Значения сигналов } \\
\hline Начальное (неопределенное) & $\begin{array}{l}\text { Отсутствуют значения ХС11 или } \\
\text { ХC12 }\end{array}$ \\
\hline Автоматический режим & $\mathrm{XC} 11=1, \mathrm{XC} 12=0$ \\
\hline Дистанционный режим & $\mathrm{XC} 11=0, \mathrm{XC} 12=1$ \\
\hline $\begin{array}{l}\text { Автоматический режим, промежу- } \\
\text { точное положение }\end{array}$ & $\mathrm{XC} 11=1, \mathrm{XC} 12=0, \mathrm{XC} 01=0, \mathrm{XC} 02=0$ \\
\hline $\begin{array}{l}\text { Дистанционный режим, промежу- } \\
\text { точное положение }\end{array}$ & $\mathrm{XC} 11=0, \mathrm{XC} 12=1, \mathrm{XC} 01=0, \mathrm{XC} 02=0$ \\
\hline $\begin{array}{l}\text { Предыдущее } \\
\mathrm{XC} 11=0, \quad \mathrm{XC} 12=0 \quad \text { или ХC11=1, } \\
\mathrm{XC} 12=1\end{array}$ \\
\hline
\end{tabular}

П3.2.5. Алгоритм обработки информации по блоку задания уставок регулятора

Состояния регулятора определяются по значениям выходных сигналов блока БРИ.

Способ использования для передачи информации в СВУ выходов блока БРИ может различаться. В таблице ПЗ.9 представлен пример перечня сигналов блока БРИ, передаваемых в СВУ.

Таблица 20

Перечень сигналов блока БРИ

\begin{tabular}{|l|l|}
\hline Выход блока & Описание (Расширение кода сигнала шлюза) \\
\hline IS11 (АО1) & Датчик положения 0-100\% (ХQ06) \\
\hline IS22 (AO2) & Рассогласование 0-100\% (XQ08) \\
\hline IS25 (AO3) & Рассогласование 0-100\% (XQ06) \\
\hline IS26(AO4) & Т Насыщения (XQ01) \\
\hline IS27(AO5) & Уставка Р, МПа (XQ07) \\
\hline IS28 (AO6) & Уставка T, С (XQ07) \\
\hline IS8 (DO1) & Неисправность регулятора (ХМ15) \\
\hline IS17 (DO2) & Диагностика (ХМ42) \\
\hline IS19 (DO3) & Неисправность измерительного канала (ХС06) \\
\hline IS5 (DO5) & Оператор 30 С/ч (VW30) \\
\hline IS6 (DO6) & Оператор 60 С/ч (VW60) \\
\hline IS7 (DO7) & Регулятор САР1 поддержка T (ХС06) \\
\hline
\end{tabular}




\begin{tabular}{|l|l|}
\hline Выход блока & Описание (Расширение кода сигнала шлюза) \\
\hline IS8 (DO8) & Отключено скорость/расход САР1 60 C/ч (XV02) \\
\hline IS24 (DO9) & $>5$ C (ZV01) \\
\hline IS29 (DO10) & Включено T=Tconst \\
\hline IS30 (DO11) & Включено dT/dt=60 C/ч (ZV01) \\
\hline IS31 (DO12) & Включено dT/dt=30 C/ч (ZV01) \\
\hline IS32 (DO13) & Включено P=6,08 МПа (ZV01) \\
\hline IS33 (DO14) & Включено P=Ртекущ (ZV01) \\
\hline
\end{tabular}

\section{П3.2.6. Алгоритм обработки информации по блоку выбора}

Состояние блоков выбора определяется по значениям дискретных сигналов, которые имеют в СВУ окончание $\mathrm{VW}<\mathrm{N}>$, где $\mathrm{N}$ может принимать значения 1, 2, 3, 4. Сигналы могут формироваться блоками БРИ УКТС.

Таблица 21

Состояние блоков выбора

\begin{tabular}{|l|l|}
\hline Состояние & Значения сигналов \\
\hline Начальное (неопределенное) & Отсутствует значение $\mathrm{VW}<\mathrm{N}>$ \\
\hline Выбран & $\mathrm{VW}<\mathrm{N}>=1$ \\
\hline Не выбран & $\mathrm{VW}<\mathrm{N}>=0$ \\
\hline
\end{tabular}




\section{ПРИЛОЖЕНИЕ 4}

\section{АЛГОРИТМЫ ОБРАБОТКИ ИНФОРМАЦИИ ПРИ ВЗАИМОДЕЙСТВИИ С СИСТЕМОЙ SІСАМ}

\section{П4.1. Обмен данными между СBУ и SICAM}

ПТК на базе технико-программных средств SICAM используются в ПТК электрической части АСУ ТП энергоблоков АЭС «Куданкулам» (Индия).

Обмен данными между СВУ и смежными ПТК, основанными на системе SICAM, реализуется в шлюзах с использованием телеграмм, передаваемых по интерфейсу ТСР/ІР в соответствии с протоколом [12]. Существуют следующие форматы данных при обмене данными между шлюзом и СВУ:

- для передачи аналоговых сигналов, значений уставок формат числа с плавающей точкой;

- для передачи дискретных сигналов - формат целого числа со значащим младшим битом.

Значения сигналов поступают от шлюзов в СВУ с метками времени и атрибутами достоверности. Различаются следующие значения атрибутов достоверности:

- достоверность значения сигнала;

- достоверность метки времени.

При взаимодействии по протоколу [12] используются следующие виды телеграмм: M_ME_NC_1, M_ME_TF_1, M_SP_NA_1, M_DP_NA_1, M_ST_NA_1, M SP_TB_1, M_DP_TB_1, M_ST_TB_1. При управлении по протоколу ГОСТ Р МЭК 8770-5-104-2001 используются следующие виды телеграмм: C_DC_NA_1, C_SC_NA_1, C_RC_NA_1. Соответствие телеграммы коду сигнала устанавливается по атрибутам адресов телеграммы. 


\section{П4.2. Контроль и управление технологическим оборудова- нием с использованием системы SICAM}

\section{П4.2.1. Прием дискретных сигналов, используемых в}

качестве сигнализации

Значения дискретных сигналов формируются на основе телеграмм M SP_NA_1, M_DP_NA_1, M_ST_NA_1, M_SP TB_1, M_DP_TB_1, M_ST_TB_1. Tелеграммы $\mathrm{M}$ SP_NA_1, M_DP_NA_1, M_ST_ $\bar{N} A-1$ используются при приеме сигналов по генеральному опросу. В процессе работы шлюза используются телеграммы M_SP_TB_1, M_DP_TB_1, M_ST_TB_1.

Если используются телеграммы M_SP_TB_1, M_SP_NA_1, то

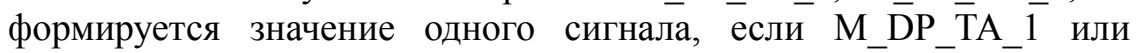
M_DP_NA_1, то двух одновременно. При получении телеграмм M_ST_NA_1 и M_ST_TB_1 формируется 19 дискретных сигналов (положений отпаек РПН)

При использовании M_SP_NA_1 значение сигнала берется из бита SPI байта SIQ информационного объекта телеграммы, а метка времени сигналу присваивается по системному времни шлюзового компьютера, с установкой признака недостоверности времени.

При использовании M_SP_TB_1 значение сигнала берется из бита SPI байта SIQ информационного объекта телеграммы, а метка времени сигналу присваивается в соответствии с меткой времени информационного объекта телеграммы. Достоверность сигналов присваивается в соответствии с параметрами качества из телеграммы. Сигнал считается недостоверным, если один из битов IV или NT байта SIQ телеграммы установлен в 1. Сигнал имеет недостоверность времени, если бит IV метки времени информационного объекта телеграммы равен 1.

При использовании телеграммы M_DP_NA_1 значение первого сигнала берется из бита 0 атрибута DPI байта DIQ информационного объекта телеграммы, второго из бита 1, а метка времени обоим сигналам присваивается по системному времени шлюзового компьютера с установкой признака недостоверности времени.

При использовании телеграммы M_DP_TA_1 значение первого сигнала берется из бита 0 атрибута DPI, второго - из бита 1 DPI, a метка времени сигналу присваивается в соответствии с меткой вре- 
мени информационного объекта телеграммы. Достоверность сигналов присваивается в соответствии с параметрами качества из телеграммы. Сигнал считается недостоверным, если один из битов IV или NT байта DIQ телеграммы установлен в 1. Сигнал имеет недостоверность времени, если бит IV метки времени информационного объекта телеграммы равен 1.

При использовании телеграммы M_ST_NA_1 и M_ST_TB_1 значения сигналов получаются из байта VTI, а признаки достоверности сигнала и метки времени присваиваются аналогично M_DP_NA_1 и M_DP_TB_1.

\section{П4.2.2. Формирование положения РПН}

Для описания положения РПН используются 19 дискретных сигналов, код которых имеет следующую структуру:

$<$ код РПН> ZVi,

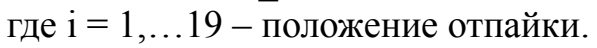

Значения сигналов формируется на основе содержания телеграммы M_ST_TB_1 Или M_ST_NA_1. Телеграмма M_ST_NA_1 используется как результат генерального опроса, M_ST_TB_1 - в процессе работы шлюза, как ответ на команду._Управление положением РПН осуществляется с помощью телеграммы C_RC_NA_1. Атрибут RCS байта RCO информационного объекта телеграммы имеет значения битов:

- для увеличения номера отпайки используется значение $\ll 10 »$;

- для уменьшения - значение «01»;

Для регистрации команд управления в СВУ используется два сигнала:

- сигнал «убавить» с кодом <код РПН> XL11;

- сигнал «прибавить» с кодом <код РПН> XL12.

Значения сигналов формируется по следующему алгоритму. При выполнении функции «прибавить» формируется сигнал <код PПH>_XL12, имеющий значение 1, и телеграмма C_RC_NA_1, атрибут ${ }^{-} \mathrm{RCS}$ которой имеет значение битов «10». При выполнении функции «убавить» формируется сигнал <код PПН> XL11, имеющий значение 1, и телеграмма C_RC_NA_1, атрибут RCS которой имеет значение битов «01». 
П4.2.3. Формирование состояния неуправляемого электротехнического выключателя

(коммуникационного

\section{annapama)}

Состояние неуправляемого выключателя определяется по нескольким группам сигналов: сигналам положения сигналам несоответствия положения. При этом в зависимости от особенностей выключателей сигналы несоответствия состояния поданной команде могут отсутствовать.

Значения сигналов определяются в шлюзе на основе соответствующих телеграмм.

Используются три сигнала положения выключателя:

- сигнал «включен» с кодом <код выключателя>_XВ01;

- сигнал «отключен» с кодом <код выключателя > ХВ02;

- сигнал «неопределенное состояние» с кодом <код выключателя >_ХВ99.

Сигналы положения определяется по значениям битов атрибута DPI байта DIQ информационного объекта телеграммы M_DP_TB_1 или M_DP_NA_1. Телеграммы M_DP_NA_1 используются в при генеральном опросе. В процессе работы шлюза используются телеграммы M_DP_TB_1. Значения битов телеграмм интерпретируются следующим образом:

- «00»- неопределенное состояние;

- «01»-отключен;

- «10»- включен;

- «11»- неопределенное состояние.

Метка времени и достоверность сигналам положения присваивается по правилам, аналогичным указанным в П4.2.1.

Таблица 22

Алгоритм определения состояния выключателя

\begin{tabular}{|l|l|}
\hline Состояние переключателя & Значения сигналов \\
\hline Начальное (неопределенное) & Отсутствуют значения ХВ01 или ХВ02 \\
\hline Включен & ХВ01 $=1$, ХВ02 $=0$ \\
\hline Выключен & ХВ01 $=0$, ХВ02 $=1$ \\
\hline $\begin{array}{l}\text { Предыдущее состояние и сигна- } \\
\text { лизация ХВ99=1 }\end{array}$ & \\
\hline
\end{tabular}


П4.2.4. Формирование состояния управляемого электротехнического выключателя

Состояние управляемого выключателя определяется по нескольким сигналам.

Значения сигналов определяются в шлюзе на основе соответствующих телеграмм.

Используются три сигнала положения выключателя:

- сигнал «включен» с кодом <код выключателя> ХB01;

- сигнал «отключен» с кодом <код выключателя $>$ XB02;

- сигнал «неопределенное состояние» с кодом <код выключателя >_XВ99.

Сигналы положения определяется по значениям битов атрибута DPI байта DIQ информационного объекта телеграммы M_DP_TB_1 или M_DP_NA_1. Телеграммы M_DP_NA_1 используются в при генеральном опросе. В процессе работы шлюза используются телеграммы M_DP_TB_1. Значения битов телеграмм интерпретируются следующим образом:

- «00»- неопределенное состояние;

- «01»- отключен;

- «10»-включен;

- «11»- неопределенное состояние.

Метка времени и достоверность сигналам положения присваивается по правилам, аналогичным указанным в П4.2.1.

В шлюзе реализованы алгоритмы анализа причин изменения положения выключателя. Выходными сигналами этих алгоритмов являются значения двух сигналов диагностики:

- сигнал «Включен спонтанно» с кодом <код выключателя>_XB91,

- сигнал «Отключен спонтанно» с кодом <код выключателя>_ХВ92.

Всего алгоритмов два:

1) алгоритм, основанный на анализе атрибута «Причина передачи» (COT) телеграммы M_DP_TB_1; 
2) алгоритм анализа невыполнения команды.

Каждый алгоритм запускается по событиям, использует специфические данные и изменяет значения указанных сигналов.

Алгоритм, основанный на анализе СОT, запускается срезу после получения телеграммы M_DP_TB_1 и формирует значения сигналов диагностики по следующему алгоритму:

- если этот атрибут равен 3, значение сигнала <код выключателя>_XB91 становится равным значению сигнала <код выключателя > XB01, а значение сигнала <код выключателя $>$ XВ92 - значению сигнала $<$ код выключателя $>$ XB02;

- если этот атрибут не равен 3 значение сигналов <код выключателя> ХВ91 и <код выключателя>_ХВ92 имеют значение 0 (сигналы отменены).

При этом метка времени и достоверность сигналам диагностики присваивается по правилам, аналогичным указанным в П4.2.1.

Алгоритм анализа невыполнения команды запускается периодически и состоит в следующем. При выполнении с CВУ команды «включить» запоминается время команды и контролируется значение сигнала «включен». Если, по истечении тайм-аута, значение сигнала <код выключателя>_XB01 не равно 1, формируется событие «невыполнение команды». При выполнении команды «отключить» запоминается время команды и контролируется значение сигнала «отключен». Если, по истечении тайм-аута, значение сигнала <код выключателя>_ХВ02 не равно 1, формируется событие «невыполнение команды». При событии «невыполнение команды» сигнал $<$ код выключателя>_XВ91 получает значение сигнала с кодом расширения <код выключателя>_XВ01 (включено), а <код выключателя>_XВ92 получает значение сигнала <код выключателя>_XB02 (отключено).

В таблице 23 представлен алгоритм определения состояния переключателя на основе указанных сигналов. 
Таблица 23

Алгоритм определения состояния переключателя

\begin{tabular}{|c|c|}
\hline $\begin{array}{c}\text { Состояние } \\
\text { переключателя }\end{array}$ & Значения сигналов \\
\hline Начальное (неопределенное) & $\begin{array}{l}\text { Отсутствуют значения ХВ01 или } \\
\text { ХВ02 }\end{array}$ \\
\hline Включен & $\mathrm{XB} 01=1, \mathrm{XB} 02=0$ \\
\hline Выключен & $\mathrm{XB} 01=0, \mathrm{XB} 02=1$ \\
\hline $\begin{array}{l}\text { Предыдущее состояние и сигнализация } \\
\text { ХВ99=1 }\end{array}$ & $\begin{array}{l}\mathrm{XB} 01=0, \quad \mathrm{XB} 01=0 \quad \text { или } \mathrm{XB} 01=1, \\
\mathrm{XB} 01=1\end{array}$ \\
\hline
\end{tabular}

По выключателю могут существовать сигналы дополнительной диагностики. К ним относятся:

Неисправность выключателя - характеризует наличие обобщенной неисправности выключателя;

Контрольное положение - характеризует контрольное положение выключателя;

Нерабочее положение характеризует нерабочее положение выключателя.

Формирование и представление этих сигналов соответствует п. П4.2.1 в части сигналов, формируемых на основе телеграмм M_SP_TB_1, M_SP_NA_1.

Управление положением выключателя осуществляется с помощью телеграммы C_DC_NA_1. Атрибут DCS байта DCO информационного объекта телеграммы имеет значения битов:

- д для включения используется значение «10»;

- для отключения - значение «01».

Для регистрации команд управления в СВУ используется два сигнала:

- сигнал «включить» с кодом <код выключателя>_XL01;

- сигнал «отключить» с кодом <код выключателя>_XL02.

Значения сигналов формируется по следующему алгоритму. При выполнении функции «включить» формируется сигнал <код выключателя>_XL01, имеющий значение 1, и телеграмма C_DC_NA_1, атрибут DCS которой имеет значение битов «10». При выполнении функции «отключить» формируется сигнал <код 
выключателя>_XL02, имеющий значение 1, и телеграмма C_DC_NA_1, атрибут DCS которой имеет значение битов «01».

Квитирование из СВУ сигнализации изменения положения выключателя осуществляется с помощью телеграммы C_SC_NA_1. Атрибут SCS байта SCO информационного объекта телеграммы имеет значения бита 1.

Для регистрации команд управления в СВУ используется сигнал <код выключателя>_ZL51.

При выполнении функции «квитировать» формируется сигнал $<$ код выключателя> XL51, имеющий значение 1, и телеграмма C_SC_NA_1, атрибут SCS которой имеет значение бита «1».

П4.2.5. Контроль режима автоматики АВР питающих элементов

Состояние индикатора режима работы АВР определяется по нескольким сигналам.

Значения сигналов определяются в шлюзе на основе соответствующей телеграммы.

Используются следующие сигналы индикатора режима АВР:

- сигнал «введен» с кодом <код индикатора>_XВ21;

- сигнал «выведен» с кодом <код индикатора > ХВ22;

- сигнал «неопределенное состояние» с кодом <код выключателя >_XВ99.

Сигналы положения определяется по значениям битов атрибута DPI байта DIQ информационного объекта телеграммы M_DP_TB_1 или M_DP_NA_1. Телеграммы M_DP_NA_1 используются в при генеральном опросе. В процессе работы шлюза используются телеграммы M_DP_TB_1. Значения битов телеграмм интерпретируются следующим образом:

- «00»- неопределенное состояние;

- «01»- выведен;

- «10»- введен;

- «11»- неопределенное состояние. 
Формирование этих сигналов соответствует п. П4.2.1 в части сигналов, формируемых на основе телеграмм M_DP_TB_1, M_DP_NA_1.

Метка времени и достоверность сигналам положения присваивается по правилам, аналогичным указанным в П4.2.1.

В шлюзе реализованы алгоритмы анализа причин изменения режима автоматики АВР. Выходными сигналами этих алгоритмов являются значения двух сигналов диагностики:

- сигнал «Введен спонтанно» с кодом <код индикатоpa> ХB91,

- сигнал «Выведен спонтанно» с кодом <код индикатоpa>_XB92.

Всего алгоритмов два:

1) алгоритм, основанный на анализе атрибута «Причина передачи» (COT) телеграммы M_DP_TB_1;

2) алгоритм анализа невыполнения команды.

Каждый алгоритм запускается по событиям, использует специфические данные и изменяет значения указанных сигналов.

Алгоритм, основанный на анализе СОТ, запускается срезу после получения телеграммы M_DP_TB_1 и формирует значения сигналов диагностики по следующему алгоритму:

- если этот атрибут равен 3, значение сигнала <код индикатора>_XВ91 становится равным значению сигнала $<$ код индикатора>_XB21, а значение сигнала <код индикатора>_XВ92 - значению сигнала <код индикатоpa> XBर22;

- если этот атрибут не равен 3 значение сигналов <код индикатора>_XВ91 и <код индикатора>_XВ92 имеют значение 0 (сигналы отменены).

При этом метка времени и достоверность сигналам диагностики присваивается по правилам, аналогичным указанным в П4.2.1.

Алгоритм анализа невыполнения команды запускается периодически и состоит в следующем. При выполнении с СВУ команды «ввести» запоминается время команды и контролируется значение сигнала «введен». Если, по истечении тайм-аута, значение сигнала $<$ код индикатора>_XB21 не равно 1, формируется событие «невыполнение команды». При выполнении команды «вывести» запоми- 
нается время команды и контролируется значение сигнала «выведен». Если, по истечении тайм-аута, значение сигнала <код индикатора>_XВ22 не равно 1, формируется событие «невыполнение команды». При событии «невыполнение команды» сигнал <код индикатора>_XВ91 получает значение сигнала с кодом расширения <код индикатора>_XB21 (введен), а <код индикатора>_XВ92 получает значение сигнала <код индикатора $>$ XВ22 (выведен).

\section{Таблица 24}

Алгоритм определения состояния индикатора $A B P$

\begin{tabular}{|l|l|}
\hline \multicolumn{1}{|c|}{ Состояние индикатора } & \multicolumn{1}{c|}{ Значения сигналов } \\
\hline Начальное (неопределенное) & Отсутствуют значения ХВ21 или ХВ22 \\
\hline Введен & ХВ21=1, ХВ22 $=0$ \\
\hline Выведен & ХВ21 $=0$, XВ22 $=1$ \\
\hline Предыдущее состояние & ХВ21 $=0$, X22 $=0$ или ХВ21=1, ХВ22 =1 \\
\hline
\end{tabular}

Управление режимом автоматики АВР осуществляется с помощью телеграммы C_DC_NA_1. Атрибут DCS байта DCO информационного объекта телеграммы имеет значения битов:

- для введения используется значение «10»,;

- для выведения - значение «01».

Для регистрации команд управления в СВУ используется два сигнала:

- сигнал «ввести» с кодом <код индикатора>_XL21;

- сигнал «вывести» с кодом <код индикатора> XL22.

Значения сигналов формируется по следующему алгоритму. При выполнении функции «ввести» формируется сигнал <код индикатора $>$ XL21, имеющий значение 1, и телеграмма C_DC_NA_1, атрибут DCS которой имеет значение битов «10». При выполнении функции «вывести» формируется сигнал <код индикатора> XL02, имеющий значение 1 , и телеграмма C_DC_NA_1, атрибут DC $\overline{\mathrm{C}}$ которой имеет значение битов «01».

Квитирование с СВУ сигнализации изменения режима автоматики ABP осуществляется с помощью телеграммы C_SC_NA_1. Атрибут SCS байта SCO информационного объекта телеграммы имеет значения бита 1.

Для регистрации команд управления в СВУ используется сигнал <код индикатора>_ZL50. 
При выполнении функции «квитировать» формируется сигнал $<$ код индикатора> XL50, имеющий значение 1, и телеграмма C_SC_NA_1, атрибут SCS которой имеет значение бита «1».

\section{П4.2.6. Датчик аналогового параметра}

Значение аналогового параметра передается в соответствующих байтах информационного объекта телеграммы M_ME_NC_1 или M_ME_TF_1. Значение передается в формате числа с плавающей точкой. Код расширения аналогового параметра $-\mathrm{XQ} 0 \mathrm{~N}$, где $\mathrm{N}=1 . .9$

Метка времени сигналам присваивается по метке времени в сигнале M_ME_TF_1 или по системному времени шлюзового компьютера, с установкой признака недостоверности времени (в случае M_ME_NC_1). Достоверность сигналам присваивается в соответствии с параметрами качества из телеграммы. Сигналы считаются недостоверным, если один из битов IV,NT или OV байта DQS телеграммы установлен в 1 . 


\section{ЛИТЕРАТУРА}

1. Бывайков М.Е., Жарко Е.Ф., Менгазетдинов Н.Э., Полетыкин А.Г., Прангишвили И.В., Промыслов В.Г. Опыт проектирования и внедрения системы верхнего блочного уровня АСУ ТП АЭС // Автоматика и Телемеханика, 2006, № 5, с. 65-79.

2. Менгазетдинов Н.Э., Бывайков М.Е., Зуенков М.А., Промыслов В.Г., Полетыкин А.Г. и др. Комплекс работ по созданию первой управляющей системы верхнего блочного уровня АСУ ТП для АЭС "Бушер" на основе отечественных информационных технологий [Электронный ресурс]: монография. М.: ИПУ РАН, 2013. - ISBN 978-5-91450-130-0.

3. ISO/IEC 9899:2011. Information technology -- Programming languages -- $\mathrm{C}$.

4. RFC 793. Transmission control protocol.

5. RFC 1122. Requirements for Internet Hosts - Communication Layers.

6. RFC 1323. TCP Extensions for High Performance.

7. RFC 1337. Time-wait Assassination Hazards in TCP.

8. RFC 3168. The Addition of Explicit Congestion Notification (ECN) to IP.

9. RFC 2581. TCP Congestion Control.

10. RFC-1305. Network Time Protocol.

11. Бармаков Ю.Н. Средства автоматизации, разрабатываемые ВНИИА в рамках программы развития атомной энергетики России // Автоматизация в промышленности, 2006, № 8, с. 49-51.

12. ГОСТ Р МЭК 60870-5-104-2004. Устройства и системы телемеханики. Часть 5. Протоколы передачи. Раздел 104 Доступ к сети для ГОСТ Р МЭК 870-5-101 с использованием стандартных транспортных профилей. 


\section{СПИСОК СОКРАЩЕНИЙ}

\begin{tabular}{|c|c|c|}
\hline CGP & - & Communication Gateway Program \\
\hline $\mathrm{ABP}$ & - & автоматический ввод резерва \\
\hline APM & - & автоматизированное рабочее место \\
\hline АCPK & - & автоматизированная система радиационного контроля \\
\hline АСУ ТП & - & $\begin{array}{l}\text { автоматизированная система управления технологическим про- } \\
\text { цессом }\end{array}$ \\
\hline АТПС & - & администрирование технических и программных средств \\
\hline АЭС & - & атомная электростанция \\
\hline БПУ & - & блочный пульт управления \\
\hline ЗИП & - & запасные инструменты и принадлежности \\
\hline ИПУ РАН & - & $\begin{array}{l}\text { Федеральное государственное бюджетное учреждение науки } \\
\text { Институт проблем управления им. В.А. Трапезникова Россий- } \\
\text { ской академии наук }\end{array}$ \\
\hline КТПС-ПН & - & $\begin{array}{l}\text { комплекс техническо-программных средств повышенной } \\
\text { надежности }\end{array}$ \\
\hline КЭСУЗ & - & комплекс электрооборудования системы управления и защиты \\
\hline СКУ & - & система контроля управления \\
\hline СКУД & - & система контроля управления и диагностики \\
\hline ЛВС & - & локальная вычислительная сеть \\
\hline МПУ & - & местный пульт управления \\
\hline НСБ & - & начальник смены блока \\
\hline ПО & - & программное обеспечение \\
\hline ПТК & - & программно-технический комплекс \\
\hline РБД & - & рабочая база данных \\
\hline $\mathrm{PC}$ & - & рабочая станция \\
\hline СВБУ & - & система верхнего блочного уровня \\
\hline CBCY & - & системе верхнего стационарного уровня \\
\hline CBY & - & система верхнего уровня \\
\hline СРВПЭ & - & система регистрации важных параметров эксплуатации \\
\hline ТАИ & - & тепловая автоматика и измерения \\
\hline TOY & - & технологический объект управления \\
\hline ТС ОДУ & - & технические средства оперативно-диспетчерского управления \\
\hline ТПТС & - & типовые программно-технические средства \\
\hline ЧМИ & - & человеко-машинный интерфей \\
\hline ШИПО & - & шлюзовое (интерфейсное) программное обеспечение \\
\hline ЭКП & - & экраны коллективного пользования \\
\hline ЭЧ & - & электрическая часть \\
\hline
\end{tabular}


к.т.н. Бывайков Михаил Евгеньевич

д.т.н. Полетыкин Алексей Григорьевич

к.т.н. Степанов Василий Николаевич

м.н.с. Сахабетдинов Ильдар Умарович

\section{Программный интерфейс между верхним и нижнем уровнями автоматизированной системы управления технологическими процессами (АСУ ТП) атомной электростанции (АЭС)}

Локальное электронное издание

Номер госрегистрации 0322101831 в НТЦ «Информрегистр»

Мин. системные требования:

Pentium 4, Internet Explorer, Acrobat reader 4.0 и выше

Дата подписания к использованию 25.05.2021

1 электронно-оптический диск (CD-R), 2,0 Мб, Тираж 100 экз.

Министерство науки и высшего образования РФ Институт проблем управления им. В.А. Трапезникова

Российской академии наук

117997

ул. Профсоюзная, д. 65

Россия, Москва

http://www.ipu.ru 